Utah State University

DigitalCommons@USU

$12-2019$

\title{
A New Approach for Evaluating the Ductility, Volumetric Stiffness, and Permeability of Cutoff Wall Backfill Materials
}

Jennifer Ostrowsky

Utah State University

Follow this and additional works at: https://digitalcommons.usu.edu/etd

Part of the Civil and Environmental Engineering Commons

\section{Recommended Citation}

Ostrowsky, Jennifer, "A New Approach for Evaluating the Ductility, Volumetric Stiffness, and Permeability of Cutoff Wall Backfill Materials" (2019). All Graduate Theses and Dissertations. 7680.

https://digitalcommons.usu.edu/etd/7680

This Thesis is brought to you for free and open access by the Graduate Studies at DigitalCommons@USU. It has been accepted for inclusion in All Graduate Theses and Dissertations by an authorized administrator of DigitalCommons@USU. For more information, please contact digitalcommons@usu.edu.

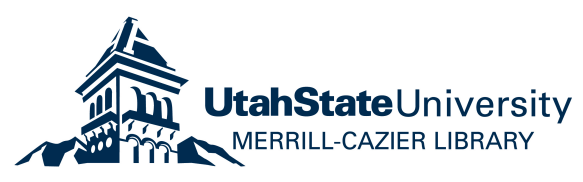




\title{
A NEW APPROACH FOR EVALUATING THE DUCTILITY, VOLUMETRIC STIFFNESS, AND PERMEABILITY \\ OF CUTOFF WALL BACKFILL MATERIALS
}

\author{
by \\ Jennifer Ostrowsky \\ A thesis submitted in partial fulfillment \\ of the requirements for the degree \\ of \\ MASTER OF SCIENCE \\ in \\ Civil and Environmental Engineering
}

Approved:

John Rice, Ph.D.

Major Professor

James Bay, Ph.D.

Committee Member
Paul Barr, Ph.D.

Committee Member

Richard S. Inouye, Ph.D.

Vice Provost for Graduate Studies

UTAH STATE UNIVERSITY

Logan, Utah 


\author{
ABSTRACT \\ A New Approach for Evaluating the Ductility, \\ Volumetric Stiffness, and Permeability \\ of Cutoff Wall Backfill Materials \\ by \\ Jennifer L. Ostrowsky, Master of Science \\ Utah State University, 2019
}

Major Professor: Dr. John Rice

Department: Civil and Environmental Engineering

The behavior of soil-cement and plastic-concrete cut-off walls in dams is critically affected by ductility and volumetric stiffness. Post-construction deformation of cut-off walls is common due to the differences in strength and stiffness of the wall and the surrounding embankment material and changes in loading due to changes in the seepage regime. Conventional concrete barriers crack as they deform creating regions of high permeability and concentrated flow in the cracked region. Ductile barriers, such as soil-bentonite walls will deform without cracking, but lack structural integrity. The behavior of intermediate materials, such as soil-cement and plastic concrete, are currently not well understood.

A laboratory testing procedure has been developed to quantify the ductility of soil-cement and plastic- concrete relative to changes in permeability (hydraulic 
conductivity) with strain. Tests were performed on a number of soil-cement specimens having varying cement and bentonite contents. The test results show that this method is effective in illustrating and quantifying the differences in behavior of the soil-cement specimens and effectively measuring low-permeability materials $\left(10^{-6}\right.$ to $\left.10^{-8} \mathrm{~cm} / \mathrm{s}\right)$. This laboratory testing procedure can be instrumental for defining and quantifying the in-situ properties of soil-cement mixtures and plastic-concrete used for cut-off wall backfill materials. 


\title{
PUBLIC ABSTRACT
}

\author{
A New Approach for Evaluating the Ductility, \\ Volumetric Stiffness, and Permeability \\ of Cutoff Wall Backfill Materials \\ Jennifer L. Ostrowsky
}

The use of plastic concrete for cutoff walls in dams for remediation of seepage issues has become more widely used in the past 25 years, however, the in-situ material properties are still not well understood. The research presents a new testing procedure that combines two existing testing methods, triaxial shear and permeability testing. By developing this laboratory testing method, material properties of the cutoff wall backfill material can be more accurately examined and explained using changes in the permeability of the material to discern the ductility and stiffness. 


\section{ACKNOWLEDGMENTS}

Utah State University would like to thank the Mountain-Plains Consortium

(MPC) for partial funding of the initial stages of this research (MPC-477).

I would like to thank Dr. John Rice and Dr. James Bay for guiding me through

this research, and providing this geologist turned engineer with this opportunity.

I give special thanks to my Dad and Granny for always supporting me, no matter

what adventures I decide to go on. Also, thank you to my friends and work colleagues

for their encouragement and moral support in my decision to go back to school.

Last but not least, I would like to thank the late, great Dr. Joe Caliendo for getting me started on this journey. You are the reason came to Utah State, and although you

didn't get to see me finish this endeavor, you knew I would get this done, someday.

Jenn Ostrowsky 


\section{CONTENTS}

Page

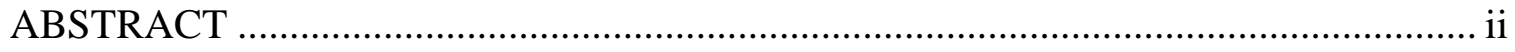

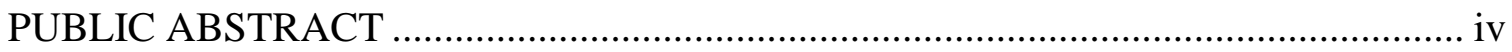

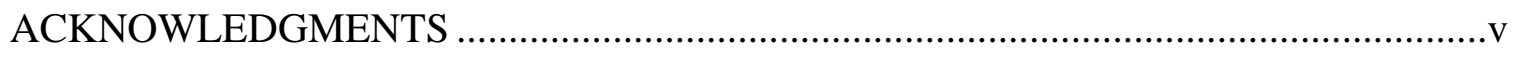

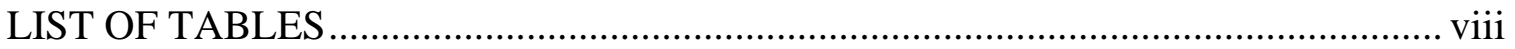

LIST OF FIGURES ..................................................................................... ix

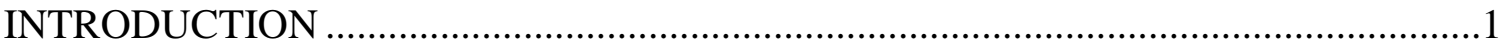

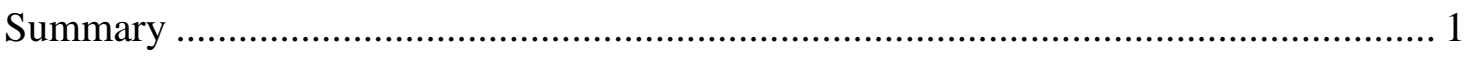

Purpose of Research .......................................................................................... 3

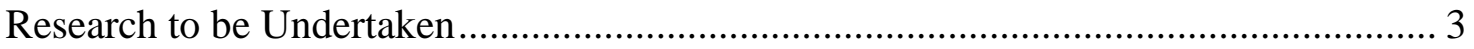

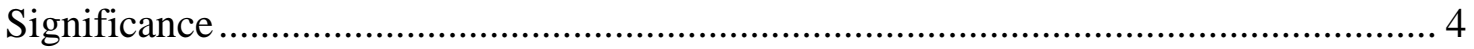

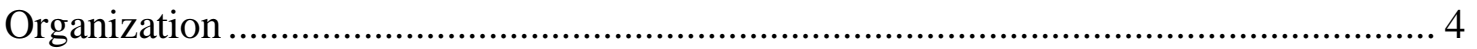

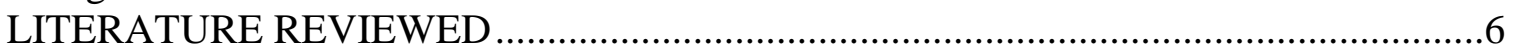

Pre-Existing Dam Remediation Projects .............................................................. 11

New Dam Pre-Construction Treatment Projects .................................................... 13

Non-Specific/ General ....................................................................................... 21

Long Term Performance ....................................................................................... 24

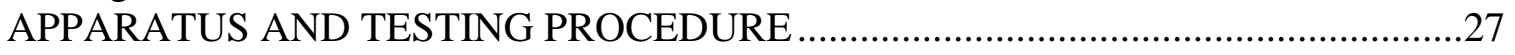

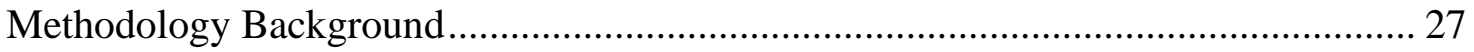

Mix Design and Specimen Preparation ................................................................... 27

Testing Procedure .............................................................................................. 31

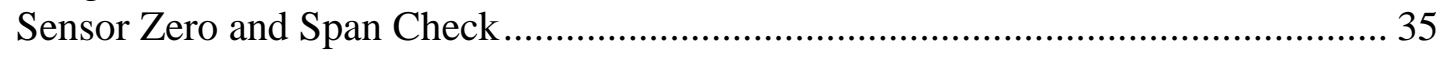

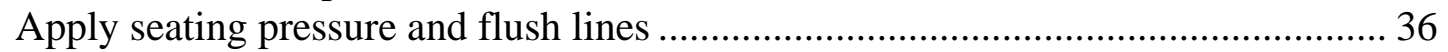

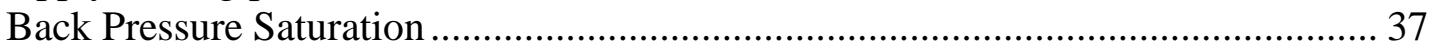

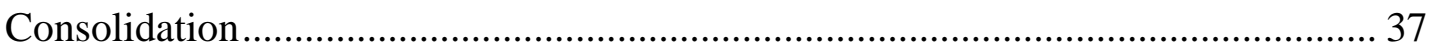

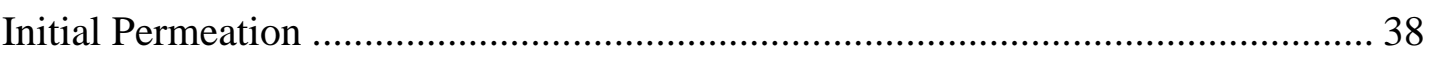

Triaxial Shear with Permeability Measurements................................................. 40 
RESULTS AND ANALYSIS OF TESTING PROCEDURE .......................................44

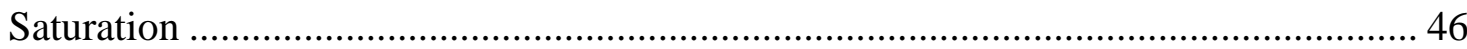

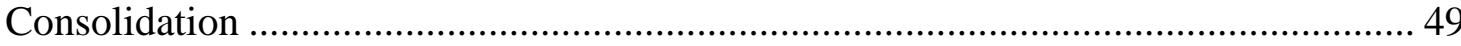

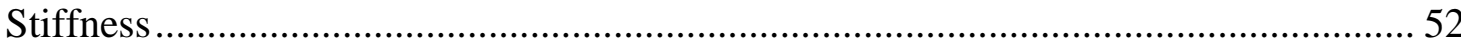

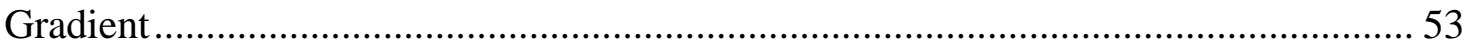

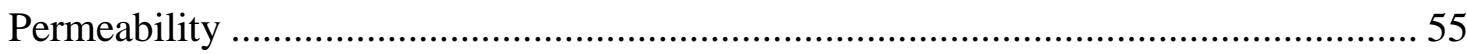

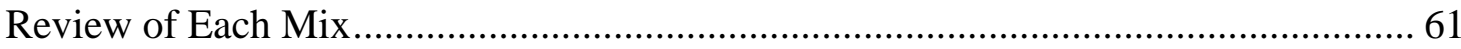

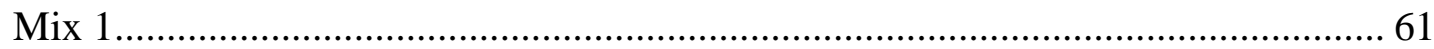

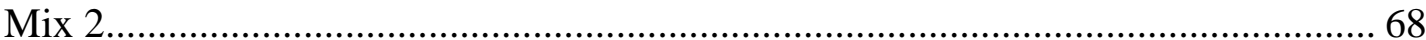

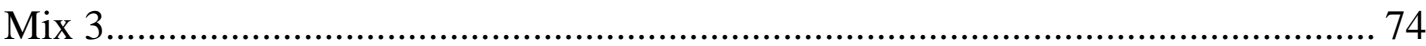

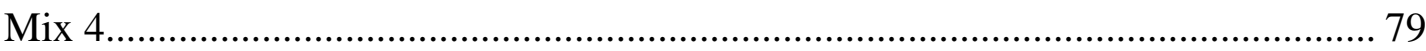

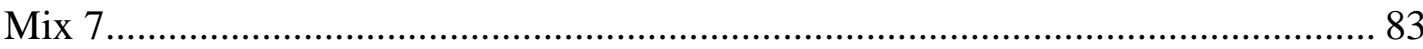

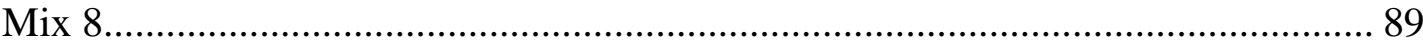

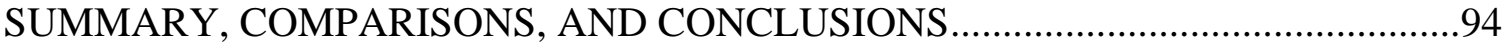

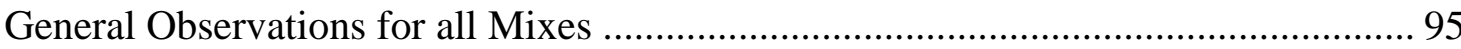

Comparison of 2 Percent Cement-Bentonite Ratio Mixes ........................................ 102

Comparison of 6 Percent Cement-Bentonite Ratio Mixes ........................................ 105

Observations on Possible Healing Behavior in Mixes Based on Permeability........... 108

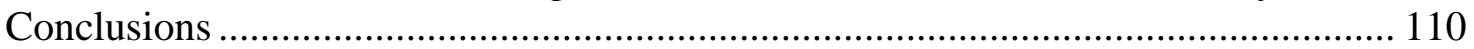

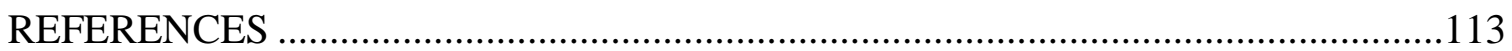




\section{LIST OF TABLES}

Table

Page

2. 1 Summary of Testing Methods Used to Characterize Plastic Concrete for Use in Pre-Existing Dam Remediation .............................................. 11

2. 2 Summary of Testing Methods Used to Characterize Plastic Concrete Used for Pre-Treatment for New Dam Construction ............................. 14

2. 3 Summary of Testing Methods Used to Characterize Plastic Concrete in

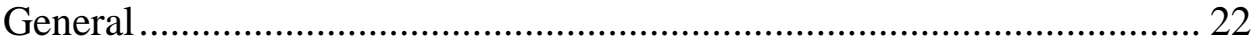

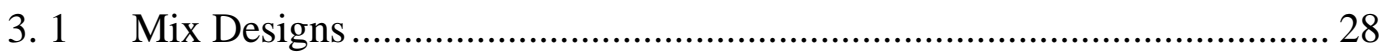

4. 1 Summary of specimens created for this research................................. 44

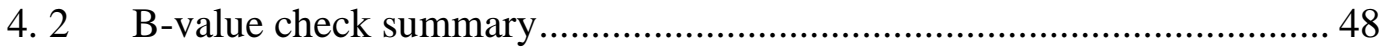

4. 3 Summary of consolidation data .................................................. 50

4. 4 Change in height and volume of specimens during consolidation ........... 52

4. 5 Bulk modulus values ........................................................................ 53

4. 6 Maximum stress and strain analyzed for each specimen ....................... 55

4. $7 \quad$ Initial Permeability, and Strain Rates .................................................... 56

4. 8 Increase in permeability compared to change in height and volume........ 58

4. 9 Evidence of healing between triaxial shears for selected specimens........ 60

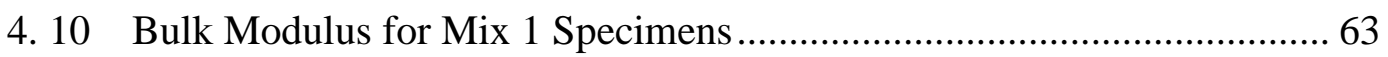

4. 11 Bulk modulus for Mix 2 specimens ............................................... 70

4. 12 Bulk Modulus values for Mix 3 ...................................................... 76

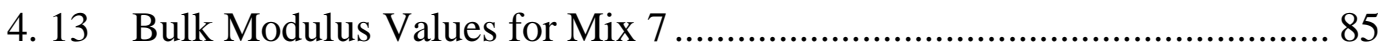




\section{LIST OF FIGURES}

Figure $\quad$ Page

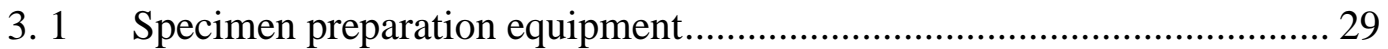

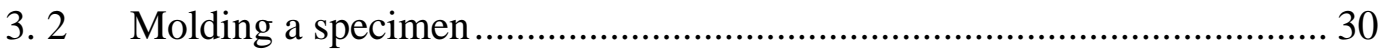

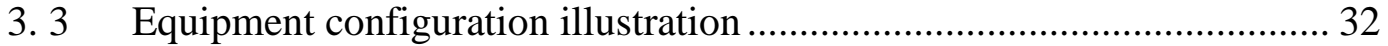

3. 4 Generalized schematic of the equipment configuration......................... 33

3. 5 Mounting a specimen onto the test cell............................................ 34

3. 6 Equipment configuration at the end of applying seating pressure step .... 36

3. 7 Equipment configuration for the start of the permeation step ................ 40

3. 8 Equipment configuration at the start of a triaxial shear testing increment........................................................................... 42

4. 1 Sample output from Digi-Flow K permeability program ....................... 45

4. 2 Sample output from Sigma1-CU program ........................................... 46

4. 3 Example of tabs used in Excel to organize data ................................... 46

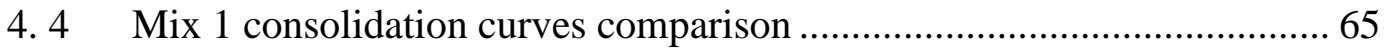

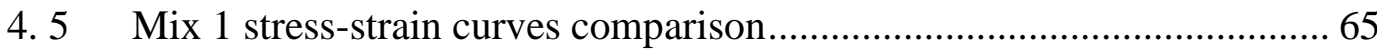

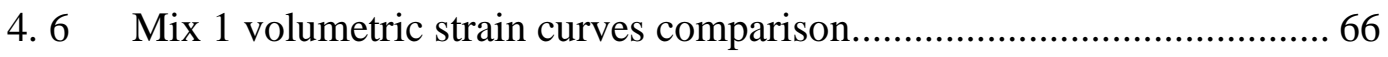

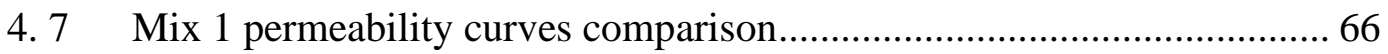

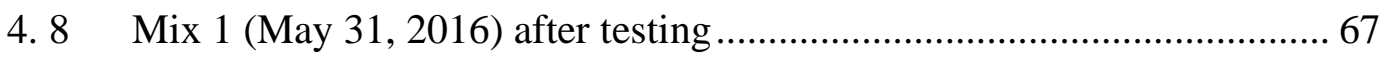

4. 9 Mix 1 (June 22, 2016) before (left) and after (right) ........................... 67

4. 10 Mix 2 consolidation curves comparison ....................................... 70

4. 11 Mix 2 stress-strain curves comparison.................................................. 71

4. 12 Mix 2 volumetric strain curves comparison........................................ 71 
Figure

4. 13 Mix 2 permeability curves comparison............................................ 72

4. 14 Mix 2 (May 31, 2016) before (left) and after (right) testing................... 72

4. 15 Mix 2 (June 28, 2016) before (left) and after (right) testing................... 73

4. 16 Mix 2 (August 3, 2016) before testing ........................................... 73

4. 17 Mix 3 consolidation curves comparison ......................................... 76

4. 18 Mix 3 stress-strain curves comparison........................................... 77

4. 19 Mix 3 volumetric strain curves comparison....................................... 77

4. 20 Mix 3 permeability curves comparison............................................... 78

4. 21 Mix 3 (June 2, 2016) before (left) and after (right) testing.................... 78

4. 22 Mix 3 (June 29, 2016) before (left) and after (right) testing................... 79

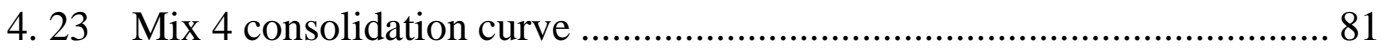

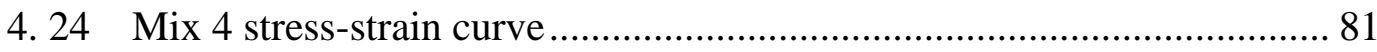

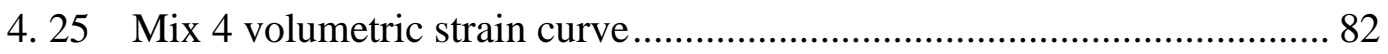

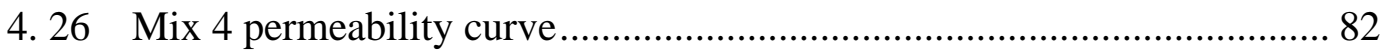

4. 27 Mix 4 (June 3, 2016) before (left) and after (right) testing.................... 83

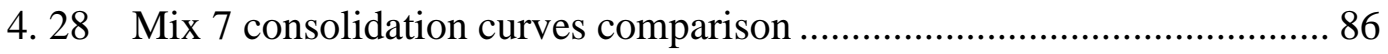

4. 29 Mix 7 stress-strain curves comparison............................................ 87

4. 30 Mix 7 volumetric strain curves comparison....................................... 87

4. 31 Mix 7 permeability curves comparison............................................. 88

4. 32 Mix 7 (July 25, 2016) before (left) and after (right) testing ................... 88

4. 33 Mix 7 (September 7, 2016) before (left) and after (right) testing ............. 89

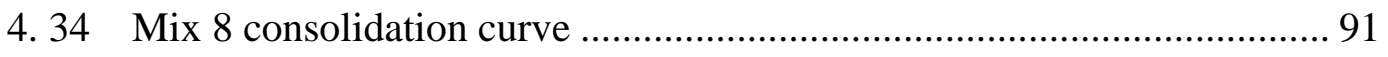


Figure

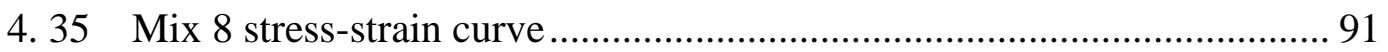

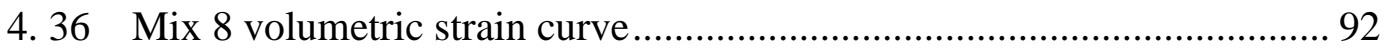

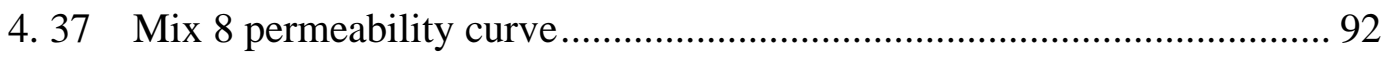

5. 1 Consolidation curves for all mixes tested ......................................... 96

5. 2 General form of the stress-strain relationship (ICOLD 1985) ................. 97

5. 3 Stress- strain curves for all mixes tested......................................... 100

5. $4 \quad$ Volumetric strain curves for all mixes tested ...................................... 101

5. 5 Permeability curves for all mixes tested ......................................... 101

5. 6 Consolidation curves for 2 percent cement mixes ............................. 103

5. 7 Stress-Strain curves for 2 percent cement mixes .............................. 104

5. 8 Volumetric strain curves for 2 percent cement mixes ......................... 104

5. 9 Permeability curves for 2 percent cement mixes .............................. 105

5. 10 Consolidation curves for 6 percent cement mixes ............................ 106

5. 11 Stress-strain curves for 6 percent cement mixes ................................. 107

5. 12 Volumetric strain curves for 6 percent cement mixes ........................ 107

5. 13 Permeability curves for 6 percent cement mixes ............................... 108

5. 14 Change in Permeability during the testing for the 10 percent cementbentonite ratio mixes......................................................................... 109

5. 15 Change in Permeability during testing for the mixes with more than 10 percent cement-bentonite ratio 


\section{CHAPTER I}

\section{INTRODUCTION}

\section{Summary}

Cutoff walls are among the feasible alternatives to reduce seepage through embankment dams. The basic approach to constructing a cutoff wall involves excavating a slurry-filled trench through the embankment and down to a less permeable layer of foundation rock or soil and filling the trench with a backfill material, usually a concrete mixture. These types of seepage barriers often experience large hydraulic loads that will result in post-construction deformation. Conventional concrete cutoff walls, using structural concrete (4,000 psi, 28-day strength), are rigid and susceptible to concentrated cracking during post-construction deformation, creating regions of high permeability and concentrated flow in the crack region. Soil-bentonite walls create a more ductile barrier and deform without cracking, but lack structural integrity. There are also depth limitations to this type of barrier wall construction. Soil-cement and plastic concrete cutoff walls represent intermediate materials, which have structural integrity and the ability to deform and potentially heal as cracking occurs. Experimentation with plastic concrete has been ongoing since the 1980s, with increased interest in the past several decades. This is due to more detailed analysis indicating that rigid wall barriers pose new threats to the stability of the dam because they are not compatible with the surrounding embankment and foundation and can drastically change to stress and strain regime of the dam. However, the behavior of these intermediate materials is still not well understood, 
and there is currently no universally accepted method on how to test the material for verification of mechanical and hydraulic properties.

Ductility and volumetric stiffness are critical properties that affect the behavior of the backfill material after placement. Ductility and brittleness in cementitious materials are controlled by the presence or absence of cracks during straining, which is also not well understood. This cracking also affects the permeability of the backfill material. Volumetric stiffness is quantified by the bulk modulus, $\mathrm{K}$, or the constrained modulus, $\mathrm{m}$, which can be obtained from the slope of the consolidation curves from the sample.

Current design and construction of new cutoff walls expend large amounts of time on research and development of compatible mixes for the specific conditions encountered with varying degrees of effort and testing procedures. This is often due to a lack of nonproprietary information on mix designs, and sparse long term performance data of previously installed cutoff walls. Tests include: unconfined compression, permeability, drained and undrained triaxial, numerical modeling, erosion testing, and tensile splitting. There is also a range of parameters used in these tests such as: strain rate, confining pressure, linearly elastic versus beam behavior of the wall, consolidation rate, and gradient, to name a few.

This research presents a testing method using consolidated, drained triaxial testing while measuring permeability to simulate in-situ conditions of the cutoff wall backfill material. It is proposed that changes in permeability during the triaxial shear process is a better indication of ductility of the material than the conventional peak strength and strain 
obtained from stress stain curves. The smaller the change in permeability, the more ductile the material.

Purpose of Research

The objective of this research is to develop a testing procedure to quantify the ductility of soil-cement mixtures and observe changes in permeability (hydraulic conductivity) during strain and after strain has occurred. This can be used to assess the behavior of the stiffness, strain behavior, changes in permeability with strain, and healing of the soil-cement backfill material when cracking occurs. Most previous research on this topic focused on comparing triaxial test results to unconfined compressive strength tests to assess probable in-situ conditions of the cutoff wall backfill material by using peak strain and strength at failure of a material. In this research, the ductility is assessed by looking at the change in permeability during the triaxial testing and then compared to the typical methods mentioned above. Tests were performed on a number of mixtures having varying cement and bentonite contents, no coarse aggregate was used in the mixtures. The intent is for this testing procedure to provide a more comprehensive understanding of the elasto-plastic and crack formation behavior of various mixture designs of plastic concrete as well as soil cement. These insights will be helpful in predicting the deformation behavior of the cutoff barriers as well as improve our ability to assess the effectiveness of the barriers in inhibiting seepage and internal erosion.

Research to be Undertaken

The testing procedure used for this research used lab-created specimens comprised of cement, bentonite, sand, and water. These mixes represented a range of 
cement and bentonite contents, and do not align with any specific previously completed cutoff wall, since the main goal of this research was to prove the concept of this testing procedure. Specimens underwent consolidated drained (CD) triaxial loading while measuring the permeability. The testing system consisted of a conventional triaxial cell, load frame, an automated loading system, flow pumps, and an automated flow pump system.

Significance

This research is the first step in better understanding and characterizing the material properties of the intermediate, soil-cement and plastic concrete, cutoff wall backfill material by providing a testing procedure and associated parameters used. Once the testing method has been proven, it will be used in conjunction with other more common testing methods to give more insights into these materials that are more commonly used as cutoff wall materials, but not well understood or explained in specifications. This gives the opportunity for owners, operators and contractors to understand the behavior of this material after placement and the long term performance.

\section{Organization}

This thesis is comprised of six chapters. Chapter 1 introduces the research, purpose, and significance. Chapter 2 discusses the literature reviewed in conjunction with this research summarizing existing methods and parameters used for testing soilcement and plastic concrete cutoff walls. Chapter 3 presents the testing system and a detailed discussion of the testing procedure. Chapter 4 describes the data analysis 
procedure. Chapter 5 compares the test results for all of the mixtures tested. Chapter 6 presents the summary, conclusions, and recommendations. 


\section{CHAPTER II}

\section{LITERATURE REVIEWED}

A Literature review was conducted as part of this research to understand previous testing methods and comparisons between methods of the mixtures used in plastic concrete cutoff walls. While this research also focuses on soil-cement mixtures for cutoff wall backfill material, there is virtually no published literature on this type of material for cutoff walls. The basis of the need for this research is based on Kahl, Kauschinger, and Perry (1991), which points out the lack of laboratory test data on plastic concrete subjected to similar in-situ field conditions. Almost 30 years later, there is still a lack of guidance on the laboratory testing procedures, types of testing (unconfined compression, drained triaxial, undrained triaxial, permeability, erosion), and parameters (strain rate, strain at failure, confining pressures) recommended to fully assess the mechanical and hydraulic properties of plastic concrete, of which many authors in this literature review discuss.

This review notes a wide range of testing methods and simulated in-situ conditions used to confirm a mixture design for plastic concrete cutoff walls. There is also a marked difference between the scale of the testing program based on the size, and most definitely, budget of the project, and for new dam construction versus pre-existing dam remediation.

Over the past 10 to 15 years, there has been an increasing amount of new dam construction outside of the United States. This is an advantage since state-of-the-art practices can be used before the dam is constructed, including increased use of triaxial 
testing of trial mixes. Building a cutoff wall before the embankment is placed on top presents a different set of issues that are not present for existing dams, and will not be discussed in detail. Plastic concrete was selected for cutoff walls in this section due to conditions such as: highly permeable nature of the non-bedrock foundation materials, seismic considerations, and increased need for ductility of the backfill material.

ICOLD (1985) is the only publication that provides guidance on the types of testing to run on the hardened cutoff wall material. They suggest crushing strength tests for strength and modulus of elasticity, undrained triaxial compression tests for cohesion and internal friction angle, permeability via a membrane permeameter, and the pin hole test for erodibility of the material. However, the most commonly used, and quickest way to assess the strength of plastic concrete, is the unconfined compressive strength test (UCS). Most contractors cited in this review use UCS tests to validate their proprietary mixture designs. The unconfined compressive test is supplemented with a separate permeability test in the lab to ensure target permeability. Long term performance instrumentation is also discussed in ICOLD (1985) including: strain gauges, inclinometers, settlement points, and piezometers.

Two papers provide the basis for this research, Kahl, Kauschinger, and Perry (1991) and Hinchberger, Weck, and Newson (2010). Kahl, Kauschinger, and Perry (1991) provided a starting point to describe the mechanical and hydraulic properties of plastic concrete in a general sense, not for site-specific design. Hinchberger, Weck, and Newson (2010) use a similar approach to this research by simultaneously recording permeability measurements during triaxial shear. 
Kahl, Kauschinger, and Perry (1991) presents the most recent comprehensive testing program of plastic concrete undertaken by the Army Corps of Engineers to understand the behavior of the backfill material under in-situ conditions in the cutoff wall. At this time, plastic concrete was not widely used in the United States, as the authors state, because of a lack performance results. The main goal of this research was to correlate triaxial testing to unconfined tests (unconfined compression, Brazilian splitting tensile tests, and flexural beam). Permeability and erosion testing were also conducted separately. Permeability testing was conducted as the samples cured in the triaxial cell. This resulted in them to develop design data for specifying plastic concrete for future projects by the creation of figures correlating bentonite content, age, confinement, and consolidation to the stress-strain-strength behavior if the elastic modulus of the embankment is known.

The triaxial testing utilized the standard panel board configuration to control the testing. Consolidated undrained and unconsolidated undrained triaxial testing was completed. The undrained unconsolidated tests were used to determine the effects of consolidation on the stress-strain characteristics and strength behavior. One particular mix was used for this type of testing, with different effective confining pressure $(50,100$, 200 and 300 psi) to simulate a wide range of horizontal confinement would experience in-situ after placement. The effective consolidation stresses ranged from 50 to 300 psi. It is important to note that the bentonite in the testing was not hydrated prior to mix creation, which allowed for a large amount of bentonite to be added (up to 60\%). 
This research showed the necessity of using consolidated triaxial testing to understand the stress-strain, strength, and permeability behavior. The current research builds on this need by using updated testing equipment with automatic data collection and the combination of permeability testing with the triaxial shear. With this configuration, the cutoff wall material can be characterized as brittle or ductile by looking at the change in the permeability over the duration of the test.

The U.S. Army Corps of Engineers REMR Technical Note GT-SR-1.3 (USACE 1992), suggests a design procedure based on results from an unconfined compression testing database that provides graphs to aid the designer to select a concrete mixture that satisfies strength and stiffness requirements. No additional testing is discussed once a preliminary mix is chosen from the tables. This Technical Note is the summary of results from the Kahl, Kauschinger, and Perry (1991) research.

Hinchberger, Weck, and Newton (2010) conducted research for a new dam construction project, presumably in Canada, and included extensive laboratory triaxial testing to characterize the mechanical and hydraulic properties of plastic concrete. This paper is the first published literature on the influence of compressive strain on the permeability of plastic concrete and is based on the thesis work of Weck (2007). The mixes tested originate from the design guidelines referenced above in Kahl, Kauschinger, and Perry (1991). This set-up is similar to the current research in that permeability measurements were taken for the duration of the triaxial testing to assess the change in permeability during shear. They use the GDS computer controlled triaxial system, that is similar to the Trautwein equipment used in this current research. Confining stress (100, 
400 and $900 \mathrm{kPa}$ ) were used to simulate in-situ conditions based on finite element analyses of the conditions. A gradient was introduced to the sample by creating a pressure differential of $10 \mathrm{kPa}$ between the top and the bottom of the samples. Stress relaxation and controlled rate of loading tests were also conducted to assess ratesensitivity and time-dependency. Concepts from this research will be closely compared to during the analysis of the current research testing procedure in a subsequent chapter.

The research makes several important conclusions based on the comparison of permeability to strain. Increases in the permeability of plastic concrete are caused by crack formation and dilation of the cracks during compression with associated axial strain. Next, the authors suggest a strain-based design criterion and present figures of axial strain versus permeability to provide a basis for developing a suitable workingstrain limit. Finally, the stress-strain response of plastic concrete is strongly influenced by rate of loading and time effects such as stress relaxation. Therefore, a time-dependent constitutive model is needed, rather than a time-independent model, which could underestimate the long-term working strains.

This remaining part of this chapter is divided into the following areas:

1. Pre-Existing Dam Remediation Projects

2. New Dam Pre-Construction Treatment Projects

3. Non-Specific/ General

4. Long Term Performance of Cutoff Walls 
Pre-Existing Dam Remediation Projects

Table 2.1 summarizes the literature reviewed for pre-existing dam remediation projects. In addition to citing the reference, the name of dam and location are given, along with the material testing methods used for each specific project. The text following the tables then recounts each project in more detail and how it relates to the current research work.

Table 2. 1 Summary of Testing Methods Used to Characterize Plastic Concrete for Use in Pre-Existing Dam Remediation

\begin{tabular}{lll}
\hline Reference & Dam/Country & Testing Methods Used \\
\hline $\begin{array}{l}\text { Anderson, Wilson, } \\
\text { Tonner, 2009 }\end{array}$ & Red Dog Mine, AK & $\begin{array}{l}\text { Triaxial, Permeability, long } \\
\text { term performance } \\
\text { instrumentation }\end{array}$ \\
Javed, Nasim, 2005 & $\begin{array}{l}\text { Jnconfined compression, } \\
\text { Indonesia } \\
\text { permeability, long term } \\
\text { performance }\end{array}$ \\
$\begin{array}{l}\text { O'Brien, Dann, Hunter, } \\
\text { Schwermer, 2009 }\end{array}$ & Hinze Dam/Australia & $\begin{array}{l}\text { Unconfined Compression, } \\
\text { permeability }\end{array}$ \\
USBR, 2014 & $\begin{array}{l}\text { Island Copper Dam } \\
\text { Unconfined Compression, } \\
\text { triaxial, permeability }\end{array}$ \\
& Meeks Cabin, WY & \\
\hline
\end{tabular}

Anderson, Wilson, Tonner (2009) describes a plastic concrete cutoff wall for a new Back Dam along the existing tailings impoundment at Red Dog Mine, Alaska. The mixture design testing was carried out by the contractor at their laboratory. The paper does not go into detail about the testing program or what testing methods were used, however the summary table of mix design results indicate permeability was measured before and after strain, deviator stress, tangent modulus and maximum strain. This would indicate that triaxial testing was performed as the main testing procedure. 
At the time of the preparation of this paper, they include plans for long term monitoring of the cutoff wall by installing instrumentation. This instrumentation includes: piezometers, surficial survey monuments, inclinometers, and extensometers. Piezometers monitor the water levels and seepage potential across the cutoff wall. Survey monuments measure settlement of the cutoff wall. Inclinometers and extensometers monitor vertical and horizontal movements of the wall. As of the writing of this thesis, no long term performance information has been shared in a paper.

Javed, Nasim, (2005) describe the plastic concrete cutoff wall that was installed in Jatiluhur Dam in Indonesia. There are very few details about the mixture design testing program, however it is assumed that unconfined compression and permeability testing were completed on the trial mixes, since compressive strength and permeability were the main design specification guidelines. For long term performance evaluation, a seepage flume was installed through the both the RCC wall and the plastic concrete wall to confirm that an upstream piezometer was no longer directly communicating with the tail race water level.

O’Brien, Dann, Hunter, Schwermer (2009) discusses the plastic concrete cutoff wall for Hinze Dam in Australia. The contractor carried out the laboratory mix trials based on the technical requirements of: a 28-day unconfined compressive strength between $2 \mathrm{MPa}$ and $4 \mathrm{MPa}$, ductile stress-strain properties defined as an axial strain at maximum compressive strength of greater than $0.6 \%$ and $50 \%$ of peak strength at $7 \%$ strain, and a low permeability of less than $1 \times 10^{-9} \mathrm{~cm} / \mathrm{sec}$. The paper does not discuss the types of testing used for the initial mix designs, except the implication that unconfined 
compression testing and permeability testing was used based on the technical requirements. During construction, it is noted that hole erosion testing was completed on some samples due to a problem with an electrical system at the batch plant that added less cement to some batches. It can be concluded that since technical requirements were given, no additional comparisons between testing methods was used by the contractor because the specifications were met with the mix design.

The U.S. Bureau of Reclamation, USBR (2014), provides technical requirements and processes to enable the preparation of design documents relating to embankment dams, specifically cutoff walls and instrumentation of cutoff walls. They note that the most important property is low permeability of cutoff wall material, followed by strength, flexibility, and resistance to cracking. "When considering the use of plastic concrete for a cutoff wall, a careful laboratory testing program should be completed to evaluate alternative mix designs to optimize the desired characteristics of the wall." That testing procedure is not specified in this design standard. For long term performance evaluation of the cutoff wall, piezometers upstream and downstream of the wall are recommended, with inclinometers and settlement points as well, if budget permits.

\section{New Dam Pre-Construction Treatment Projects}

Table 2.2 summarizes the literature reviewed for new dam pre-construction projects, meaning the cutoff wall was constructed prior to construction of the dam, which introduces additional complexities of tying the cutoff wall into the embankment of the dam. In addition to citing the reference, the name of dam and location are given, along 
with the material testing methods used for each specific project. The text following the tables then recounts each project in more detail and how it relates to the current research work.

Table 2. 2 Summary of Testing Methods Used to Characterize Plastic Concrete Used for Pre-Treatment for New Dam Construction

\begin{tabular}{|c|c|c|}
\hline Reference & Dam/Country & Testing Methods Used \\
\hline $\begin{array}{l}\text { Abbaslou, Ghamozadeh, and } \\
\text { Amlashi } 2016 \\
\text { Bagheri, Alibabaie, Babaie } \\
2007 \\
\text { Khiavi and Ghorbani } 2014 \\
\text { Mahboubi, Ajorloo } 2005 \\
\text { Mirghasemi, Pakzad, Shadravan } \\
2005 \\
\text { Naderi and Mehmood } 2005 \\
\text { Pashazadeh and Chekaniazar, } \\
2011 \\
\text { Shadravan, } 2004\end{array}$ & Karkheh/ Iran & $\begin{array}{l}\text { Unconfined compression, } \\
\text { splitting tensile } \\
\text { (Brazilian), permeability, } \\
\text { consolidated drained } \\
\text { triaxial, biaxial, water } \\
\text { penetration, numerical } \\
\text { analysis for earthquake } \\
\text { loading }\end{array}$ \\
\hline Bigras et al, 2005 & $\begin{array}{l}\text { Peribonka Dam/ } \\
\text { Canada }\end{array}$ & $\begin{array}{l}\text { Pin hole erosion, water } \\
\text { velocity, unconfined } \\
\text { compression, Brazilian } \\
\text { (splitting tensile), } \\
\text { consolidated isotropic } \\
\text { drained and undrained } \\
\text { triaxial }\end{array}$ \\
\hline Donnelly et al. 2007 & Shikwamkwa/ & Triaxial, permeability, \\
\hline $\begin{array}{l}\text { Donnelly et al. } 2013 \\
\text { Tatone et al. } 2009\end{array}$ & Canada & $\begin{array}{l}\text { long term performance } \\
\text { instrumentation }\end{array}$ \\
\hline $\begin{array}{l}\text { Ghazahi, Safarzadeh, } \\
\text { Hashemolhoseini, } 2004\end{array}$ & $\begin{array}{l}\text { Dam not specified/ } \\
\text { Canada }\end{array}$ & Finite Element Methods \\
\hline Jafaradeh, 2012 & Silve/ Iran & $\begin{array}{l}\text { Consolidated Drained } \\
\text { Triaxial }\end{array}$ \\
\hline Sherad, 2000 & Jatiluhur & Unconfined Compression \\
\hline
\end{tabular}




\begin{tabular}{lll} 
Yan, Trapp, Sy, 2008 & $\begin{array}{l}\text { Dam/Indonesia } \\
\text { New Coquitlam } \\
\text { Dam/Canada }\end{array}$ & $\begin{array}{l}\text { Consolidated undrained } \\
\text { triaxial, finite element } \\
\text { methods, permeability, } \\
\text { unconfined compression, } \\
\text { confirmation field testing }\end{array}$ \\
Zhang, 1999 & $\begin{array}{l}\text { Finite element methods, } \\
\text { triaxial testing, } \\
\text { permeability }\end{array}$ \\
\hline
\end{tabular}

An extensive amount of literature was published for the plastic concrete wall construction for the Karkheh Dam that was constructed in the early 2000s. The research looks at a wide range of comparisons of the different testing methods versus the constituent material variations. Unconfined compression, splitting tensile (Brazilian), permeability, consolidated drained triaxial, biaxial, water penetration, and numerical analysis tests were all used by the various authors for this mixture design program. A summary of those articles is presented below.

Abbaslou, Ghamozadeh, and Amlashi (2016) used unconfined compression, Brazilian tensile splitting, and water penetration testing were used on cubic samples to obtain the mechanical properties of compressive strength, tensile strength and permeability as they relate to including sepiolite into the plastic concrete mix design. The water penetration testing consisted of exposing the top surface of the concrete cylinder to a certain water height above the sample and waiting a specified time period, then splitting the sample to see how far down the sample the water had penetrated. This does not appear to be a currently documented testing procedure. They also state that kaolinite and 
illite have been tested by other researchers and they have not recommended using these clays in plastic concrete mixture designs, although no references were given.

Bagheri, Alibabaie, Babaie (2008), and Khiavi and Ghorbani (2014) used unconfined compression for compressive strength and elastic modulus, and a U.S. Bureau of Reclamation testing procedure for water permeability of concrete. Compressive strength was compared to both elastic modulus and permeability but only as a function of silica fume and micro-silica contents, respectively.

Mahboubi and Ajorloo (2005) present a large parametric study of a range of plastic concrete samples in unconfined and consolidated drained triaxial tests. The effect of age, cement factor, bentonite content, and confining pressure were compared to shear strength and permeability. They mention checking the saturation of the samples using B values and conclude that a B value of 1.0 is considered fully saturated. The run the B value checks for a minimum of 1 hour, according to their results. The confining pressures are also varied, but it does not implicitly imply this is done to simulate different in-situ conditions, however there is a noticeable change in the failure mode with different confining pressures (brittle versus ductile).

The mechanical behavior of plastic concrete in this research is equated to bonded geomaterials (such as artificially cemented soils), which leads them to use a MohrCoulomb failure envelope to calculate the cohesion and internal friction angle. Several other authors use this theory and it may not be an appropriate assumption that plastic concrete behaves in a linearly elastic fashion at all strains. The effect of age is then 
compared to these shear strength parameters. Permeability is compared to the effect of confining pressure, cement factor, and bentonite content.

Mirghasemi, Pakzad, Shadravan (2005) include a brief discussion of the finite difference and non-linear model used to study the interaction of the cutoff wall and the surrounding stratified rock for different loading conditions. It is assumed that this information was used in the other articles in this section as parameters for the other testing methods.

Naderi and Mehmood (2005) critiques cutoff wall backfill mix designs created for specific projects that have failed, according to the author. No specific project is stated. The unique aspect of this paper is that a statistical analysis is completed and then coefficients of influence on compressive strength and modulus of elasticity are provided. One mix was selected as the preferred mix out of the 225 different mixes prepared for this study. Triaxial, biaxial and permeability tests were completed on the preferred mix samples. The comparison graphs focus only on the constituent material to the material behavior (compressive strength, cohesion, friction angle). They do note a comparison between triaxial and biaxial testing was completed, and concluded that the triaxial test was more appropriate due to the lateral pressures induced in-situ.

Pashazadeh and Chekaniazar (2011) provide a series of graphs to aid in the mixture design selection for plastic concrete cutoff walls and reduce research and development time, similar to the work completed by Kahl, Kauschinger, and Perry (1991). Numerical analyses were conducted with compressive strength, modulus of elasticity and permeability as dependent variables and bentonite, cement and water 
content as independent variables, however the testing program to obtain these values is not discussed.

Jafarzadeh and Mousavi (2012) describe the testing program for Silve Dam in Iran. They note that as of the publication date of the article, there is no explicit recommendation about the mechanical characterization of plastic concrete. The primary objectives of the research were to describe their approach to measuring the effect of the confining pressures during triaxial compression on the mechanical strength, and to characterize time effects on plastic concrete. Constant rate of strain loading was used for the computer controlled triaxial system. They also note a lack of accepted guidelines for suitable rate of strain for plastic concrete, so they chose $0.1 \mathrm{~mm} / \mathrm{min}$ for the axial strain rate, modifying the guidelines for soil mechanics. This rate keeps the test in the drained condition. The results compare different mechanical properties. Strength is compared to confining pressure, stress versus strain, age is then compared to the strength and confining pressure, specimen age to strength, and elastic modulus to age.

Yan, Trapp, and Sy (2008) describe the plastic concrete cutoff wall constructed under New Coquitlam Dam, a replacement dam of a hydraulic fill dam, in a region of high seismic hazard in British Columbia, Canada. The paper describes the field and laboratory testing performed to confirm design wall stiffness, strength and permeability requirements.

The dam owner completed a preliminary laboratory trial mix test to assess their design criteria. Triaxial consolidated undrained tests with the specified confining pressure were used to develop the design criteria. Unconfined compressive strength testing, and 
triaxial permeability testing with gradients of 20 and 40 were also used. This information was provided to the contractors during the bid process, and the contractor was ultimately responsible for the final mix design.

The strength and stiffness parameters of the cutoff wall were determined based on 2-dimensional static and dynamic finite element stress analyses using FEADAM and FLUSH computer programs. The strength and stiffness parameters were specified with an effective confining soil stress of $300 \mathrm{kPA}$, which replicates the in-situ conditions where the highest bending stresses were anticipated based on the computer models. This paper also discusses field testing of the placed plastic concrete consisting of: unconfined compression testing, permeability of cylinders from pours, and in-situ falling head tests.

Ghazahi, Safarzadeh, Hashemolhoseini (2004) uses finite element methods to look at the dynamic behavior of a plastic concrete cutoff wall installed in an earth embankment dam subject to a certain seismic load before reservoir impoundment. Assumptions made for the model input include: the dam, foundation, and cutoff wall have linear and elastic behavior, unit weights, and modulus of elasticity for each component. The paper does not elaborate on how the unit weights and modulus of elasticity were selected or calculated. The study concludes that there is an increase in wall material stiffness that leads to increasing stresses generated in the wall, with the highest values at the ground surface, or the contact between the embankment and the foundation. 
This is an interesting way to analyze the performance of a cutoff wall and it would be beneficial to run this type of an analysis in conjunction with a cutoff wall design or for long term performance.

Zhang, Hu, Pu, Yin (1999) discuss the testing program for the plastic concrete cutoff walls used under the cofferdams during the 3 Gorges Dam project. Plastic concrete both with and without coarse aggregate was used in different locations of the cofferdams.

Testing of the plastic concrete consisted of: permeability in a specialized permeameter developed for plastic concrete, unconfined compression testing, consolidated drain triaxial, and finite element methods. The paper does not discuss how the mix designs were selected. The Duncan Chang nonlinear elastic model was used for numerical modeling of the cutoff wall. Most of the Duncan and Chang parameters used were obtained from the triaxial testing. Tangent modulus and Poisson ratio were derived. This analysis provided maximum settlement and maximum horizontal displacements along the cutoff wall, which for this research occurred at the crest of the cofferdam. For the finite element method, a method called THEPD, developed by Tsinghua University was used to evaluate the stresses and deformations of the cofferdams and cutoff walls.

Bigras et al. (2005) detail the plastic concrete cutoff wall of Peribonka Dam in Canada. They note an extensive testing program to assess the mechanical behavior of the plastic concrete and an assessment of the sensitivity to erosion of the different mixes in the development stage. Unconfined compression, consolidated isotropic drained and undrained compression triaxial, and Brazilian (splitting tensile) tests were completed for 
the mechanical properties. Erosion resistance testing consisted of high pressure water tests, modified pin-hole erosion tests and controlled water velocity tests. Unfortunately, no results or comparisons were given in the paper. The testing program was based from the research of Kahl, Kauschinger, and Perry (1991), described earlier.

Donnelly et al. (2007) describes a cutoff wall for a replacement new construction dam. The initial of the mix design used numerical modeling that was later adjusted with actual compression test results from trial mixes, and was completed after an advanced analysis to determine parameters of the foundation soils and the embankment. The initial design modeled the cutoff wall as a concrete beam element, then was later re-designed with the consideration that the cutoff wall behaved as an elastic-perfectly plastic material. Trial mixes subjected to compression testing were then completed and the model was adjusted on those values. Strain was determined to be the most significant parameter in the design, and the specification was written to define a minimum of $4.5 \%$ strain at failure. By designing for the strain, the cost of the project decreased significantly due to decreased amount of cement needed. Donnelly et al. (2013) follows up on the cutoff wall construction by providing long term performance data 5 years after construction. 42 vibrating wire piezometers and 3 seepage monitoring locations were installed to determine the effectiveness of the cutoff wall based on hydraulic efficiency. Tatone et al. (2009) describes the hydraulic efficiency calculations. This hydraulic efficiency is compared to other dams with cutoff walls installed, however the dams are not specified.

\author{
Non-Specific/ General
}


Table 2.3 summarizes the literature reviewed that discuss material testing, but are not necessarily associated with a specific dam remediation project. In addition to citing the reference, the topic discussed in the paper is given. The text following the tables then recounts each project in more detail and how it relates to the current research work.

Table 2. 3 Summary of Testing Methods Used to Characterize Plastic Concrete in General

\begin{tabular}{ll}
\hline Reference & Topics Discussed \\
\hline Alzayani, Royal, Ghataora, and Jefferson 2016 & Mechanical Properties \\
Banzhaf and Colmorgen 2001 & Mixture Designs \\
Shi, Li, 2015 & Mechanical Properties \\
Zhang, Guan, Li, 2013 & Mechanical Properties \\
\hline
\end{tabular}

Alzayani, Royal, Ghataora, and Jefferson (2016), cited a lack of knowledge about in-situ performance of cement-bentonite (CB) materials as the basis for conducting their research. They attempt to gain more information about in-situ behavior of cementbentonite by reviewing the deformation behavior of other commonly encountered materials: concrete, rock, clay and cemented soils, and then compare them to CB stressstrain response. The research is does not yield any direct comparisons between materials and it also brings to light that micro-cracking of the $\mathrm{CB}$ before reaching peak strength can cause a substantial loss of seepage reduction.

This paper also provides insights to the current lack of testing procedures and parameters to ensure a thorough characterization of the $\mathrm{CB}$, which also applies for plastic concrete. Most of the time there are no specific tests requested to check for minimum shear strength and maximum allowable strain, and that decision is left to the owner or 
contractor. Parameters for triaxial testing such as drained versus undrained loading conditions, magnitude of confining stress, and rate of strain for unconfined compression strength (UCS) tests are left up for interpretation. These parameters should be carefully chosen to reflect in-situ conditions to validate the mixture design. They also state that UCS testing should be used as an "indicative test, rather than authoritative means of determining shear strength."

Banzhaf and Colmorgen (2011) was written by one of the main contractors installing plastic concrete cutoff walls. All of their mixture designs are proprietary and tailored to specific sites, without going into detail about the testing program employed. In the conclusions, they note their experience in creating "project required concrete mixes."

Shi and $\mathrm{Li}$ (2015) present work on a cemented soil from a railroad subgrade to show the relationship between strength and stiffness of soil using consolidated-undrained triaxial testing. They note that most researches focus on strength and deformation, not stiffness when presenting data. Stiffness is represented in their data using the Secant Modulus. For this research, the Bulk Modulus was used to characterize stiffness.

Zhang, Guan, $\mathrm{Li}$ (2013) looks at the effect bentonite on the mechanical properties of plastic concrete, specifically water cement ratio and amount of bentonite. The mechanical properties studied are compressive strength, tensile strength, shear strength, ductility, and stiffness using separate tests to obtain each property. They briefly mention that bentonite and kaolinite were used and have a large effect on the strength of plastic concrete, and plasticity of the concrete, but they don't go into detail. 


\section{Long Term Performance}

Limited information is available for the long-term performance of plastic concrete cutoff walls. The following references were reviewed that give insight into this aspect, as well as the numerical modeling, laboratory testing, and field testing conducted to determine long-term performance.

- Bruce, Ressi di Cervia, Amos-Venti 2006

- Joshi, et. al 2010

- Rice, Duncan 2010A

- Rice, Duncan 2010B

- USACE 1993

Bruce et al. (2006) provides a wealth of information on constructability issues but not necessarily testing procedures for cutoff wall mix designs. However, they mention the need to publish long term performance papers on installed cutoff walls since most papers are written within a very short time of the completion of remediation.

Joshi, et al. (2010) looks at the long term hydraulic performance of a slag-cementbentonite cutoff wall using different in-situ and laboratory tests. Piezocone tests (CPT), packer tests, and self-boring permeameter tests were conducted in field to determine the suitability of different in-situ techniques and compare with the laboratory results. Laboratory tests measured hydraulic conductivity (permeability) with constant-flow tests performed in a standard triaxial flexible wall permeameter cell. They also note that a B value of 0.9 was considered acceptable for this material since the permeability was so low. Finally, they note that "at present, no approved method exists for the determination 
of all of the required parameters for slag-CB walls. A goal of their research was to prove that the in-situ techniques, the self-boring permeameter (SBP) specifically, could provide a good correlation to the laboratory testing data, and provide long-term performance data of cutoff walls.

Rice and Duncan (2010a) present a finite element seepage analysis procedure to look at post-construction deformation of cutoff walls due to changes in the pore pressure regime. This procedure is applied to 5 dams with cutoff walls. They conclude that deformation due to the pore pressure regime change is the likely mechanism causing cracking of cutoff walls. This illustrates the importance of predicting the changes in stress when installing a cutoff wall. A crack in the seepage barrier is not necessarily detrimental to the overall reduction in seepage, other factors that would cause an enlargement of the cracking are just as important to consider. These factors are: aperture of the crack or size of the defect, the permeability of the surrounding soil, and the erodibility of the seepage material. All of these variables can be determined in the predesign phase of a project.

Rice and Duncan (2010b) investigates cutoff wall installations that have been in place for over 10 years and how the barrier has changed the potential failure modes of the dams, that may not have been consider during the design and construction of the wall. Finite-element soil-structure interaction analyses were completed with the performance data to show that the differential pore pressure acting across the cutoff wall provides a mechanism for cracking to occur. This shows the importance of understanding the 
ductility and healing behavior of the cutoff wall material in-situ by using laboratory testing methods to simulate these conditions prior to construction.

The U.S. Army Corps of Engineers Engineering Manual, EM-1110-2-1901 (USACE 1993) provides long-term performance instrumentation options after a cutoff wall has been installed. Piezometers, drains, relief wells, seepage measurement weirs or flumes, can be installed as permanent performance indicators. Remotes sensing methods such as: resistivity, refraction seismic surveys seepage acoustic vibrations, and annual photography are also possible selections to determine long term performance of the cutoff wall. While cutoff walls are discussed for seepage control, the mix design procedure is not discussed. 


\section{CHAPTER 3}

\section{APPARATUS AND TESTING PROCEDURE}

\section{Methodology Background}

Based on the current published literature, it is not common to combine permeability measurement equipment with triaxial testing equipment. However, this concept was first suggested in the 1980s in Olsen et al (1988) and Menzies (1988). They note the biggest advantage to the this set up is that it reduces the amount of equipment needed and the number of test specimens needed to define permeability, compressibility and strength of soil. Several manufacturers of geotechnical laboratory testing equipment offer this configuration, including GEOTAC and GDS. The GEOTAC system was used for this research. Single specimens were batched to complete this testing, with multiple specimens made for each mix.

\section{Mix Design and Specimen Preparation}

Mix designs prepared for this research were chosen to illustrate the proof of concept for this testing method by presenting a wide variety of cement and clay (bentonite or kaolinite) contents. Success of this testing method is based on the effectiveness of illustrating and quantifying the differences in behavior of the different mixes. Mixes consisted of cement, sand, water and clay (bentonite or kaolinite), no coarse aggregate was used due to the size limitations of the testing apparatus. One sample used kaolinite (Helmer/low plasticity) clay. Table 3.1 presents the mix design 
proportions, by weight. Mixes 1,2,3,7 and 8 used bentonite as the clay, Mix 4 used kaolinite.

Table 3. 1 Mix Designs

\begin{tabular}{lllllll}
\hline Mix \# & 1 & 2 & 3 & $4^{\mathrm{a}}$ & 7 & 8 \\
\hline \% cement (by weight) & 2 & 4 & 6 & 2 & 6 & 6 \\
\% bentonite (by weight) & 8 & 6 & 4 & 23 & 2 & 6 \\
\% sand (by weight) & 90 & 90 & 90 & 75 & 92 & 88 \\
\hline
\end{tabular}

${ }^{\mathrm{a}}$ Kaolinite used in lieu of bentonite

Specimens were prepared in batches using a stand kitchen mixer. The procedure described below provided an accelerated curing time of the specimen to replicate the properties that are comparable to a conventional 28-day cure used for testing in a shorter amount of time. Fig. 3.1 shows the specimen preparation set up.

The initial mass of water for the specific mix (by weight) was added to the mixer bowl. The prescribed mass of bentonite for that mix was then added to the water in the mixer bowl and stirred slightly by hand to allow for exposure of most of the bentonite to the water initially. The water and bentonite were then left to hydrate for at least 24 hours.

After the 24-hour hydration period, the bentonite and water were gel-like. The cement was added to the bentonite and mixed on low speed for at least 10 minutes. Since the bentonite absorbed almost all of the free water, more water was then gradually added before the sand was introduced to the mix. The sand was then added along with more water as needed to obtain the desired slump of 1 to 2 . The mass of the additional water 
was recorded during this process. After all the components of the mix was added, the specimen was mixed for approximately 5 to 10 minutes to allow for even distribution of constituents throughout the mix.

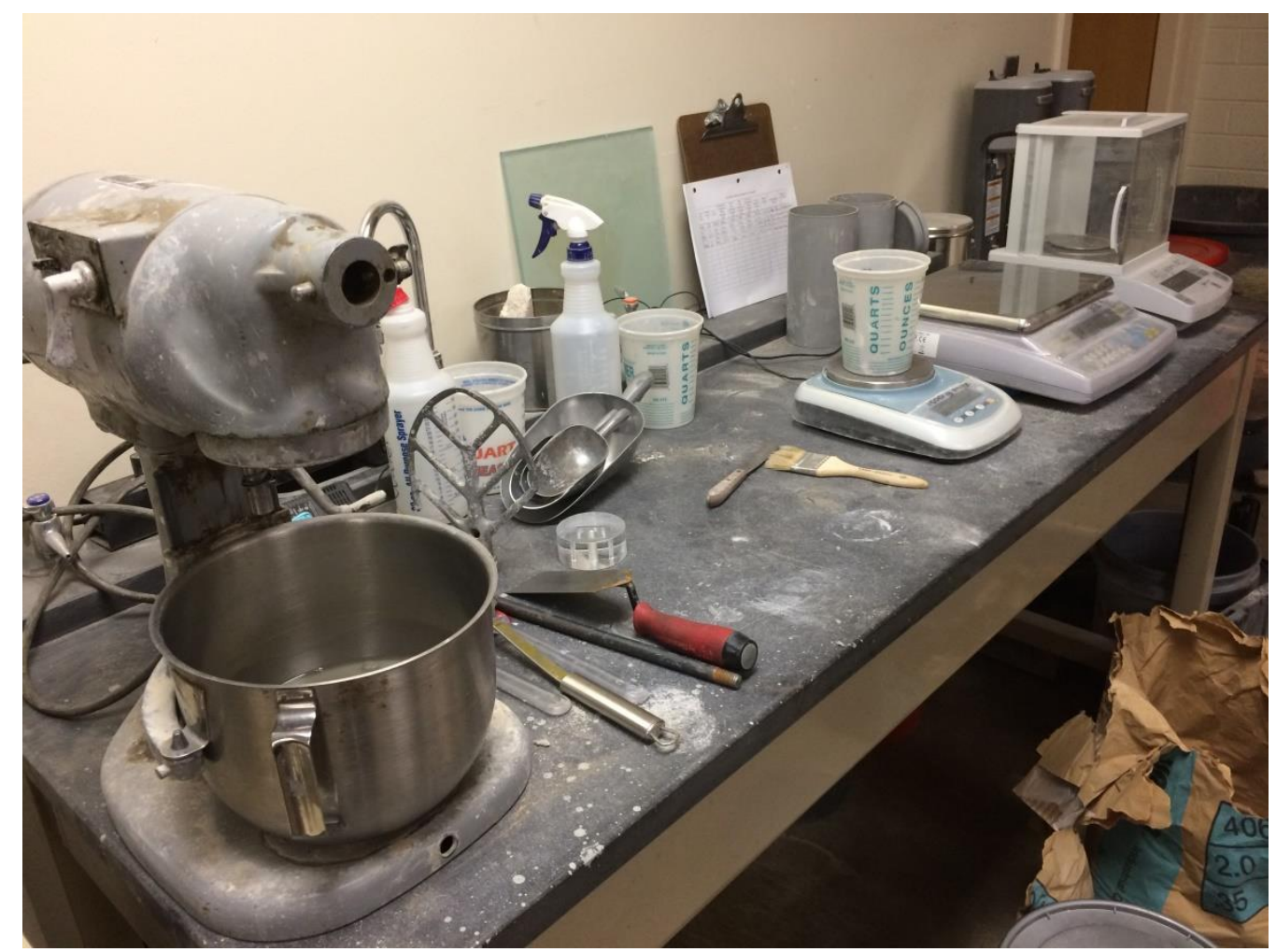

Fig. 3. 1 Specimen preparation equipment

For this research, a 2.8-inch diameter specimen was used, allowing for a minimum 2:1 height to diameter ratio as required by ASTM D7181-11 standards for triaxial testing. The mold was lined with a rubber membrane. The use of the membrane enabled easier removal of the sample from the mold. A vacuum was pulled on the 
membrane to ensure the maximum diameter was being achieved. A platen was placed at the bottom of the mold to provide a plug to keep the mix in the mold. The specimen was placed in the mold in 3 lifts, and tamped 25 times with a rod at each lift. The top of the specimen was leveled using a masonry trowel. The filled mold was then placed in room temperature water for the initial 24-hour cure. Fig. 3.2 shows a freshly molded specimen.

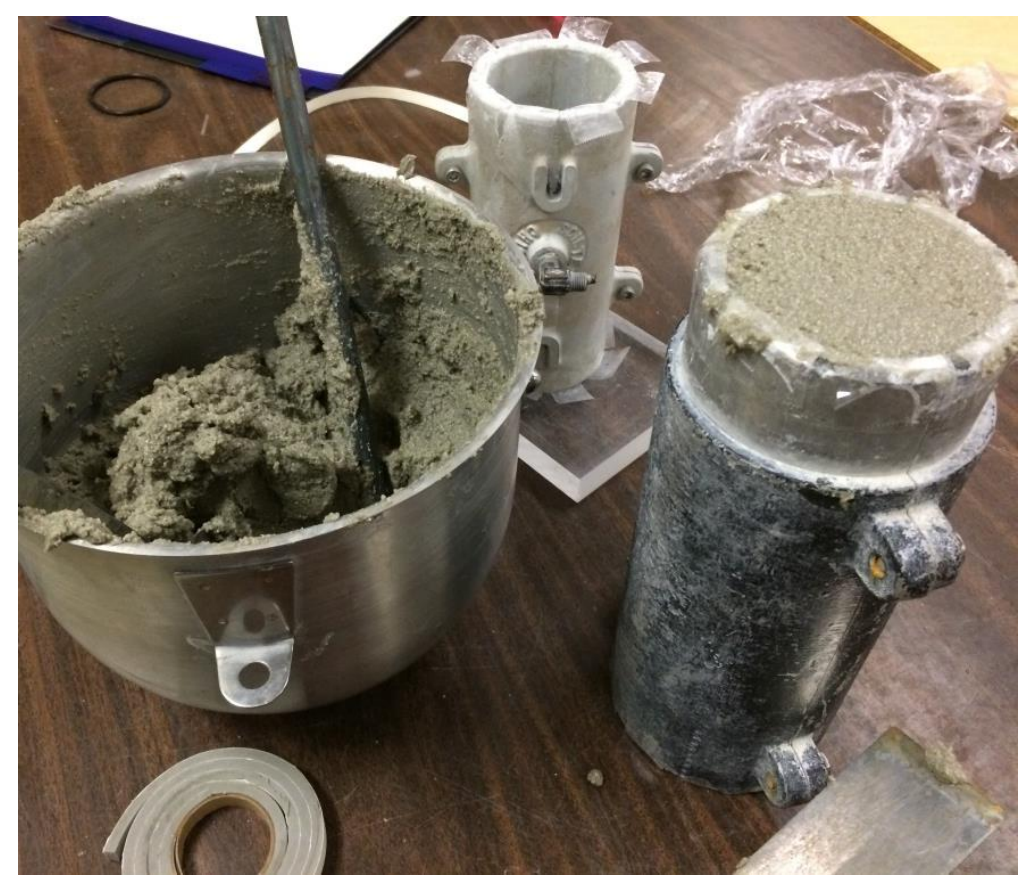

Fig. 3. 2 Molding a specimen

After the initial cure in the room temperature water bath, the specimen was removed from the mold and the rubber membrane. The specimen was then placed in a heat-resistant container deep enough for the specimen to be completely submerged in water. The specimen and the water bath were then placed in a $90^{\circ} \mathrm{C}$ oven for 24 hours to 
complete the curing process. After the oven cure completed, the specimen in the water bath were allowed to slowly cool back to room temperature for 12 to 24 hours.

The cooled specimen was then placed in a water-filled vacuum chamber for a minimum of 24 hours, until the specimen was to be used for testing. This step aided in the full saturation of the specimen necessary for testing.

\section{Testing Procedure}

The following sections described in detail the processes used in each step of the testing method. Schematic figures are used to illustrate the valve configurations during steps of the testing procedure. Fig. 3.3 illustrates the testing equipment configuration, which combines the Sigma1-CU Automated Load Test System (Trautwein 2000A) and the DigiFlow-K General Purpose Automated Hydraulic Conductivity (Permeability) (Trautwein 2000B) Measurement System for Geotechnical Laboratories. Fig. 3.4 is the basic schematic that is used throughout the testing procedure.

As previously mentioned, the specimen used for this research measured a nominal 2.8-inch diameter. Based on ASTM 4767 (2011), the width to length ratio ideally should be to be at least 2.5. Due to the constraints of the testing apparatus, the sample lengths ranged between six (6) and (7) inches, for a ratio of 2.1 to 2.5. Each specimen was trimmed down to length using a grinding stone submerged under running water.

Careful measurements of the length, width, and weight of the specimen were recorded. The length of the specimen was measured using a caliper at 2 locations, to obtain an average length. The diameter of the specimen was measured using a pi tape at 2 
locations, to obtain the average diameter. The specimen was weighed before and after testing to obtain a unit weight of each mix.

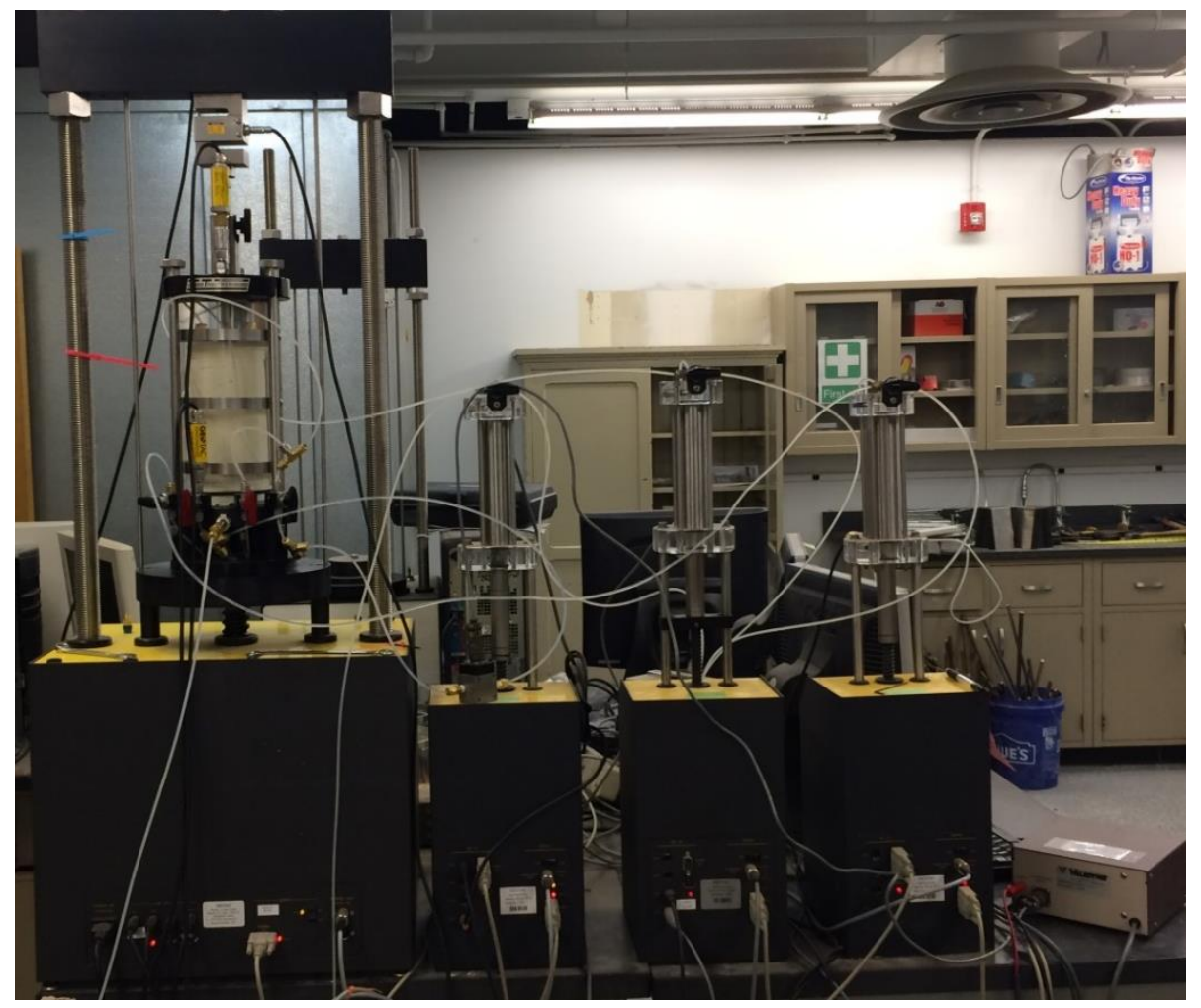

Fig. 3. 3 Equipment configuration illustration 


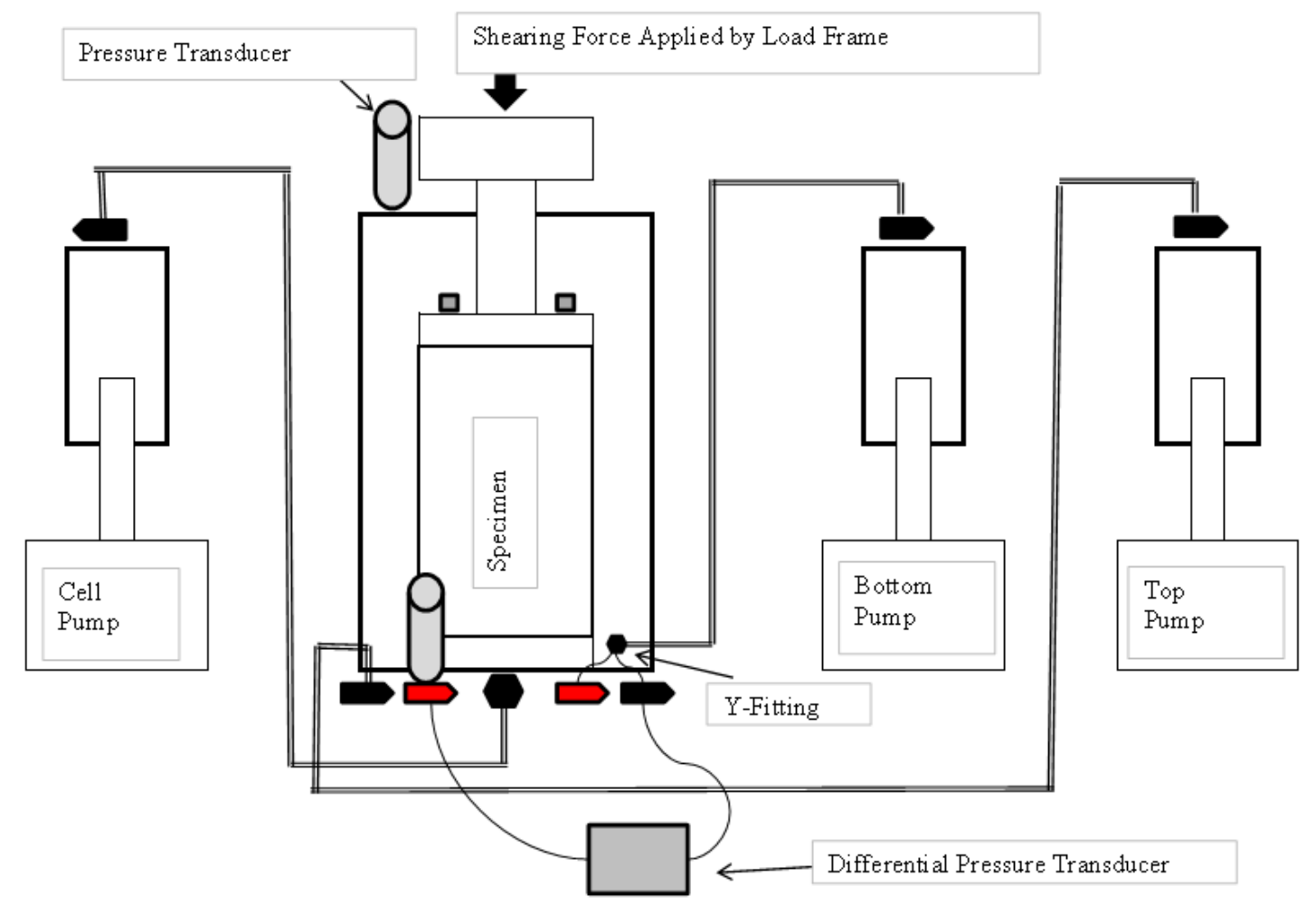

Fig. 3. 4 Generalized schematic of the equipment configuration

The specimen was then assembled for testing. Porous stones, which were also hydrated in the water-filled vacuum apparatus, were placed on the top and bottom of the sample. Top on bottom platens were placed on top of the porous stones on the top and bottom of the specimen. A rubber membrane was placed on the outside of the specimen, porous stones, and platens. The specimen was then moved onto the test cell base. Rubber gaskets secured the membrane to the top and bottom platens. The poly-lines used for water permeation into the sample were secured to the top platen, and the test cell outer cylinder was then lowered onto the base. Fig. 3.5 illustrates the components described above to mount the specimen onto the test cell. 


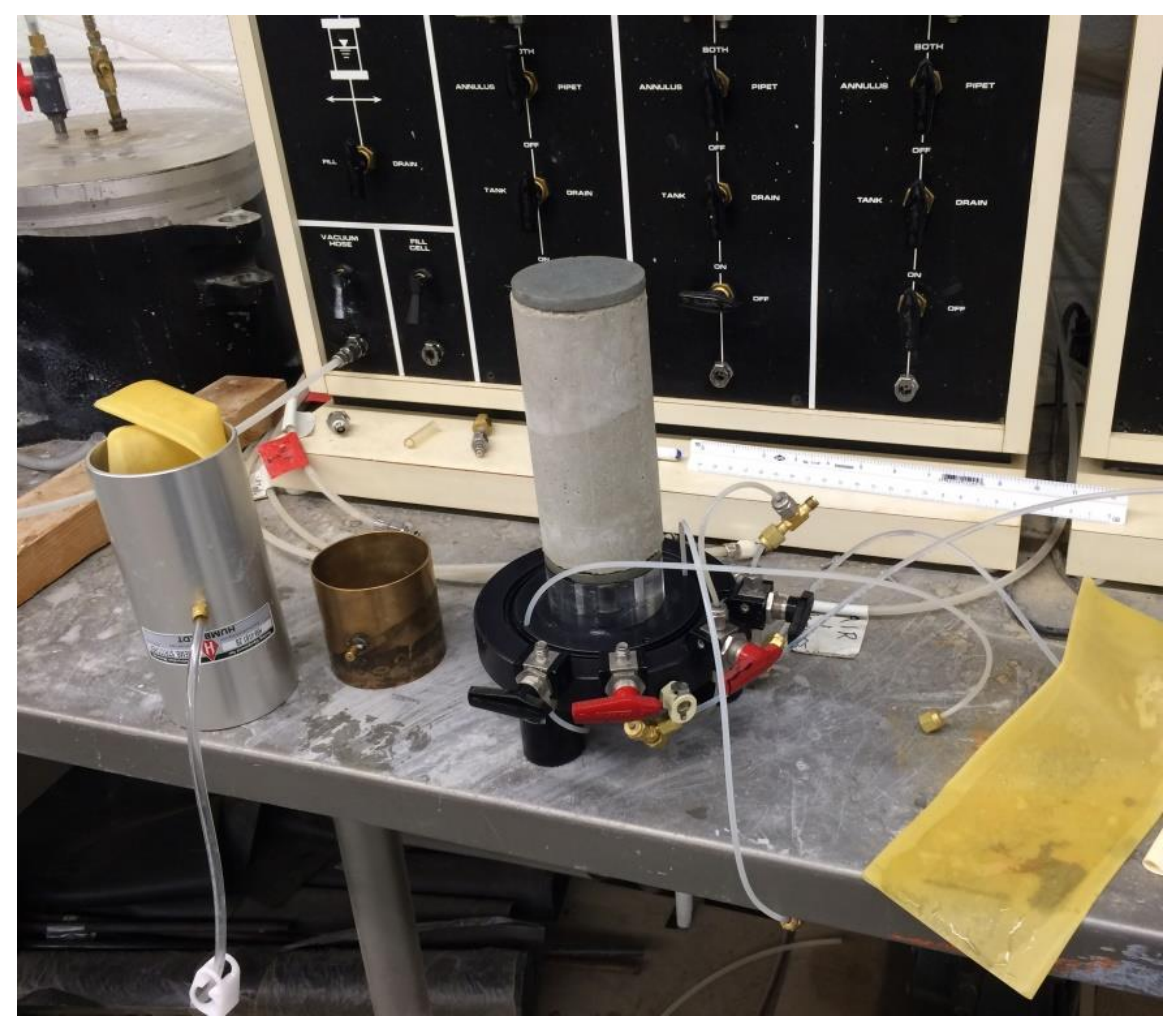

Fig. 3. 5 Mounting a specimen onto the test cell

The top of the test cell was placed on the cylinder and a relief vent was added to allow for air to escape as the cell was filled with water. De-aired water was slowly added to the cell from the bottom port until the entire cell was filled; making sure minimal air bubbles remained in the cell after filling.

Two computer programs, Digi-Flow K and Sigma1-CU, both manufactured by GEOTAC, were used simultaneously during the testing procedure. The Digi-Flow K program controlled and recorded the permeability and flow data. The Sigma1-CU program controlled and recorded the consolidated-drained (CD) triaxial testing. 
Sensor Zero and Span Check

The first step in the testing procedure provided the calibration of the pressure sensors. The test cell and flow pumps have a total of 5 pressure transducers, all 200 psi capacity. The test cell has 2 transducers, one to measure cell pressure and one to measure pore pressure of the specimen. Each of the three flow pumps has a pressure transducer attached. For this step, a calibration triaxial test cell was used. This calibration cell is the same as the actual triaxial test cell used for the specimen, except it contained no specimen, only water. One of the lines on this calibration cell was replaced with a standtube to allow for pressure equalization during the calibration. All of the transducers were first zeroed to atmospheric pressure by opening the stand-tube line. Then the transducers were calibrated to the cell pump pressure transducer by raising the pressure to $100 \mathrm{psi}$ and using Equations 3.1 and 3.2.

For transducers reading lower than the calibration transducer:

$$
\text { New Cal factor }=\frac{\text { cal pump }}{\text { other pump }} * \text { old cal factor of other pump }
$$

For transducers reading higher than the calibration transducer:

$$
\text { New cal factor }=\frac{\text { other pump }}{\text { cal pump }} * \text { old cal factor of other pump }
$$

Successful calibration ensured that all transducers were within $+/-0.05 \mathrm{psi}$ of the each other. Calibration was repeated until this range was obtained. 
Apply seating pressure and flush lines

The purpose of this step is to apply the initial seating pressure on the specimens. A pressure difference of 2 psi was used for testing the specimens, $10 \mathrm{psi}$ in the specimen, 12 psi in the cell. Each flow pump line was transferred from the calibration cell to the test cell and the lines were flushed to remove as much air as possible. Fig. 3.6 illustrates the configuration of the valves at the end of this testing procedure step.

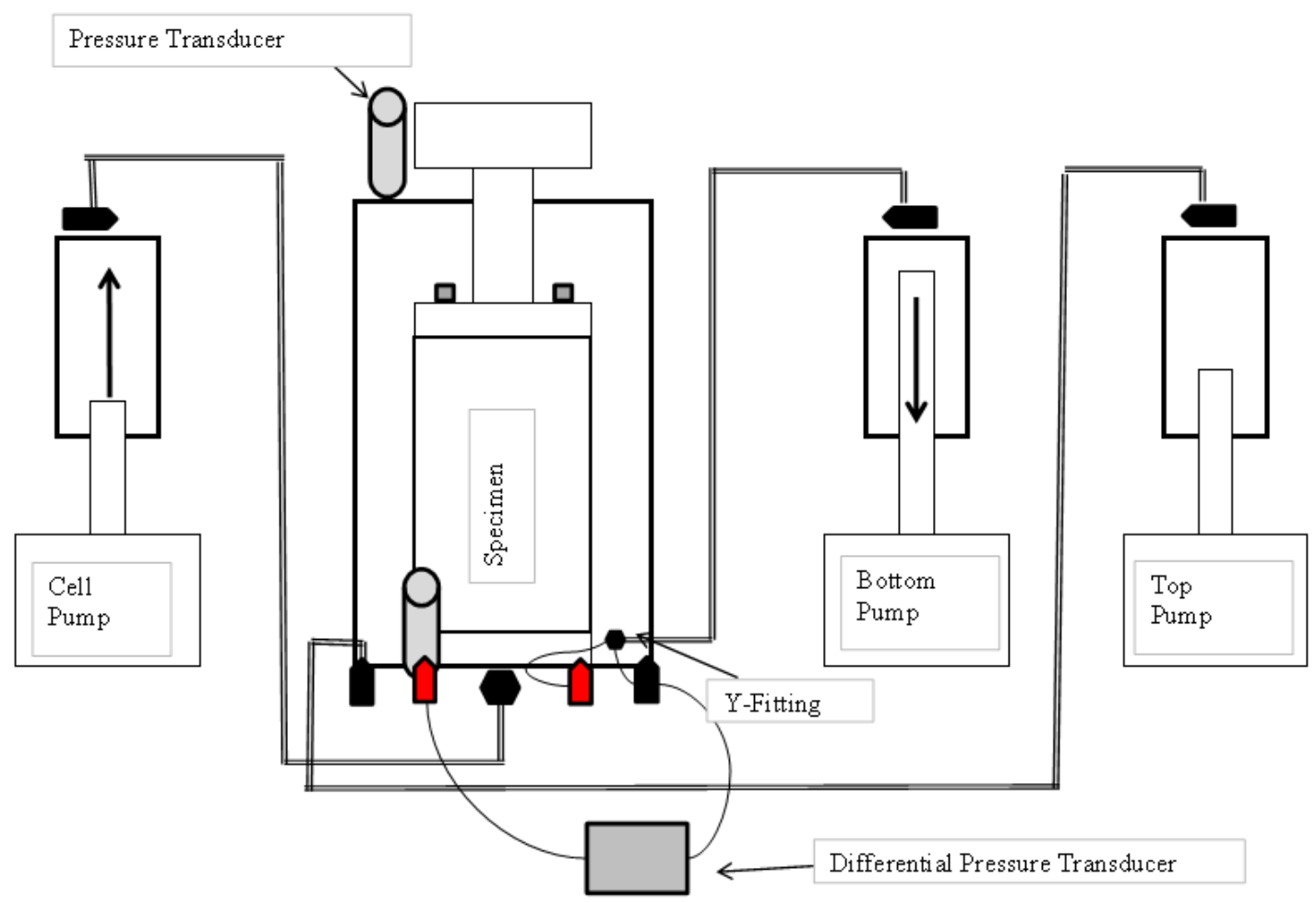

Fig. 3. 6 Equipment configuration at the end of applying seating pressure step 


\section{Back Pressure Saturation}

The purpose of this step is to ensure saturation of the specimen. This allowed for more accurate pore water pressures to be recorded. Saturation was checked by using Skempton B-value checks in the Digi-Flow K program. Pressures were ramped at a specified rate and B-value checks were performed at certain pressures, from 30 to $100 \mathrm{psi}$ during the ramping process. B-value checks were performed at 1 and 3 minutes after the check was started. Typical B-values ranges are between 0.9 to 1.0 for clays, and due to the nature of the backfill material these values also are appropriate. Values greater than 1.0 indicated a leak somewhere inside the testing system (in the test cell). Values less than 0.9 , or decreasing values also indicated a leak outside of the system (in the lines from the flow pumps or the fittings) or lack of complete saturation of the specimen. When that happened, the test was stopped and the test cell was dismantled to check all of the connections for tightness.

\section{Consolidation}

The purpose of this step is to bring the specimen to the effective stress required for shearing. A consolidation pressure of $30 \mathrm{psi}$ was used for this testing. The time of consolidation was adjusted several times during the evolution of this testing procedure. On some initial tests, the time for consolidation was not sufficient enough to reach the end of primary consolidation, and therefore it appeared that there was a large amount of secondary consolidation that occurred. Primary consolidated was considered complete when the volumetric strain vs time curve leveled off. At least 12 hours was needed for each specimen to reach the end of primary consolidation at a rate of 2 psi/hour, however 
this time varied for each mix based on the cement/bentonite ratio in the mix. From the consolidation curves, a measure of the stiffness of the backfill material was calculated (Bulk Modulus, K) using the volumetric strain versus effective stress curves, using the slope of the consolidation curve.

Initial Permeation

For this testing procedure, permeation can be performed under undrained (constant volume) or drained conditions. Undrained field conditions are applicable to materials that have been fully consolidated under one set of stresses then are subjected to a change in stress without time for further consolidation to take place (ASTM D4767-11). This condition represents the short term behavior of a cut-off wall backfill material, directly after placement, since pore pressure is building up. Since this research looks more at the long-term in-situ behavior of the cutoff wall backfill material, the drained condition is more applicable.

For undrained permeation, the flow rates in and out of the sample are controlled to be equal, but opposite throughout the test. Thus, the volume of the sample remains the same and the effective stress will adjust to maintain a constant volume. Due to the maximum limitation of the triaxial cell used and the volume of the flow pumps, a sufficient back-pressure to maintain saturation in the sample could not be achieved. Future research may aid in the understanding of the deformation that occurs directly after placement of the cutoff wall backfill material and how it affects long term behavior, but is not discussed in this research. 
Drained permeation can be accomplished by either maintaining a constant gradient or constant flow rate. For a constant gradient, the pressures at the top and bottom of the specimen are controlled to maintain a constant head-loss across the specimen, and the flow rate then varies with permeability. For constant flow rate, the top flow pump was set to maintain a constant flow rate into the specimen, and the bottom flow pump was set to maintain a constant pressure, so that the flow rate remained constant, but the gradient across the sample changed with permeability. This research used a combination of the drained permeation conditions. In an actual in-situ cut-off wall condition, it is feasible for either pressure control of flow control to occur, depending on the subsurface conditions. Running the pumps in flow control also provides a better test because it removes the lash from the flow pump screw jack trying to regulate the pressure. For approximately the first 30 minutes of permeation, the flow pumps were turned to pressure control. A pressure difference of 5 psi was used, which is equivalent to a gradient of 20. After the inflow and outflow converged, the flow pumps were changed to flow control with that convergent value. At the beginning of this research, the gradient was measured using the flow pump pressure transducers. To provide a more accurate gradient measurement, a differential pressure transducer was added to the system after the first few tests.

The specimens were permeated for at least 24 hours before the first triaxial shear increment. Fig. 3.7 illustrates the configuration of the equipment at the start of the permeation testing procedure step. 


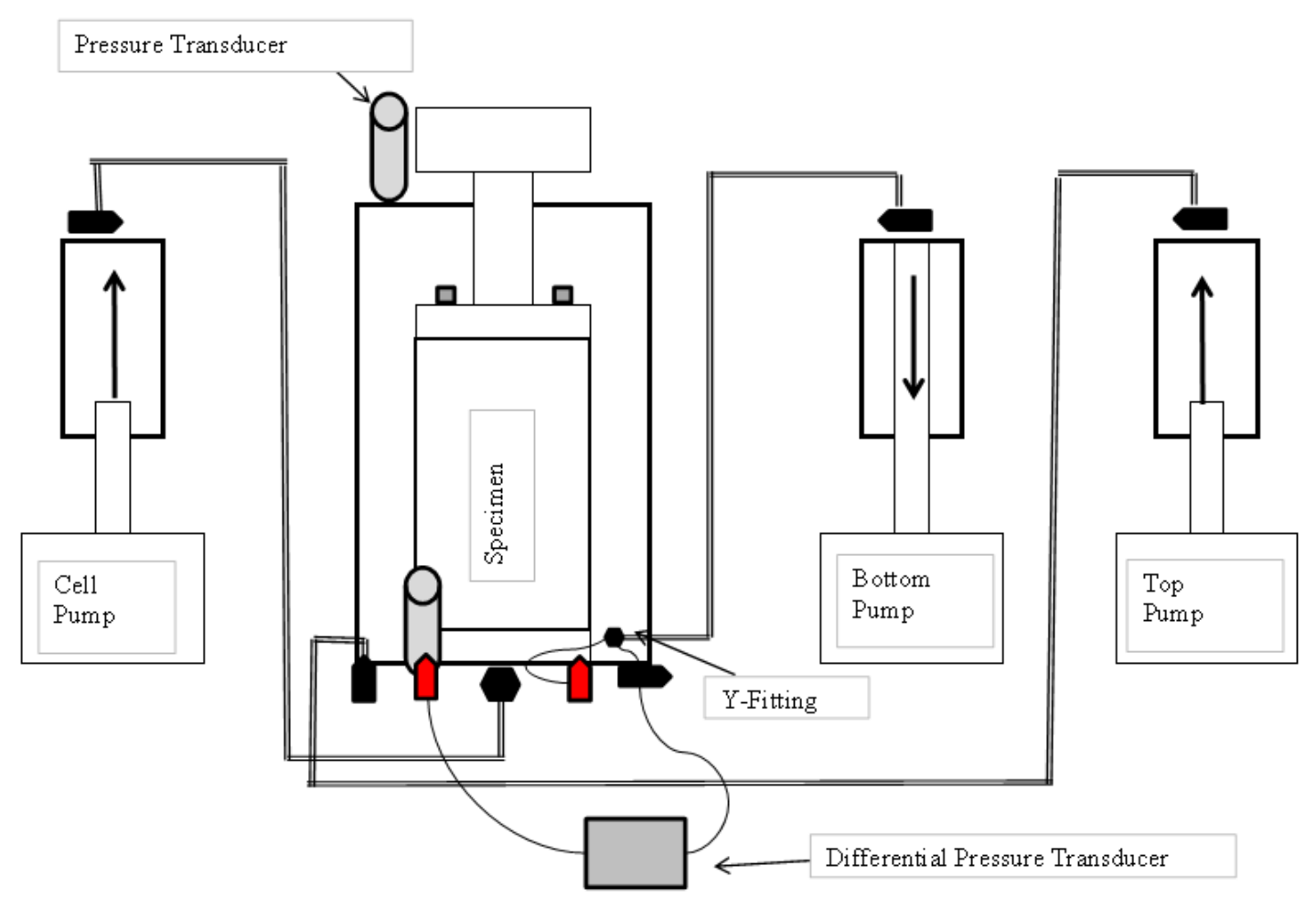

Fig. 3. 7 Equipment configuration for the start of the permeation step

Triaxial Shear with Permeability Measurements

After the specimen had undergone constant flow rate initial permeation for at least 4 hours to ensure a high quality initial permeability measurement, the top pump controlling the flow rate was turned off for at least 30 minutes before the triaxial shear increment. This allowed effective stress to equalize across the specimen. This was to minimize non-uniform deformation throughout the sample. During preliminary testing, the failure mechanisms, bulging, cracking and fissures, tended to concentrate at the inflow end (top) of the specimen because this was the area with the lowest effective stress. This also creates non-uniform permeability across the specimen. 
During drained loading, the inflow and outflow were unequal due to volume change in the specimen so accurate permeability measurements could not be achieved. Because of this, incremental, or staged, triaxial testing was used. Permeability measurements were then taken between the increments to assess the behavior throughout the deformation of the specimen, in both the plastic and elastic regions of the stress-strain curve. ASTM D4767 recommends a rate of axial strain that will produce approximate equalization of pore pressures throughout the specimen at failure using Equation 3.3 and assuming failure after $4 \%$ strain:

$$
\varepsilon^{\prime}=\frac{4 \%}{(10 * \mathrm{t} 50)}
$$

Where:

$\varepsilon^{6}=$ rate of strain

$\mathrm{t}_{50}=$ time for $50 \%$ primary consolidation

A strain control rate of $1.5 \%$ per hour was chosen using the Sigma1-CU computer program, with incremental maximum strain values as follows: $0.8 \%, 1.6 \%, 3.2 \%, 4.8 \%$, $8.0 \%, 11.2 \%, 14.4 \%$ and if necessary $15 \%$. Permeability measurements were calculated between the shear increments after inflow and outflow through the specimens equalized. Permeation was run for at least 4 hours between shear increments to also assess any healing (or possibly clogging) behavior that occurred during the relaxation intervals. Average permeability measurements were reported for the initial permeability after the inflow and outflow had converged (inflow/outflow ratio of at least 0.9 ) directly after a shear increment, and permeability change during permeation before the next shear 
increment. Figure 3.8 shows the valve configuration of the testing equipment at the start of a triaxial shear testing increment and the water flow directions from the pumps.

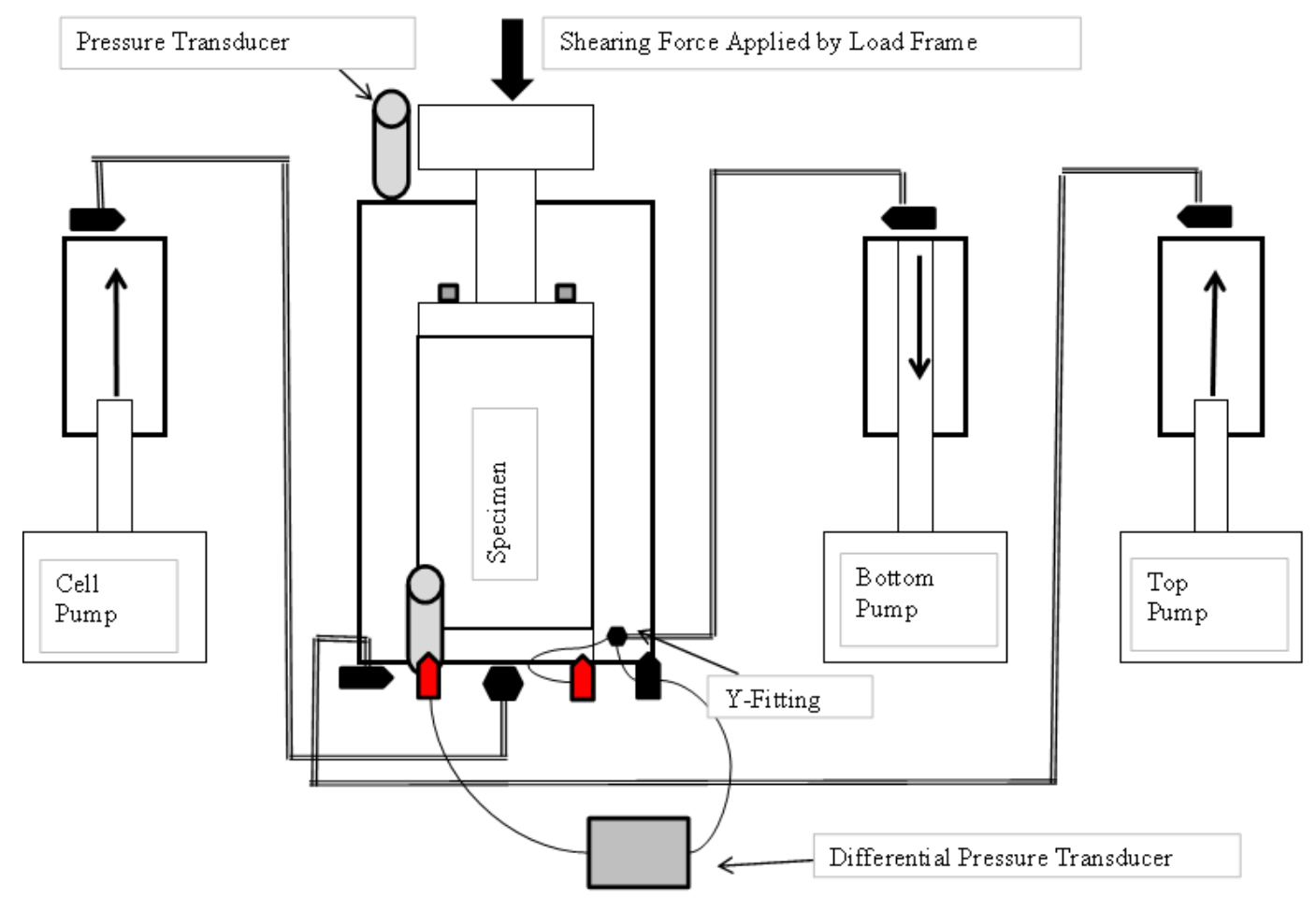

Fig. 3. 8 Equipment configuration at the start of a triaxial shear testing increment

This sequence of permeation and triaxial shear continued through the strain increments discussed above, until the point during the shear increments where the principal stress/strain rate graph either peaked or leveled off. This indicated that the specimen had reached failure, or the end of the plastic region of the material, and the test was complete. The permeation was run for at least 4 hours to record the final permeation measurements. Then the specimen was removed from the test cell, photographed, weighed and dried in the oven to obtain unit weight and moisture content. 
The testing procedure configuration of this research closely resembles that discussed in Hinchberger, Weck, and Newton (2010). A GDS computer-controlled triaxial system, similar to the GEOTAC system, was used to allow for permeability measurements during constant rate of strain triaxial testing. Their research was the first to publish the influence of compressive strain on the permeability of plastic concrete. Based on the literature reviewed in the previous chapter, this testing was completed for a cutoff wall in a new dam that was constructed in Canada. The main difference in their purpose was to illustrate an approach to measure the effect of axial strain during triaxial strain on permeability, to characterize the effects of time and compression rate on the response of plastic concrete, and to characterize the effect of axial strain on the permeability. A strain rate of $0.012 \mathrm{~mm} / \mathrm{min}$ was used with maximum shear value increments of $0.5 \%, 1 \%, 2 \%, 4 \%, 6 \%, 8 \%$, and $10 \%$. The strain was held constant to measure the permeability for at least 8 hours between increments. A gradient control of 6.5 was used. They noted that it took approximately 5 hours for the inflow and outflow to equilibrate after shear increments, therefore they only took 1 permeability measurement, and did not look at the change in permeability during permeations. Multiple confining stresses were tested in their program of 15,58 , and 130 psi. The 130 psi confining pressure corresponds to this thesis research and show similar small changes in permeability throughout the triaxial shear testing, which will be discussed in the next chapter. 


\section{CHAPTER 4}

\section{RESULTS AND ANALYSIS OF TESTING PROCEDURE}

Since the focus of the research was to develop the testing procedure, the results have been provided in brief summary format only. The results are included as a validation of the testing procedure. The analysis of the results, and therefore, the testing procedure are then discussed. Data analysis in this chapter is organized by testing procedure step, which is as follows: saturation, consolidation, stiffness, ductility, and permeability. Table 4.1 presents the specimens tested during this research.

Table 4. 1 Summary of specimens created for this research

\begin{tabular}{ccccccc}
\hline Mix & $\begin{array}{c}\text { Number } \\
\text { of } \\
\text { Specimens }\end{array}$ & $\begin{array}{c}\text { Cement } \\
(\% \text { by } \\
\text { weight })\end{array}$ & $\begin{array}{c}\text { Bentonite } \\
(\% \text { by } \\
\text { weight })\end{array}$ & $\begin{array}{c}\text { Sand } \\
(\% \text { by } \\
\text { weight })\end{array}$ & $\begin{array}{c}\text { Water- } \\
\text { cement } \\
\text { ratio }\end{array}$ & $\begin{array}{c}\text { Average Unit } \\
\text { Weight } \\
\left(\text { lb/ft }{ }^{3}\right)\end{array}$ \\
\hline 1 & 3 & 2 & 8 & 90 & 0.7 & 164 \\
2 & 3 & 4 & 6 & 90 & 0.7 & 162 \\
3 & 3 & 6 & 4 & 90 & 0.7 & 187 \\
4 & 1 & 2 & $23^{\mathrm{a}}$ & 75 & 0.7 & 202 \\
7 & 2 & 6 & 2 & 92 & 0.7 & 150 \\
8 & 1 & 6 & 6 & 88 & 0.7 & 173 \\
\hline
\end{tabular}

${ }^{a}$ Kaolonite

Data was simultaneously compiled by the Digi-Flow K and Sigma1-CU programs during the testing procedure. Data was synced between programs via Excel spreadsheets and interpolation functions, where needed. Examples of the raw data from the Digi- 
Flow K and Sigma1-CU are presented in Fig. 4.1 and Fig. 4.2, respectively. An example of the tabs used in the spreadsheets is presented in Fig. 4.3.

\begin{tabular}{|c|c|c|c|c|c|c|c|c|c|}
\hline \multicolumn{10}{|c|}{1 [HEADER] } \\
\hline 2 & \multicolumn{9}{|c|}{ Created by DigiFlow-K Version 4.2.1; Copyright 2004, GEOTAC } \\
\hline 3 & Project: & Plastic Concrete & & & & & & & \\
\hline 4 & Date: & $9 / 26 / 2016$ & Time: & 3:54:44 PM & & & & & \\
\hline 5 & Boring: & N/A & Sample: & N/A & & & & & \\
\hline 6 & Specimen: & Mix 7 & Depth (ft): & 50 & & & & & \\
\hline 7 & Diameter (inch): & 2.838 & Height (inch): & 6.835 & & & & & \\
\hline 8 & Comments: & & & & & & & & \\
\hline \multicolumn{10}{|l|}{9} \\
\hline 10 & [SENSORS] & & & & & & & & \\
\hline 11 & Name & Cell Pressure & Bottom Pressure & Temperature & Top Pressure & Displacement & Cell Pump Encoder & Top Pump Encoder & Bottom Pump Encoder \\
\hline 12 & ID & ID1 & ID3 & ID5 & ID2 & ID4 & N/A & N/A & N/A \\
\hline 13 & Module & Cell Pump ADIO & Bottom Pump ADIO & Cell Pump ADIO & Bottom Pump ADIO & Cell Pump ADIO & N/A & N/A & N/A \\
\hline 14 & Channel & 1 & 1 & 3 & 2 & & N/A & N/A & N/A \\
\hline 15 & Unit & psi & psi & c & psi & inch & $\mathrm{mL}$ & $\mathrm{mL}$ & $\mathrm{mL}$ \\
\hline 16 & Cal. Factor & 30373.5 & 20132.2 & 512.733 & 20128.3 & 517.838 & 303021.5922 & 136057.56 & 136057.56 \\
\hline 17 & Excitation & 10 & 10 & 10 & 10 & 10 & $N / A$ & N/A & N/A \\
\hline 18 & Zero & $-3.24 E-04$ & 2.67E-04 & 0.01954 & $-1.32 \mathrm{E}-04$ & $-1.99 \mathrm{E}-03$ & N/A & N/A & N/A \\
\hline 19 & Min. Reading & -14 & -14 & -350 & -14 & -999999 & 0 & 0 & 0 \\
\hline 20 & Max. Reading & 290 & 190 & 350 & 190 & 99999 & 75 & 175 & 175 \\
\hline \multicolumn{10}{|l|}{21} \\
\hline 22 & [PERMEATION] & & & & & & & & \\
\hline 23 & Time & Cell Pressure & Bottom Pressure & Temperature & Top Pressure & Displacement & Cell Volume & Top Volume & Bottom Volume \\
\hline 24 & 9/27/2016 15:43 & 4.25E-02 & 4.98E-02 & $-6.78 \mathrm{E}-04$ & $5.19 \mathrm{E}-02$ & 1.979174614 & -6302706 & -581277 & -1802631 \\
\hline 25 & 9/27/2016 15:44 & 4.25E-02 & 4.99E-02 & $-1.15 \mathrm{E}-03$ & $5.17 \mathrm{E}-02$ & 2.495416403 & -6290397 & -580579 & -1809255 \\
\hline
\end{tabular}

Fig. 4. 1 Sample output from Digi-Flow K permeability program 


\begin{tabular}{|c|c|c|c|c|c|c|}
\hline 1 & [HEADER] & & & & & \\
\hline 2 & \multicolumn{3}{|c|}{ Created by Sigma-1 CU Version 5.5.1; Copyright 2005, GEOTAC } & & & \\
\hline 3 & Project: & Plastic Concrete & Load Frame Name: & Load Frame & & \\
\hline 4 & Date: & $9 / 27 / 2016$ & Time: & 2:30:04 PM & & \\
\hline 5 & Boring: & N/A & Sample: & $\mathrm{N} / \mathrm{A}$ & & \\
\hline 6 & Specimen: & Mix 7 & Depth $(\mathrm{ft})$ : & 50 & & \\
\hline 7 & Diameter (inch): & 2.838 & Height (inch): & 6.835 & & \\
\hline 8 & Piston Correction (lbs): & 0 & & & & \\
\hline 9 & Comments: & & & & & \\
\hline \multicolumn{7}{|l|}{10} \\
\hline 11 & [SENSORS] & & & & & \\
\hline 12 & Name & External Load Cell & DCDT & Pore Pressure & Cell Pressure & Load Frame Encoder \\
\hline 13 & ID & 303744 & LP-848 & ID3 & ID4 & $\mathrm{N} / \mathrm{A}$ \\
\hline 14 & Module & Load Frame ADIO & Load Frame ADIO & Load Frame ADIO & Load Frame ADIO & N/A \\
\hline 15 & Channel & 1 & 2 & 3 & 4 & $\mathrm{~N} / \mathrm{A}$ \\
\hline 16 & Unit & Ibs & inch & psi & psi & inch \\
\hline 17 & Cal. Factor & -1000132.136 & 3.02246 & 20252.9 & 20227.7 & 3940000 \\
\hline 18 & Excitation & 10.01980591 & 10.01980591 & 10.01980591 & 10.01980591 & $\mathrm{~N} / \mathrm{A}$ \\
\hline 19 & Zero & 0 & 0 & 0.000139 & $7.80 \mathrm{E}-05$ & $\mathrm{~N} / \mathrm{A}$ \\
\hline 20 & Min. Reading & -200 & -0.05 & -14 & -14 & 0 \\
\hline 21 & Max. Reading & 2000 & 3 & 190 & 190 & 1.5 \\
\hline \multicolumn{7}{|l|}{22} \\
\hline 23 & [SHEAR] & & & & & \\
\hline 24 & Time & External Load Cell & DCDT & Pore Pressure & Cell Pressure & Platen Position \\
\hline 25 & $9 / 27 / 201615: 10$ & $-4.28 \mathrm{E}-04$ & 6.688577535 & $4.98 \mathrm{E}-02$ & $6.43 E-02$ & 3632703 \\
\hline
\end{tabular}

Fig. 4. 2 Sample output from Sigma1-CU program

consolidation $/$ inital permeation $/ 0.8 \%$ DF $/ 0.8 \%$ int $\quad 0.8 \% \mathrm{CU} /$ permeation 2

Fig. 4. 3 Example of tabs used in Excel to organize data

Saturation

The Skempton B-Values were checked three times during back pressure saturation to ensure adequate saturation of the specimen before consolidation. Visible saturation of air bubbles near the membrane were visible during the initial pressures of the back pressure saturation on most specimens. Complete saturation of the specimen is imperative to successful consolidation since all of the voids are filled with water instead 
of air. Checks were made for bottom pump pressures of $30 \mathrm{psi}, 70 \mathrm{psi}$, and a final check at 100 psi. The B-value check was run for three minutes, values were recorded after one minute and after three minutes. In most cases the B-value decreased slightly between the two times, indicating a leak somewhere in the system. The leak was taken to be negligible and most times could not be located. The final B-value was taken as an indication that the specimen was fully saturated. This does not necessarily mean that the value was 1.0. Values ranged from 0.90 to 1.0 . This could be attributed to the specimens being placed in a water vacuum bath until they were tested. Future testing will investigate why all the values were so close together. A summary table of all the Bvalues for the specimens tested is presented in Table 4.2.

Some possible reasons for the change in B-values during the check period for the different specimens with the largest changes are summarized. Slight decreases in the Bvalues during the duration of the check indicated a miniscule leak somewhere in the testing equipment set-up. Some of the leaks could be located, while most could not. The increasing B-values during the pressure increases indicated that there was some air between the specimen and the membrane, or between the double membranes (if used). For the Mix 2 June 28, 2016 specimen, it was noted that there was a leak around the top O-ring at a back pressure of approximately 70 psi and the test was stopped, the test cell was dis-assembled and the leak was fixed. Some equipment limitations were noted with the Mix 3 design. During the back pressure saturation, the bottom pump ran out of travel and had to be re-set due to the higher permeability of the specimens. 
Table 4. 2 B-value check summary

\begin{tabular}{|c|c|c|c|c|}
\hline Mix & Specimen & $\begin{array}{l}\text { Bottom Pump } \\
\text { Pressure (psi) }\end{array}$ & $\begin{array}{c}\text { 1-minute } \\
\text { value }\end{array}$ & $\begin{array}{l}\text { 3-minute } \\
\text { value }\end{array}$ \\
\hline \multirow{3}{*}{1} & \multirow{3}{*}{$5 / 31 / 2016$} & 30 & 1.01 & 1.01 \\
\hline & & 70 & 0.98 & 0.98 \\
\hline & & 100 & 0.97 & 0.97 \\
\hline \multirow{3}{*}{1} & \multirow{3}{*}{$6 / 22 / 2016$} & 30 & 0.90 & 0.88 \\
\hline & & 70 & 0.94 & 0.90 \\
\hline & & 100 & 0.96 & 0.96 \\
\hline \multirow{3}{*}{1} & \multirow{3}{*}{$6 / 23 / 2016$} & 30 & 0.84 & 0.77 \\
\hline & & 70 & 0.93 & 0.90 \\
\hline & & 100 & 0.97 & 0.95 \\
\hline \multirow{3}{*}{2} & \multirow{3}{*}{$5 / 31 / 2016$} & 30 & 0.75 & 0.66 \\
\hline & & 70 & 0.90 & 0.85 \\
\hline & & 100 & 0.96 & 0.95 \\
\hline \multirow{3}{*}{2} & \multirow{3}{*}{$6 / 28 / 2016$} & 30 & 0.83 & 0.82 \\
\hline & & 70 & 0.95 & 0.93 \\
\hline & & 100 & 0.97 & 0.96 \\
\hline \multirow{3}{*}{2} & \multirow{3}{*}{ 8/3/2016 } & 30 & 0.93 & 0.90 \\
\hline & & 70 & 0.97 & 0.96 \\
\hline & & 100 & 1.00 & 0.99 \\
\hline \multirow{3}{*}{3} & \multirow{3}{*}{ 6/2/2016 } & 30 & 0.69 & 0.57 \\
\hline & & 70 & 0.89 & 0.82 \\
\hline & & 100 & 0.95 & 0.91 \\
\hline \multirow{3}{*}{3} & \multirow{3}{*}{$6 / 29 / 2016$} & 30 & 0.71 & 0.62 \\
\hline & & 70 & 0.92 & 0.87 \\
\hline & & 100 & 0.96 & 0.94 \\
\hline \multirow{3}{*}{3} & \multirow{3}{*}{$9 / 28 / 2016$} & 30 & 0.85 & 0.79 \\
\hline & & 70 & 0.94 & 0.94 \\
\hline & & 100 & 1.02 & 1.00 \\
\hline
\end{tabular}


Table 4.2 B-value check summary (continued)

\begin{tabular}{ccccc}
\hline Mix & Specimen & $\begin{array}{c}\text { Bottom Pump } \\
\text { Pressure }(\mathrm{psi})\end{array}$ & $\begin{array}{c}\text { 1-minute } \\
\text { value }\end{array}$ & $\begin{array}{c}\text { 3-minute } \\
\text { value }\end{array}$ \\
\hline \multirow{3}{*}{4} & \multirow{3}{*}{$6 / 3 / 2016$} & 70 & 0.91 & 0.88 \\
& & 100 & 0.96 & 0.96 \\
& & & 1.00 & 0.99 \\
7 & \multirow{2}{*}{$7 / 25 / 2016$} & 70 & 0.96 & 0.95 \\
& & 100 & 0.96 & 0.95 \\
& & & 0.99 & 0.98 \\
7 & & 30 & 0.92 & 0.91 \\
& $9 / 7 / 2016$ & 70 & 0.98 & 0.99 \\
& & 100 & 1.00 & 1.00 \\
& & & & \\
& & 30 & 0.76 & 0.75 \\
& $7 / 26 / 2016$ & 70 & 0.92 & 0.91 \\
& & 100 & 0.94 & 0.95 \\
\hline
\end{tabular}

\section{Consolidation}

Consolidation of the specimens was completed to obtain a higher effective stress for the triaxial shear. The effective stress was increased by increasing the cell pressure while maintaining a constant backpressure of 100 psi. The target effective stress for this research was 30 psi. During the initial part of this research, specimens were consolidated rapidly at 3,600 $\mathrm{psi} / \mathrm{hr}$, leading to excessive secondary consolidation, which was actually still primary consolidation. Later testing slowed the consolidation rate down to $10 \mathrm{psi} / \mathrm{hr}$ and then finally $2 \mathrm{psi} / \mathrm{hr}$. The slower consolidation rate is thought to more closely mimic the in-situ pressures the backfill material would be subjected to in the field.

Consolidation curves were then generated for each mix using effective stress and volumetric strain data. Both primary and secondary consolidation is represented on the 
curves. Post- testing back calculations of actual time needed for adequate consolidation could be made based on the calculated bulk modulus. A summary of this information is presented in Table 4.3.

Table 4. 3 Summary of consolidation data

\begin{tabular}{ccccc}
\hline Mix & $\begin{array}{c}\text { Specimen } \\
\text { Date }\end{array}$ & $\begin{array}{c}\text { Consolidation } \\
\text { Pressure (psi) }\end{array}$ & $\begin{array}{c}\text { Consolidation } \\
\text { Rate (psi/hr) }\end{array}$ & $\begin{array}{c}\text { Consolidation } \\
\text { time (hours) }\end{array}$ \\
\hline 1 & $5 / 31 / 2016$ & 10 & 3,600 & 2 \\
1 & $6 / 22 / 2016$ & 10 & 10 & 4 \\
1 & $6 / 23 / 2016$ & 10 & 10 & 12 \\
2 & $5 / 31 / 2016$ & 10 & 10 & 4 \\
2 & $6 / 28 / 2016$ & 2 & 10 & 4 \\
2 & $8 / 3 / 2016$ & 2 & 10 & 12 \\
3 & $6 / 2 / 2016$ & 2 & 2 & 6 \\
3 & $6 / 29 / 2016$ & 2 & 2 & 11 \\
3 & $9 / 28 / 2016$ & 2 & 2 & 16 \\
4 & $6 / 3 / 2016$ & 2 & 2 & 19 \\
7 & $7 / 25 / 2016$ & 2 & 2 & 20 \\
7 & $9 / 7 / 2016$ & 2 & 2 & 17 \\
8 & $7 / 26 / 2016$ & 2 & 2 & 12 \\
\hline
\end{tabular}

Typically, the consolidation, stress-stain, and volumetric strain curves are presented together to fully illustrate the behavior of a material. Therefore, all of the consolidation curves are located at the end of this chapter with the other curves. In general, the longer consolidation time was adequate to reach the end of primary consolidation and begin secondary consolidation. Since it was assumed there was no volume change during permeation, only triaxial shear, initial values of volume change, height, and area of each specimen were the final recorded values from the consolidation step. 
Table 4.4 attempts to illustrate the underlying cause of the variability of the changes in height and volume during consolidation of each of the specimens. Several factors should be considered including: Consolidation pressure, consolidation rate, consolidation time (Table 4.3), amount of cement, amount of clay (bentonite or kaolinite), and curing methods. Mix 1 experienced more height and volume change with lower consolidation pressure, consolidation rate, and longer consolidation time. The mix on 5/31/2016 was un-molded and placed in the hot water cure earlier than the latter two samples, which could explain the difference. Mix 1 samples also contain the most clay of all the specimens, inferring that would cause the largest height and volume changes. Whereas Mix 7 has the least amount of clay, but still exhibits the next largest changes in height and volume. Mix 3, specimens with the most cement, have smaller changes in height and volume, which can be expected given the mix should be the stiffest of all of the mixes. Mix 4, the kaolinite specimen, exhibits one of the smallest changes in height and volume while having the largest amount of clay, indicating a stiff, brittle mix. However, this mix is later shown to be stiff, yet ductile. 
Table 4. 4 Change in height and volume of specimens during consolidation

\begin{tabular}{cccccc}
\hline Mix & $\begin{array}{c}\text { Cement } \\
(\%) \text { dry } \\
\text { weight }\end{array}$ & $\begin{array}{c}\text { Clay } \\
(\%) \text { dry } \\
\text { weight }\end{array}$ & $\begin{array}{c}\text { Specimen } \\
\text { Date }\end{array}$ & $\begin{array}{c}\text { Change in } \\
\text { height during } \\
\text { consolidation } \\
(\%)\end{array}$ & $\begin{array}{c}\text { Change in } \\
\text { volume during } \\
\text { consolidation } \\
(\%)\end{array}$ \\
\hline 1 & 2 & 8 & $5 / 31 / 2016$ & $1 \%$ & $3 \%$ \\
1 & 2 & 8 & $6 / 22 / 2016$ & $2 \%$ & $7 \%$ \\
1 & 2 & 8 & $6 / 23 / 2016$ & $6 \%$ & $18 \%$ \\
2 & 4 & 6 & $5 / 31 / 2016$ & $0.2 \%$ & $0.8 \%$ \\
2 & 4 & 6 & $6 / 28 / 2016$ & $1 \%$ & $4 \%$ \\
2 & 4 & 6 & $8 / 3 / 2016$ & $0.7 \%$ & $2 \%$ \\
3 & 6 & 4 & $6 / 2 / 2016$ & $0.3 \%$ & $0.7 \%$ \\
3 & 6 & 4 & $6 / 29 / 2016$ & $0.6 \%$ & $2 \%$ \\
3 & 6 & 4 & $9 / 28 / 2016$ & $0.4 \%$ & $1 \%$ \\
4 & 2 & $23^{\mathrm{a}}$ & $6 / 3 / 2016$ & $0.4 \%$ & $1 \%$ \\
7 & 6 & 2 & $7 / 25 / 2016$ & $3 \%$ & $9 \%$ \\
7 & 6 & 2 & $9 / 7 / 2016$ & $2 \%$ & $7 \%$ \\
8 & 6 & 6 & $7 / 26 / 2016$ & $0.2 \%$ & $0.7 \%$ \\
\hline \multicolumn{5}{c}{${ }^{a}$ Kaolinite } \\
\end{tabular}

\section{Stiffness}

Using values from the consolidation curves, the bulk modulus, $\mathrm{K}$, the stiffness of the specimen, was calculated using the formula:

$$
K=\frac{\Delta \sigma c}{\varepsilon v o l}
$$

Where $\Delta \sigma_{\mathrm{c}}$ is the change in the consolidation stress and $\varepsilon_{\mathrm{vol}}$ is the last volumetric strain value from secondary consolidation which the slope of the consolidation curve. Bulk modulus calculations are presented for each mix design then compared between different mixes in Table 4.5. There is large variability within the same mixes of the stiffness, which can be accounted for by looking at several aspects. The bentonite was not hydrated in some of the early specimens, which can account for a higher bulk modulus, as well as the percentage of cement used in each mix and the age of the specimen at 
testing. Each mix subsection discusses these noted discrepancies in the bulk modulus values.

Table 4. 5 Bulk modulus values

\begin{tabular}{llccc}
\hline Mix & Specimen & $\begin{array}{c}\text { Age at } \\
\text { testing } \\
\text { (days) }\end{array}$ & $\begin{array}{c}\text { Bulk Modulus } \\
(\mathrm{ksi})\end{array}$ & $\begin{array}{c}\text { Bentonite } \\
\text { Hydrated }\end{array}$ \\
\hline 1 & May 31, 2016 & 7 & 57.9 & No \\
1 & June 22, 2016 & 6 & 38.9 & No \\
1 & June 23, 2016 & 12 & 26.9 & Yes \\
2 & May 31, 2016 & 10 & 341.9 & No \\
2 & June 28, 2016 & 19 & 66.9 & Yes \\
2 & August 8, 2016 & 45 & 140.7 & Yes \\
3 & June 2, 2016 & 17 & 166.7 & No \\
3 & June 29, 2016 & 32 & 386.4 & Yes \\
3 & Sept 28, 2016 & 28 & 229 & Yes \\
4 & June 3, 2016 & 19 & 231.7 & No \\
7 & July 25, 2016 & 14 & 35.6 & Yes \\
7 & Sept 7, 2016 & 19 & 41.3 & Yes \\
8 & July 26, 2016 & 31 & 390.9 & Yes \\
\hline
\end{tabular}

Since the specimen preparation accelerates the curing process from 28 days to approximately 4 days, it is important to note the amount of time between preparation and testing of each specimen for the analysis of the testing procedure. In all cases, the specimens were well beyond the typical 28-day testing window used to determine strength parameters of the cutoff wall material.

\section{Gradient}

With the use of the differential pressure transducer, the differential head across the specimen was more accurately measured. The differential pressure transducer was added to the equipment on June 14, 2016. A head correction was calculated if the head 
was not zero before triaxial shear since the gradient was removed prior to the shear. The average of the last ten (10) values is used for the head correction in permeation calculations. The gradient for every specimen in this testing was set at 20 , using a differential pressure across the specimen of 5 psi. The gradient can be adjusted for future testing to simulate the anticipated stresses on the cutoff wall in-situ.

\section{Ductility}

Ductility is traditionally measured by stress stain curve and volumetric strain curve analysis. Ductile materials exhibit a more gradual increase to failure, then a gradual decrease after failure, while brittle materials have steep curves to failure, then a sharp drop after failure. The main purpose of this research was to look at this traditional approach and compare it to the change in permeability of the specimen during the testing procedure. This section briefly discusses the data analysis to construct the stress strain curves. This is due to the calculations requiring the integration of both the Digi-Flow K and Sigma1-CU data. An Excel interpolation function between spreadsheets was used since neither computer was connected to the internet and the time stamps differ slightly. The reading schedules were also different, so the values had to be interpolated for gaps in data. Volumetric strain curves used volumetric strain vs axial strain, while stress-strain used axial strain and deviator stress. Negative values of volumetric strain indicate contraction, while positive values indicate dilation. Initial values for volumetric strain (height and volume) and axial strain were taken as the last value from consolidation, as discussed in the previous consolidation section of this chapter. A seating force for the 
specimens of approximately $25-35$ pounds was also chosen based on the calculated piston uplift force on the top platen.

Table 4.6 summarizes the maximum strain analyzed and maximum deviator stress achieved for each specimen. Maximum strain analyzed does not, in most cases, represent the maximum strain tested on a specimen. Equipment issues, such as leaks, and computer issues, such as data limitations, are the source of the discrepancy between the maximum strain analyzed and maximum strain tested. This is discussed in more detail in the following sections of this chapter.

Table 4. 6 Maximum stress and strain analyzed for each specimen

\begin{tabular}{cccc}
\hline Mix & Specimen & $\begin{array}{c}\text { Maximum Strain } \\
\text { analyzed }^{\mathrm{a}}(\%)\end{array}$ & $\begin{array}{c}\text { Maximum deviator stress } \\
\text { (psi) at Maximum Strain } \\
\text { analyzed }\end{array}$ \\
\hline 1 & $5 / 31 / 2016$ & 7.2 & 49.2 \\
1 & $6 / 22 / 2016$ & 8.0 & 75.2 \\
1 & $6 / 23 / 2016$ & 8.0 & 48.1 \\
2 & $5 / 31 / 2016$ & 5.6 & 145.6 \\
2 & $6 / 28 / 2016$ & 11.2 & 92.6 \\
2 & $8 / 3 / 2016$ & 4.8 & 63.8 \\
3 & $6 / 2 / 2016$ & 4.8 & 198.9 \\
3 & $6 / 29 / 2016$ & 8 & 136.7 \\
3 & $9 / 28 / 2016$ & 3.2 & 66.8 \\
4 & $6 / 3 / 2016$ & 8 & 112.6 \\
7 & $7 / 25 / 2016$ & 11.0 & 62.8 \\
7 & $9 / 7 / 2016$ & 13.13 & $43.7^{\mathrm{b}}$ \\
8 & $7 / 26 / 2016$ & 8.2 & 122.6 \\
\hline
\end{tabular}

${ }^{\mathrm{a}}$ Different than maximum strain tested

${ }^{\mathrm{b}}$ After failure

Permeability

A distinction is made here between initial permeation of the specimens and subsequent permeation steps. During the initial permeation, permeability of the specimen 
was made after approximately 30 minutes of pressure controlled flow, then the flow pumps were switched to flow control based on that value, as discussed in Chapter 3. This initial permeability value was then used for all subsequent permeations between triaxial shear increments. Table 4.7 presents this initial permeability reading of each of the specimens, and the duration of the initial permeation before triaxial shear testing commenced.

Table 4. 7 Initial Permeability, and Strain Rates

\begin{tabular}{cccc} 
Mix & Specimen & $\begin{array}{c}\text { Initial } \\
\text { permeability } \\
(\mathrm{cm} / \mathrm{s})\end{array}$ & $\begin{array}{c}\text { Initial permeation time } \\
\text { before Triaxial shear }(\mathrm{hrs})\end{array}$ \\
\hline 1 & $5 / 31 / 2016$ & $4.67 \times 10^{-4}$ & 16 \\
1 & $6 / 22 / 2016$ & $5.10 \times 10^{-4}$ & 4 \\
1 & $6 / 23 / 2016$ & $1.08 \times 10^{-4}$ & 5 \\
2 & $5 / 31 / 2016$ & $1.10 \times 10^{-3}$ & 13.5 \\
2 & $6 / 28 / 2016$ & Not recorded & 12 \\
2 & $8 / 3 / 2016$ & $2.27 \times 10^{-4}$ & 17 \\
3 & $6 / 2 / 2016$ & $4.50 \times 10^{-3}$ & 9 \\
3 & $6 / 29 / 2016$ & $1.80 \times 10^{-3}$ & 4 \\
3 & $9 / 28 / 2016$ & $5.75 \times 10^{-4}$ & 22 \\
4 & $6 / 3 / 2016$ & $6.08 \times 10^{-4}$ & 17 \\
7 & $7 / 25 / 2016$ & $4.87 \times 10^{-4}$ & 4 \\
7 & $9 / 7 / 2016$ & $1.70 \times 10^{-4}$ & 5 \\
8 & $7 / 26 / 2016$ & $2.88 \times 10^{-4}$ & 19 \\
\hline
\end{tabular}

Permeation was flow controlled for most of the time, as described in Chapter 3. During the last 30 minutes of permeation, the control was switched from flow to pressure control to remove the gradient from the sample and prepare each triaxial shear step, so that the actual gradient across the specimen could be measured during shear. The head correction, discussed in the gradient section of this chapter, was applied during the period when the gradient was removed from the specimen. To calculate the flow in (at the top of 
the specimen), the flow out (bottom of the specimen), and the gradient, an average value of at last 10 data points was used. This also applies for the flow ratio. ASTM defines the flow ratio at the flow in divided by the flow out, and should be between 0.8 and 1.2. For this research, a values of at least 0.9 was used. The permeability of the specimen was calculated using Darcy's Equation $\mathrm{Q}=\mathrm{kiA}$, solved for permeability.

$$
k=\frac{Q}{i * A}
$$

Where flow (Q) was the flow in at the top of the specimen, gradient (i) was the average gradient, and area (A) was assumed to be constant during permeation, so the value used was from the end of consolidation for the first triaxial shear, and the value from previous triaxial shears for subsequent shears.

Table 4.8 provides a comparison between the increase in permeability during triaxial shearing and the change in height and volume. As the height and volume decreases, the permeability should also decrease until the initiation of the failure mechanism of the specimens. The mixes with more cement should produce more brittle failures, with distinct failure surfaces that would potentially increase the permeability more than the more-ductile mixes. The largest increase in permeability of $668 \%$ occurred with a Mix 7 specimen that had the largest change in height during shear, but a lower change in volume than the average of all of the specimens. When the stress-strain curve for this specimen is discussed later in this chapter, it is noted that this mix is within the 
more ductile behavior region. This comparison does not necessarily fully explain the behavior of the materials.

Table 4.8 Increase in permeability compared to change in height and volume

\begin{tabular}{|c|c|c|c|c|c|c|}
\hline Mix & $\begin{array}{l}\text { Cement } \\
\text { (\%) dry } \\
\text { weight }\end{array}$ & $\begin{array}{l}\text { Clay } \\
\text { (\%) dry } \\
\text { weight }\end{array}$ & $\begin{array}{c}\text { Specimen } \\
\text { Date }\end{array}$ & $\begin{array}{l}\text { Change } \\
\text { in height } \\
\text { during } \\
\text { shear }(\%)\end{array}$ & $\begin{array}{l}\text { Change in } \\
\text { volume } \\
\text { during } \\
\text { shear }(\%)\end{array}$ & $\begin{array}{c}\text { Increase in } \\
\text { Permeability } \\
\text { during shear } \\
(\%)\end{array}$ \\
\hline 1 & 2 & 8 & $5 / 31 / 2016$ & 36 & 5 & $\mathrm{~N} / \mathrm{A}^{\mathrm{c}}$ \\
\hline 1 & 2 & 8 & $6 / 22 / 2016$ & 18 & 9 & 297 \\
\hline 1 & 2 & 8 & $6 / 23 / 2016$ & 14 & 15 & 145 \\
\hline 2 & 4 & 6 & $5 / 31 / 2016$ & 16 & 2 & $N / A^{c}$ \\
\hline 2 & 4 & 6 & $6 / 28 / 2016$ & 34 & 15 & 17 \\
\hline 2 & 4 & 6 & $8 / 3 / 2016$ & 10 & 3 & 32 \\
\hline 3 & 6 & 4 & 6/2/2016 & 10 & $-0.3^{b}$ & $\mathrm{~N} / \mathrm{A}^{\mathrm{c}}$ \\
\hline 3 & 6 & 4 & $6 / 29 / 2016$ & 13 & 3 & 245 \\
\hline 3 & 6 & 4 & $9 / 28 / 2016$ & 6 & 2 & 26 \\
\hline 4 & 2 & $23^{\mathrm{a}}$ & $6 / 3 / 2016$ & 15 & 4 & 15 \\
\hline 7 & 6 & 2 & $7 / 25 / 2016$ & 29 & 20 & 43 \\
\hline 7 & 6 & 2 & 9/7/2016 & 44 & 7 & 668 \\
\hline 8 & 6 & 6 & $7 / 26 / 2016$ & 18 & 4 & 71 \\
\hline
\end{tabular}

Another aspect of the material properties studied in this research is the potential healing behavior of the mixes during triaixial shearing. Since the permeability testing was run simultaneously with the triaxial shear, the change in permeability throughout the entire test, as well as between testing was recorded and analyzed. Table 4.9 provides a summary of the change in permeability of the specimens between the triaxial shear increments. A negative value represents a decrease in permeability, while a positive value represents an increase. To understand the last column, the time between initial and final permeability measurements, a brief review of the procedure is described. Triaxial 
shearing was completed in increments specifically to observe this healing behavior. For example; after the $0.8 \%$ triaxial shear increment, the specimen was allowed to rest while leaving the load applied. After approximately one hour after the completion of the shear increment, an average permeability measurement was taken, ensuring a flow ratio of at least 0.9 as discussed above. The specimen then continued to rest for a varying amount of time until the next triaxial shear increment. At approximately one hour before the commencement of the next shear increment, an average permeability measurement was taken. This change is given in the table as the change in permeability between shears. The last column of the table presents the amount of time between these initial and final measurements that took place during the specimen resting period between triaxial shear increments.

The time between initial and final permeability measurements was intentionally varied to observe magnitude of change in permeability based on time. This part of the research attempts to discern if a greater change in permeability occurs if the specimens are allowed to permeate for longer times between triaxial shears. The permeability of Mix 2 specimens ( 4 percent cement, 6 percent bentonite) increased over time after each triaxial shear increment. This would indicate that as cracks formed in the specimen from shearing, no healing occurred. Conversely, Mix 3 specimens ( 6 percent cement, 4 percent bentonite) and Mix 4 (2 percent cement, 23 percent kaolinite) decreased in permeability over every triaxial shear increment, indicating that some kind of healing mechanism occurred in the cracking caused by the shearing. Mix 7 specimens exhibited a larger decrease in permeability at higher strains, while Mix 1 exhibited a decrease in 
permeability at lower strains. Overall, amount of time for permeation between triaxial shearing increments does not seem to have an effect on the change in permeability of the specimens.

Table 4. 9 Evidence of healing between triaxial shears for selected specimens

\begin{tabular}{|c|c|c|c|c|}
\hline Mix & Specimen & $\begin{array}{c}\text { Triaxial } \\
\text { shear } \\
\text { increment } \\
(\%)\end{array}$ & $\begin{array}{l}\text { Change in } \\
\text { permeability } \\
\text { between } \\
\text { shears }(\%)\end{array}$ & $\begin{array}{l}\text { Time between initial } \\
\text { and final permeability } \\
\text { measurements (hours) }\end{array}$ \\
\hline \multirow[t]{5}{*}{1} & $6 / 22 / 2016$ & 0.8 & -20.9 & 17 \\
\hline & & 1.6 & -4.0 & 3.6 \\
\hline & & 3.2 & -3.5 & 2.7 \\
\hline & & 4.8 & -5.3 & 9.2 \\
\hline & & 8.0 & 2.7 & 2.8 \\
\hline \multirow[t]{5}{*}{1} & $6 / 23 / 2016$ & 0.8 & 15.9 & 9.4 \\
\hline & & 1.6 & 0.0 & $0^{\mathrm{a}}$ \\
\hline & & 3.2 & 10.4 & 11.2 \\
\hline & & 4.8 & 8.4 & 1.7 \\
\hline & & 8.0 & 0.5 & 94.7 \\
\hline \multirow[t]{6}{*}{2} & $6 / 28 / 2016$ & 0.8 & -0.5 & 3 \\
\hline & & 1.6 & 3.5 & 2 \\
\hline & & 3.2 & 1.0 & 67 \\
\hline & & 4.8 & 4.6 & 11.7 \\
\hline & & 8.0 & 0.7 & 2.7 \\
\hline & & 11.2 & 1.0 & 13.4 \\
\hline \multirow[t]{4}{*}{2} & $8 / 3 / 2016$ & 0.8 & 2.0 & 1.6 \\
\hline & & 1.6 & 3.1 & 94.5 \\
\hline & & 3.2 & -3.2 & 11.5 \\
\hline & & 4.8 & 3.7 & 2 \\
\hline \multirow[t]{4}{*}{3} & $6 / 2 / 2016$ & 0.8 & -2.5 & 2.7 \\
\hline & & 1.6 & -2.5 & 2.8 \\
\hline & & 3.2 & -1.2 & 2.9 \\
\hline & & 4.8 & 1.3 & 3 \\
\hline \multirow[t]{5}{*}{3} & $6 / 29 / 2016$ & 0.8 & -1.8 & 2.9 \\
\hline & & 1.6 & -3.1 & 10.8 \\
\hline & & 3.2 & -2.1 & 2.9 \\
\hline & & 4.8 & -1.9 & 2.7 \\
\hline & & 8.0 & -13.1 & 10.2 \\
\hline \multirow[t]{3}{*}{3} & $9 / 28 / 2016$ & 0.8 & -2.2 & 71 \\
\hline & & 1.6 & -2.3 & 21 \\
\hline & & 3.2 & 0.1 & 17.5 \\
\hline
\end{tabular}

\footnotetext{
${ }^{\mathrm{a}}$ Bad flow ratios
} 
Table 4.9 Evidence of healing between triaxial shears for selected specimens (continued)

\begin{tabular}{|c|c|c|c|c|}
\hline Mix & Specimen & $\begin{array}{l}\text { Triaxial } \\
\text { shear } \\
\text { increment } \\
(\%)\end{array}$ & $\begin{array}{l}\text { Change in } \\
\text { permeability } \\
\text { between } \\
\text { shears }(\%)\end{array}$ & $\begin{array}{l}\text { Time between initial } \\
\text { and final permeability } \\
\text { measurements (hours) }\end{array}$ \\
\hline \multirow[t]{5}{*}{4} & $6 / 3 / 2016$ & 0.8 & -1.2 & 2.7 \\
\hline & & 1.6 & -0.7 & 3 \\
\hline & & 3.2 & 1.2 & 10 \\
\hline & & 4.8 & -0.6 & 2.4 \\
\hline & & 8.0 & -3.6 & 31 \\
\hline \multirow[t]{7}{*}{7} & $9 / 7 / 2016$ & 0.8 & 0.3 & 14.5 \\
\hline & & 1.6 & 3.2 & 2.1 \\
\hline & & 3.2 & 0.8 & 15.5 \\
\hline & & 4.8 & 2.3 & 3.3 \\
\hline & & 8.0 & -2.0 & 14.6 \\
\hline & & 11.2 & -14.4 & 68 \\
\hline & & 13.13 & -6.5 & 2.5 \\
\hline \multirow[t]{5}{*}{8} & $7 / 26 / 2016$ & 0.8 & 1.1 & 2.6 \\
\hline & & 1.6 & 2.7 & 15.8 \\
\hline & & 3.2 & 2.6 & 2.3 \\
\hline & & 4.8 & 0.1 & 19.7 \\
\hline & & 8.0 & -5.8 & 72 \\
\hline
\end{tabular}

Review of Each Mix

Mix 1

Mix 1 specimens consist of: $2 \%$ cement, and $8 \%$ bentonite, by dry weight. Since these are some of the first mixes tested, the procedures changed during the process. The following paragraphs describe processes that may account for non-uniform results for this mix. Figures 4.4 through 4.7 present the consolidation, stress-strain, volumetric strain, and permeability curves for Mix 1 . 
The bentonite for the May 31, 2016 specimen was not hydrated for 24 hours before molding, and a consolidation rate of 3,600 psi/hour was used with a consolidation pressure of 10 psi. This could account for the dilative behavior shown on Figure 4.6. The gradient initially used was approximately 40, then changed to 20 . No differential pressure transducer was used for this specimen; therefore, permeability measurements were not calculated for this test. Problems with the flow pumps were noted after the 11.2\% strain testing increment. The pumps ran out of travel and had to re-set, common do to the duration of the testing. However, the pumps were not re-started after the re-set over the weekend; therefore, the data after the $11.2 \%$ strain may be erroneous.

The bentonite for the June 22, 2016 specimen was not hydrated for 24 hours before molding, however the consolidation pressure was changed to 2 psi with a consolidation rate of $10 \mathrm{psi} /$ hour. A slight decrease in B-values was noted, indicating a small leak in the testing equipment. Problems with the flow pumps were noted before the $11.2 \%$ strain testing increment. The pumps ran out of travel and had to re-set but ran out of travel again before the test was ended. Therefore, the final permeation values were taken before this issue for the calculations. There is a gap in the volumetric strain curve which needs to be investigated, which may represent a re-set of the flow pumps during the test. The permeability curves, presented in Figure 4.7, illustrate the change in permeability of the specimen throughout the duration of the test and changes between triaxial shear increments. In general, the permeability changed very little from $0.8 \%$ to $4 \%$ triaxial shear increments. Then the permeability increased more for the $4 \%$ to $11.2 \%$ triaxial shear increments. 
For the third specimen (June 23, 2016), the bentonite was hydrated for 24 hours, however this led to addition of water not initially accounted for in the other mix designs. The specimen was consolidated at $10 \mathrm{psi} /$ hour with a consolidation pressure of $2 \mathrm{psi}$, however excessive secondary consolidation was noted in Figure 4.4, which is obviously not all secondary. This suggested to the researcher that the consolidation rate was too rapid for this mix, therefore the consolidation rate was changed in subsequent testing. This specimen was tested up to $11.2 \%$, however due to data storage limitations, the computers stopped recording between the $8 \%$ and $11.2 \%$ increments. Therefore, calculations for this test stopped after the $8 \%$ strain triaxial shear increment. In general, the permeability changed very little from $0.8 \%$ to $4.8 \%$ triaxial shear increments. Then the permeability decreased more for the $4 \%$ to $8.0 \%$ triaxial shear increments, as shown in Figure 4.7.

Three specimens of Mix 1 were prepared during this research. These mixes were prepared and testing near the initial portion of this research. In general, it appears the consolidation time should be increased for this mix, as there was excessive secondary consolidation. However, the slope of each of the tests is nearly the same. Table 4.10 summarizes the bulk modulus $(\mathrm{K})$, an indicator of stiffness of the specimen. The average bulk modulus for Mix 1 was $37.3 \mathrm{ksi}$.

Table 4. 10 Bulk Modulus for Mix 1 Specimens

\begin{tabular}{lc}
\hline Specimen & Bulk Modulus (ksi) \\
\hline May 31, 2016 & 57.9 \\
June 22, 2016 & 38.9 \\
June 23, 2016 & 15 \\
\hline
\end{tabular}


The comparison of the stress-strain curves show each specimen starts out about the same trajectory. The early mix (May 31, 2016) exhibits a more ductile stress-strain curve, whereas the other two mixes did not fail during the test. All three specimens exhibited contractive behavior on the volumetric strain curves, which also indicated ductile behavior. The permeability of two of the three specimens could be compared because the differential pressure was not installed at that time. Values at lower strains are close; however, strain could not be compared at higher strains since only one specimen was tested in that range. In general, the change in permeability was less than one order of magnitude, indicating that the specimen was ductile.

Figures 4.8 and 4.9 show the Mix 1 specimens before and after testing. The failure mechanism appears to be bulging of the sample, distinct failure planes are not readily visible. No photographs were taken of the June 23, 2016 specimen. 


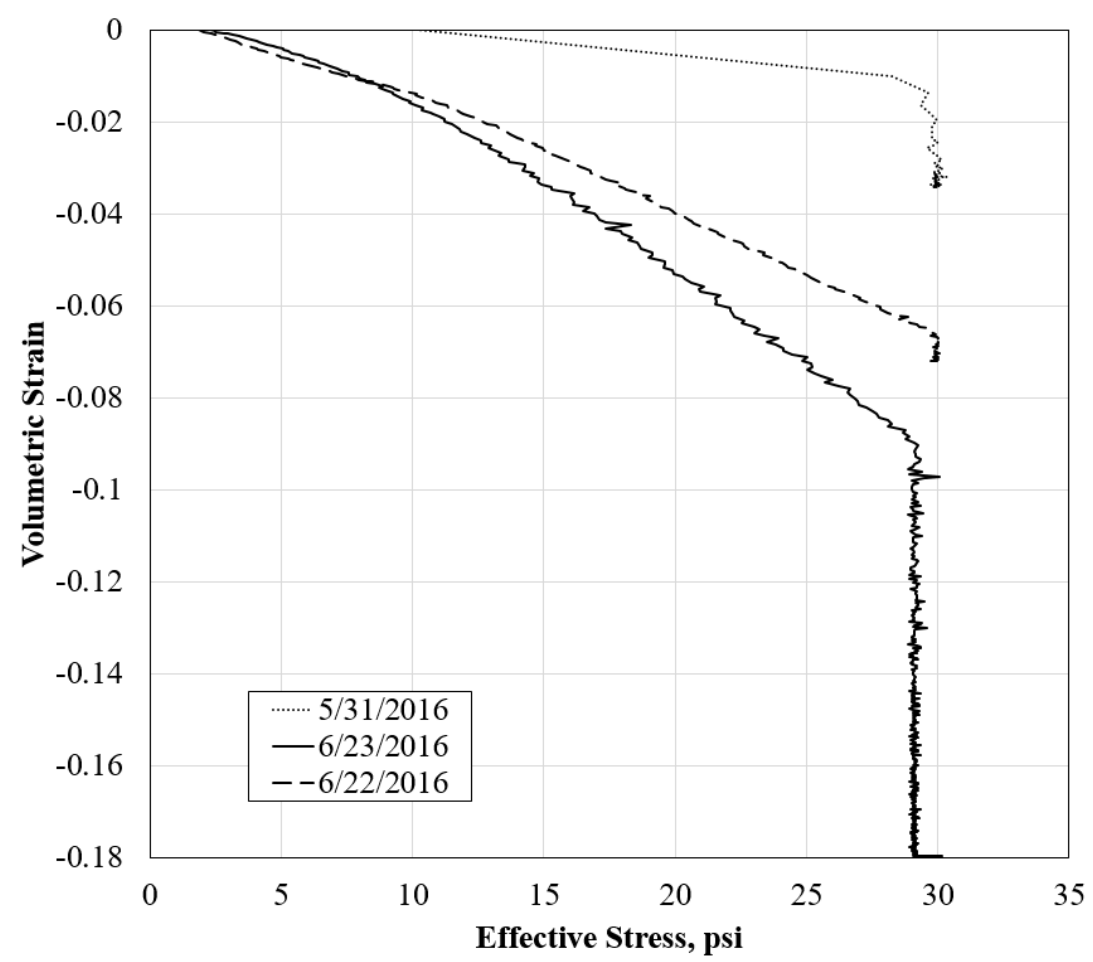

Fig. 4. 4 Mix 1 consolidation curves comparison

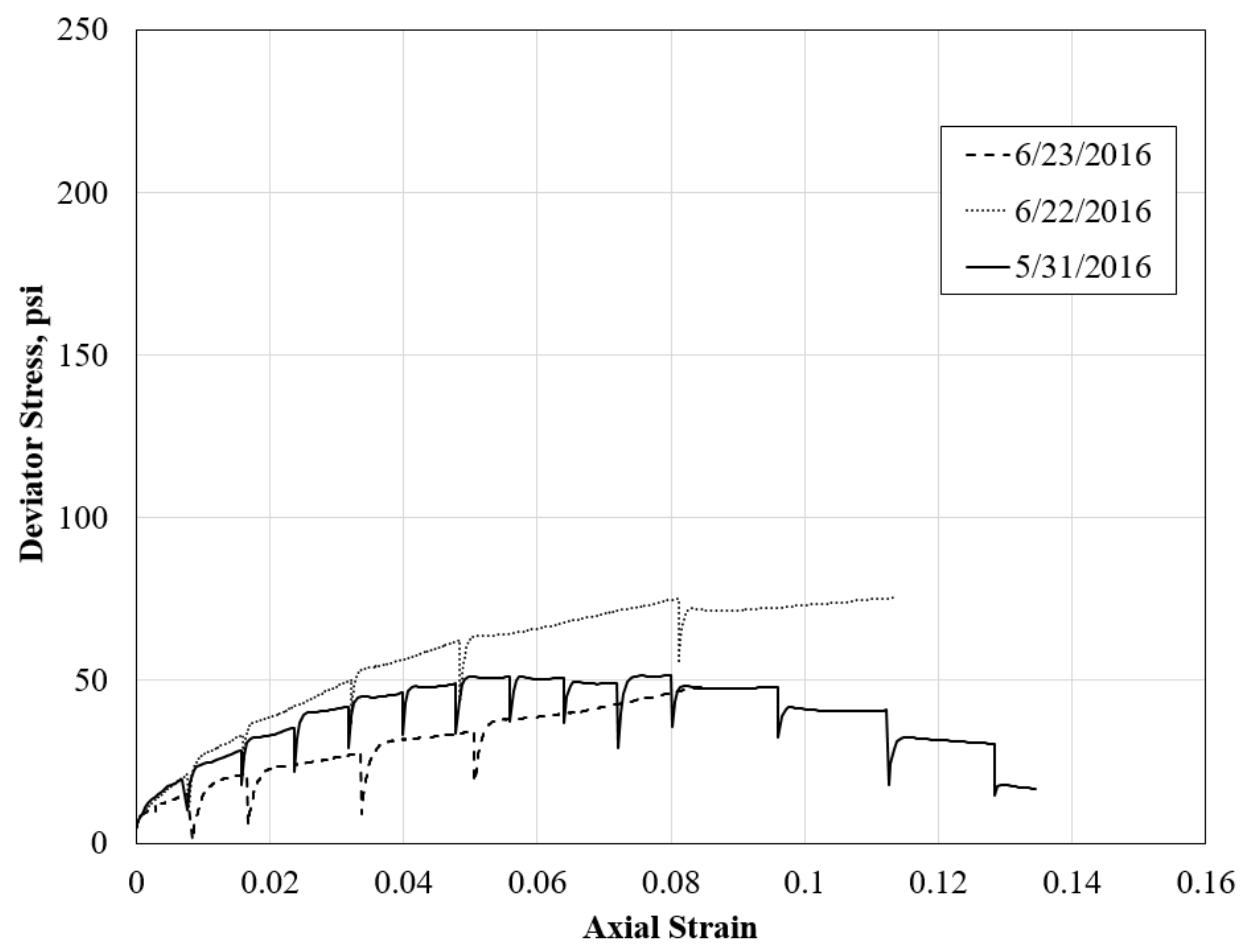

Fig. 4. 5 Mix 1 stress-strain curves comparison 


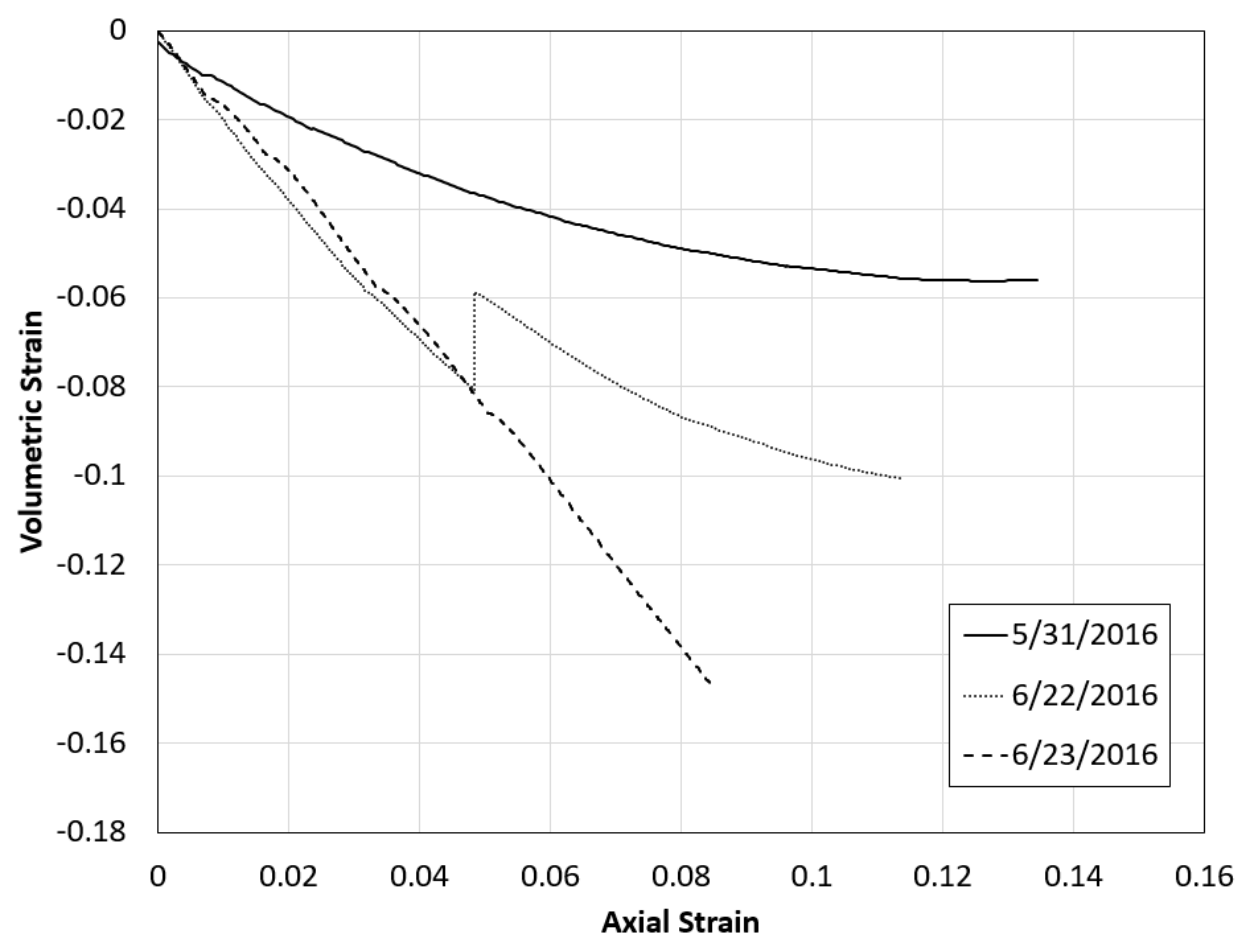

Fig. 4. 6 Mix 1 volumetric strain curves comparison

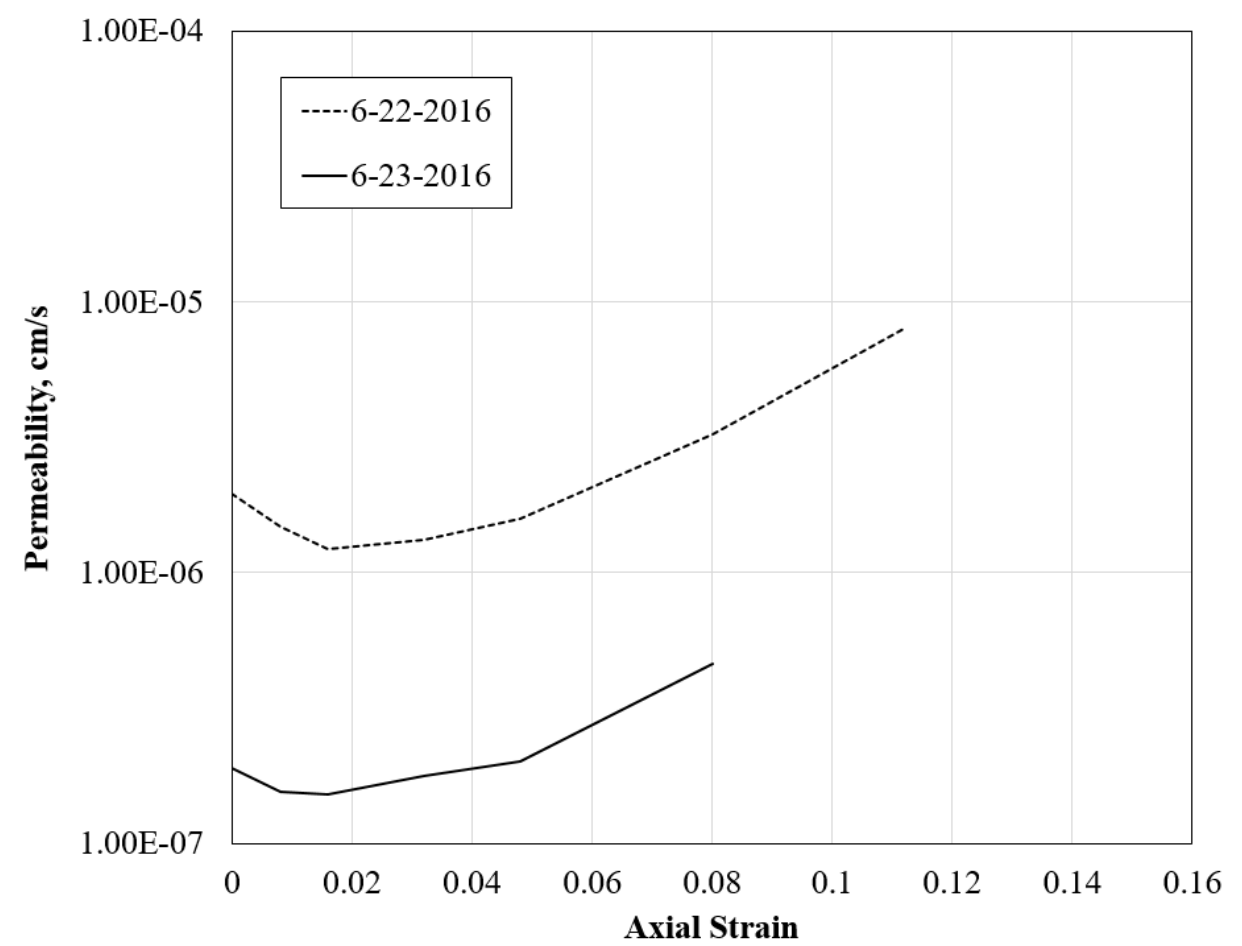

Fig. 4. 7 Mix 1 permeability curves comparison 


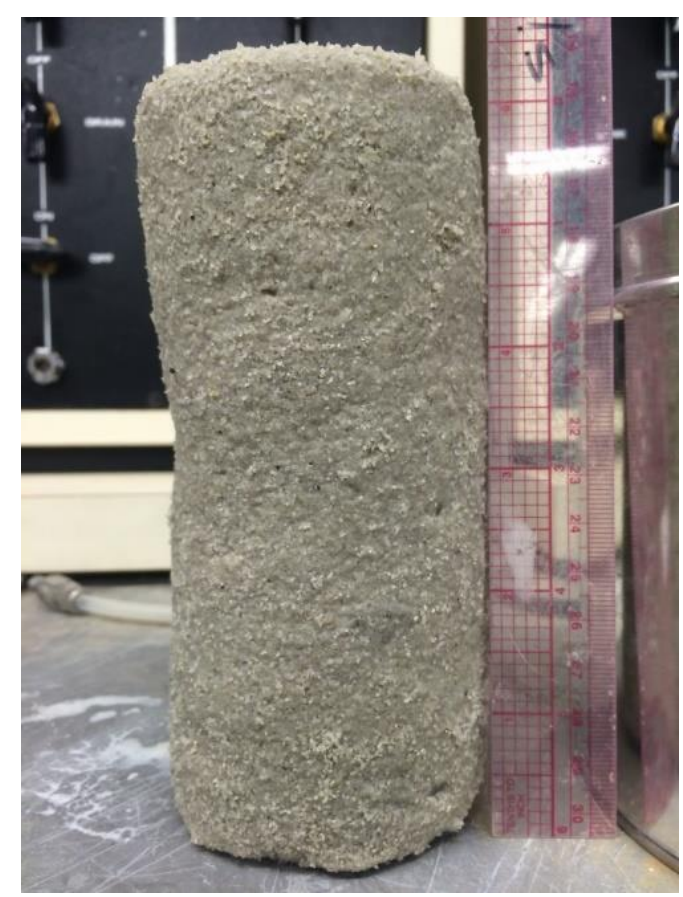

Fig. 4. 8 Mix 1 (May 31, 2016) after testing

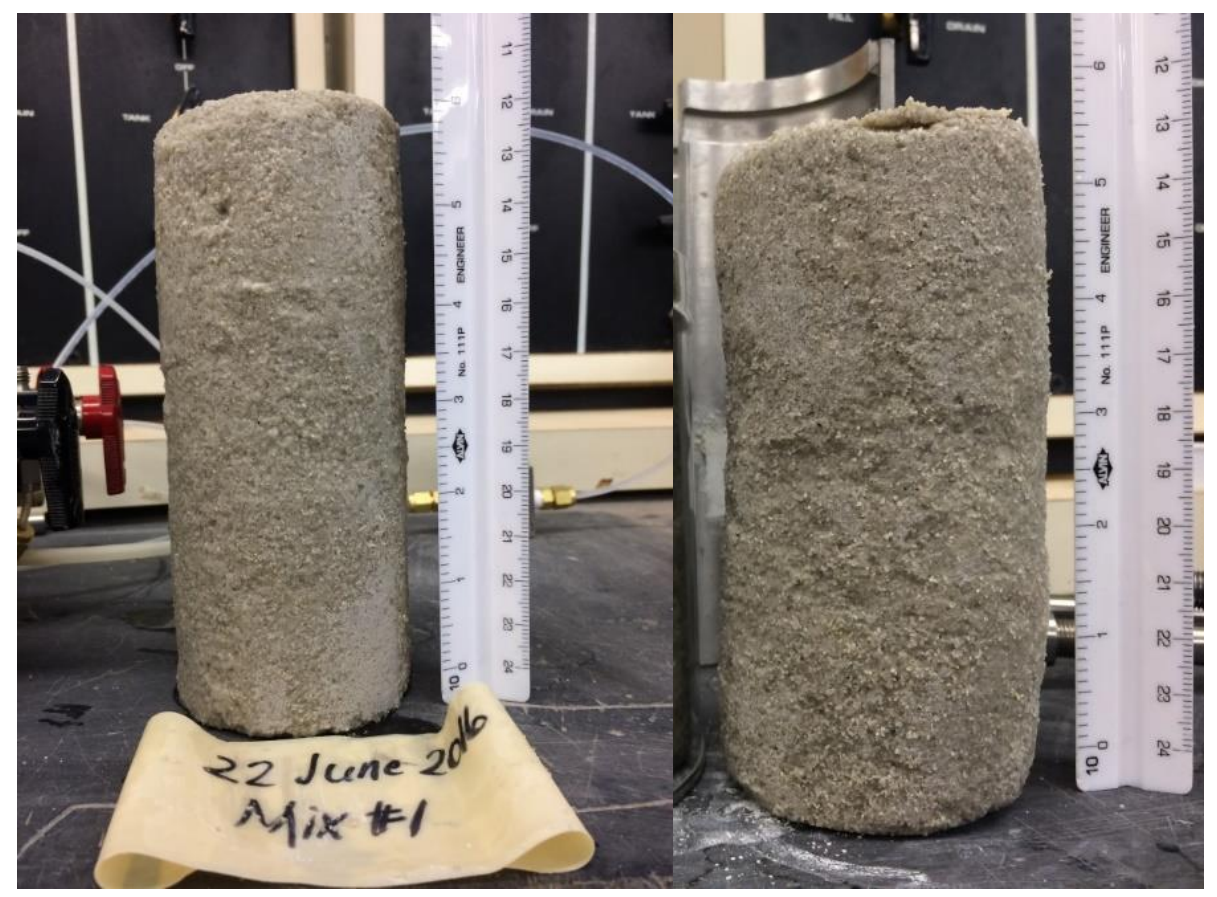

Fig. 4. 9 Mix 1 (June 22, 2016) before (left) and after (right) 
Mix 2

Mix 2 specimens consist of: $4 \%$ cement, and $6 \%$ bentonite, by dry weight. These specimens encompass different times in the research period and shows how the procedures changed during the process. The following paragraphs describe processes that may account for non-uniform results for this mix. Figures 4.10 through 4.13 are the consolidation, stress-strain, and volumetric strain curves for Mix 2.

The bentonite for the May 31, 2016 specimen was not hydrated for 24 hours before molding, and a consolidation rate of $10 \mathrm{psi} /$ hour was used with a consolidation pressure of 10 psi. This could account for the additional secondary consolidation shown in Figure 4.9. The flow pumps ran out of travel between the $5.6 \%$ and $6.4 \%$ strain increment, therefore those values may provide erroneous data. This may be evident in the Figure 4.12 starts to show a change from contractive to dilative behavior, however Figure 4.11 illustrates this was the most brittle of the Mix 3 specimens tested.

For the June 28, 2016 specimen, the bentonite was hydrated for 24 hours, however this led to the need to add additional water to the mix that was not initially accounted for in the other mix designs. The specimen was consolidated at 2 psi at a consolidation rate of 2 psi/hour, however this still appears rapid based on Figure 4.10. A final strain $15.2 \%$ was achieved with this specimen, the highest strain of all of the testing. The permeability decreased from $0.8 \%$ to $3.2 \%$ triaxial shear increments. Then the permeability increased from the $3.2 \%$ to $14.4 \%$ triaxial shear increments before decreasing sharply past the $14.4 \%$ strain increment as shown in Figure 4.13 . 
The third specimen (August 3, 2016) used hydrated bentonite, with additional water added. The specimen was consolidated the same as the second specimen. Triaxial shear increments up to $14.4 \%$ strain were completed, however due computer recording issues, only data up to the $4.7 \%$ strain increment were used in the analysis. In general, the permeability decreased for all triaxial shear increments. This extremely small change in permeability also indicates the ductility of the specimen.

Three specimens of Mix 2 were prepared during this research. These mixes encompass all different times during the research period. In general, it appears the consolidation time was adequate for the mix after the consolidation rate was changed from $10 \mathrm{psi} / \mathrm{hr}$ to $2 \mathrm{psi} / \mathrm{hr}$. The slopes of the curves follow mostly the same slope. The comparison of the stress-strain curves shows two of the specimens behaved nearly the same, while the earlier mix was anomalous. The early mix (May 31, 2016) exhibits a more brittle stress-strain curve, whereas the other two mixes were more ductile, with gradual failures. The two later specimens exhibited contractive behavior on the volumetric strain curves, which also indicated ductile behavior, while the early mix becomes more dilative, indicative of the brittle behavior on the stress-strain curve. Changes in permeability during the testing procedure were small, also indicating the ductility of the mix, with the specimen from August 8, 2016 having the smallest change in permeability, but the lowest strain tested. The stiffness of the mix was compared using the bulk modulus. Table 4.11 summarizes the bulk modulus for each specimen of Mix 2 . The average bulk modulus for Mix 2 was $183.2 \mathrm{ksi}$. 
Table 4. 11 Bulk modulus for Mix 2 specimens

\begin{tabular}{lc}
\hline Specimen & Bulk Modulus (ksi) \\
\hline May 31, 2016 & 341.9 \\
June 28, 2016 & 66.9 \\
August 8, 2016 & 140.7 \\
\hline
\end{tabular}

Figures 4.14 through 4.16 shows the Mix 2 specimens before and after testing.

The failure mechanism appears to be bulging of the sample, distinct failure planes are not readily visible. A picture was not taken of the August 3, 2016 specimen after testing was completed.

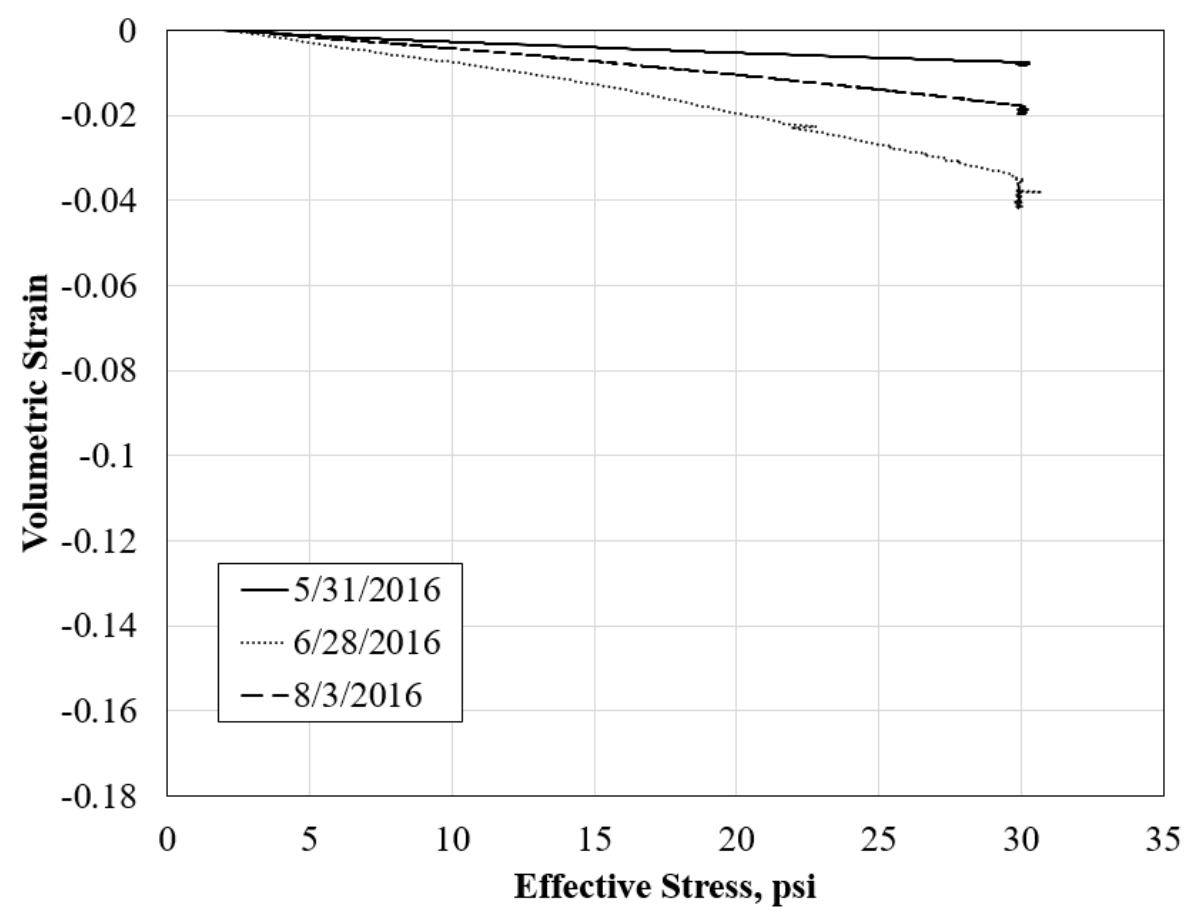

Fig. 4. 10 Mix 2 consolidation curves comparison 


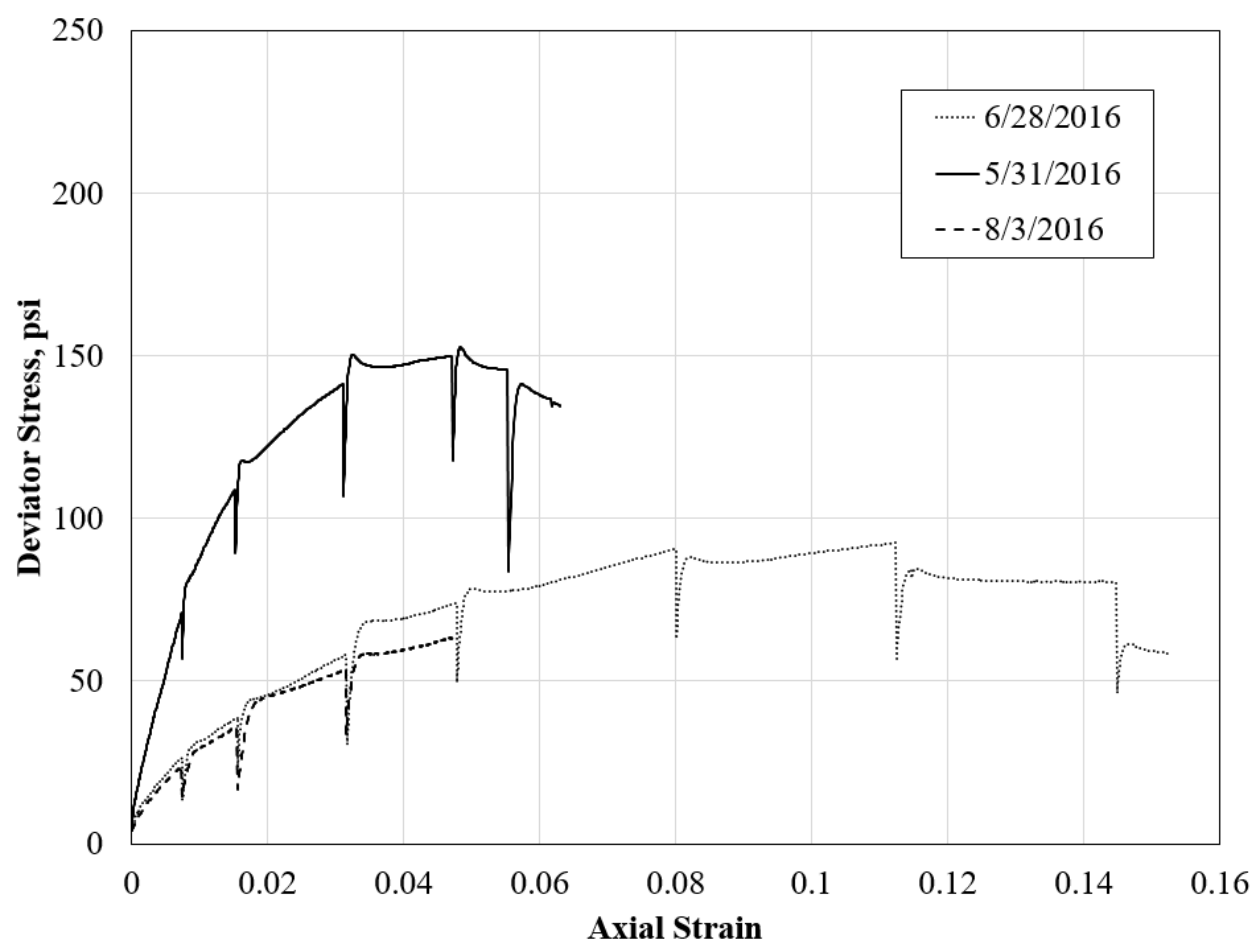

Fig. 4. 11 Mix 2 stress-strain curves comparison

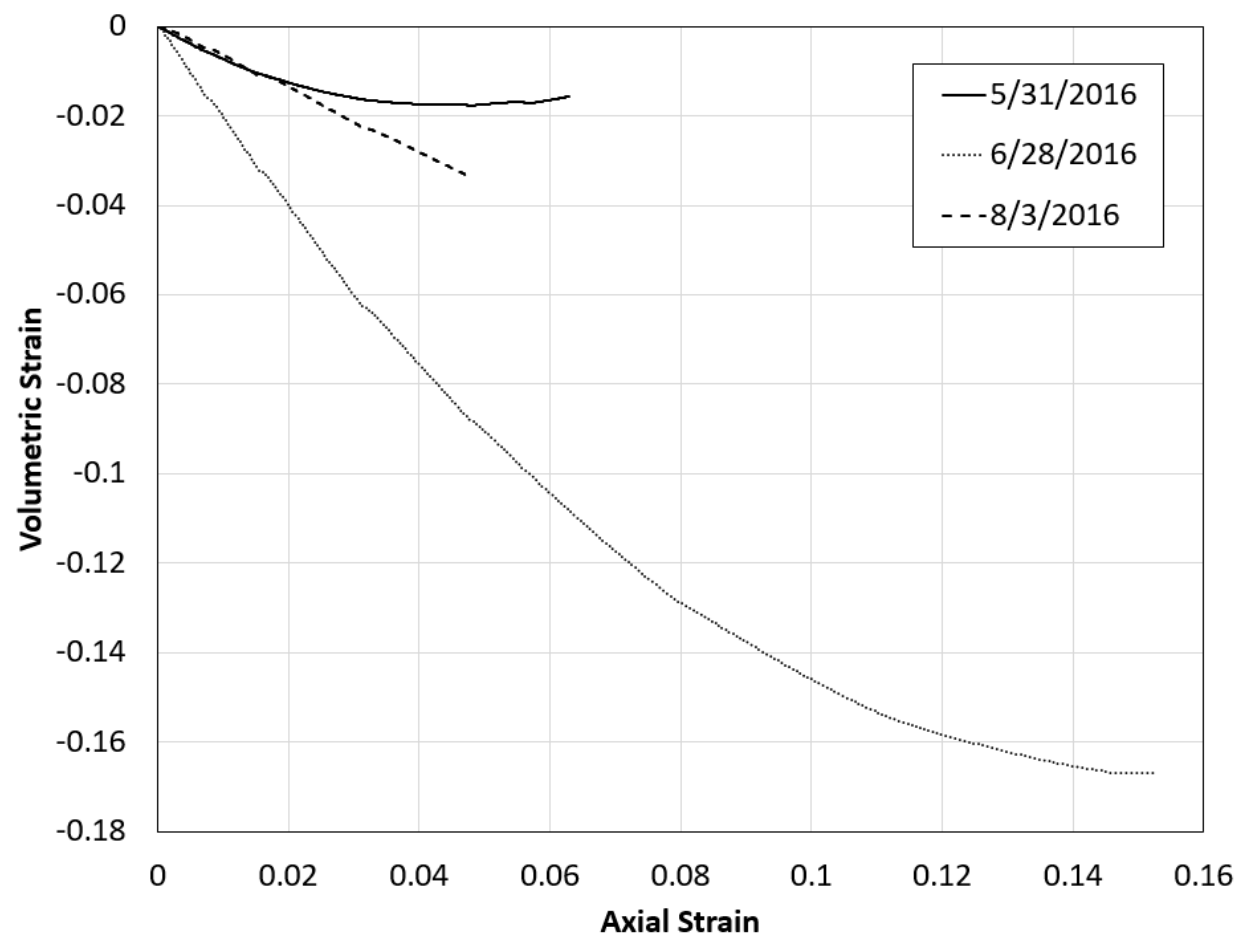

Fig. 4. 12 Mix 2 volumetric strain curves comparison 


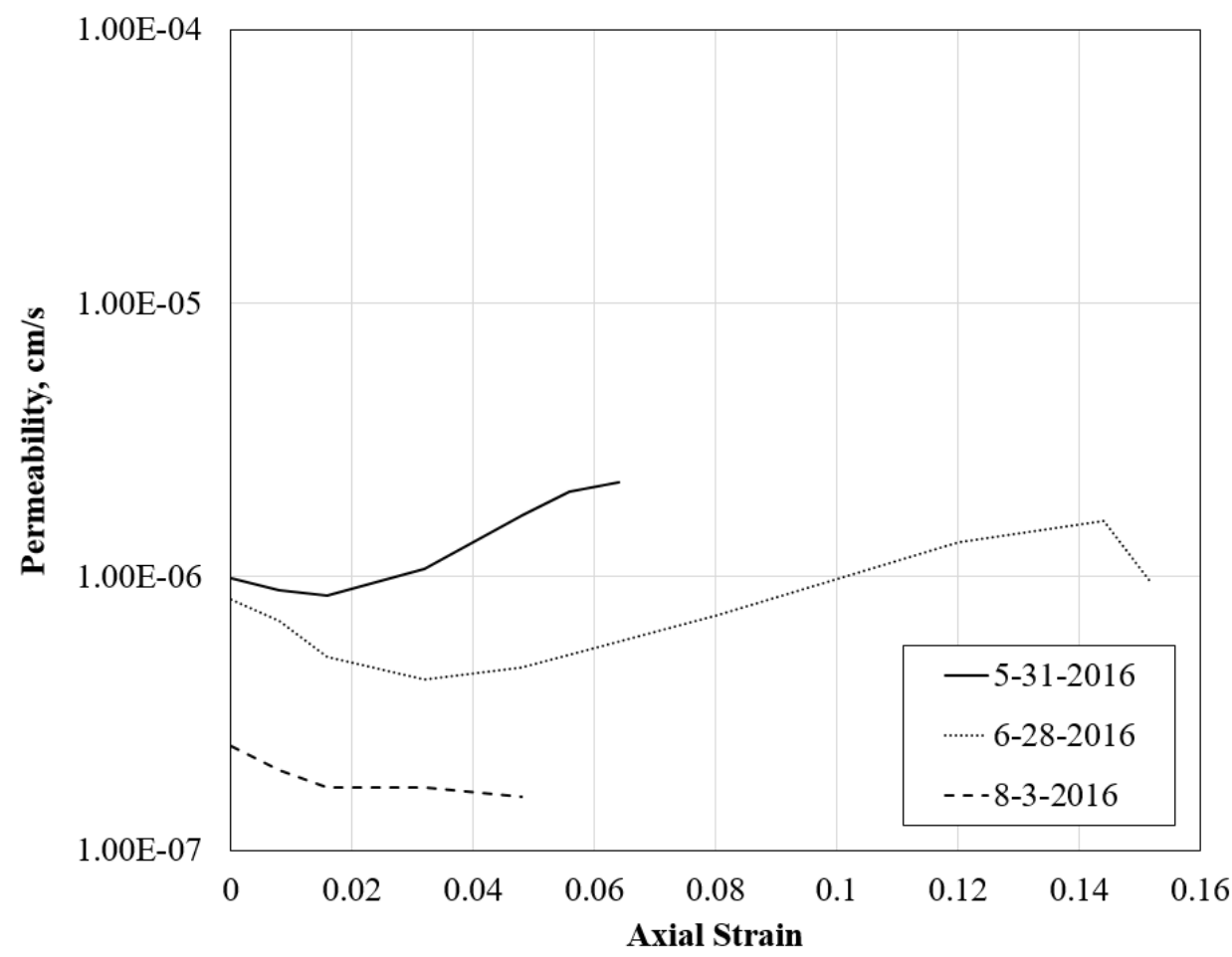

Fig. 4. 13 Mix 2 permeability curves comparison

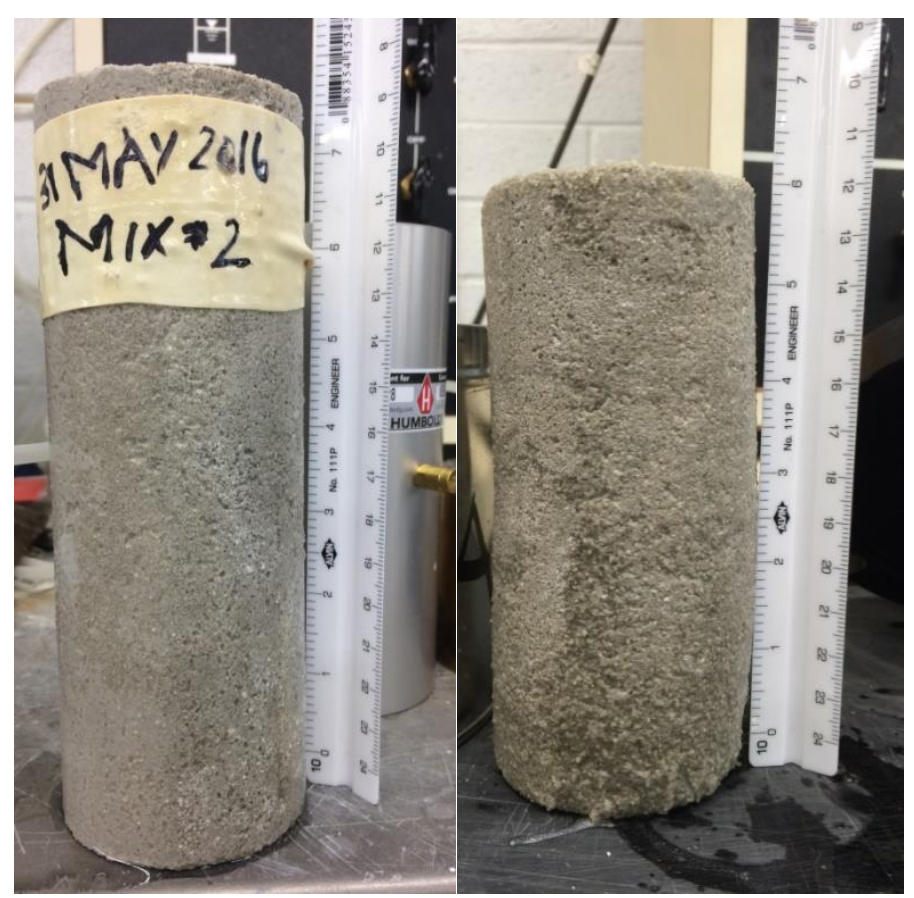

Fig. 4. 14 Mix 2 (May 31, 2016) before (left) and after (right) testing 


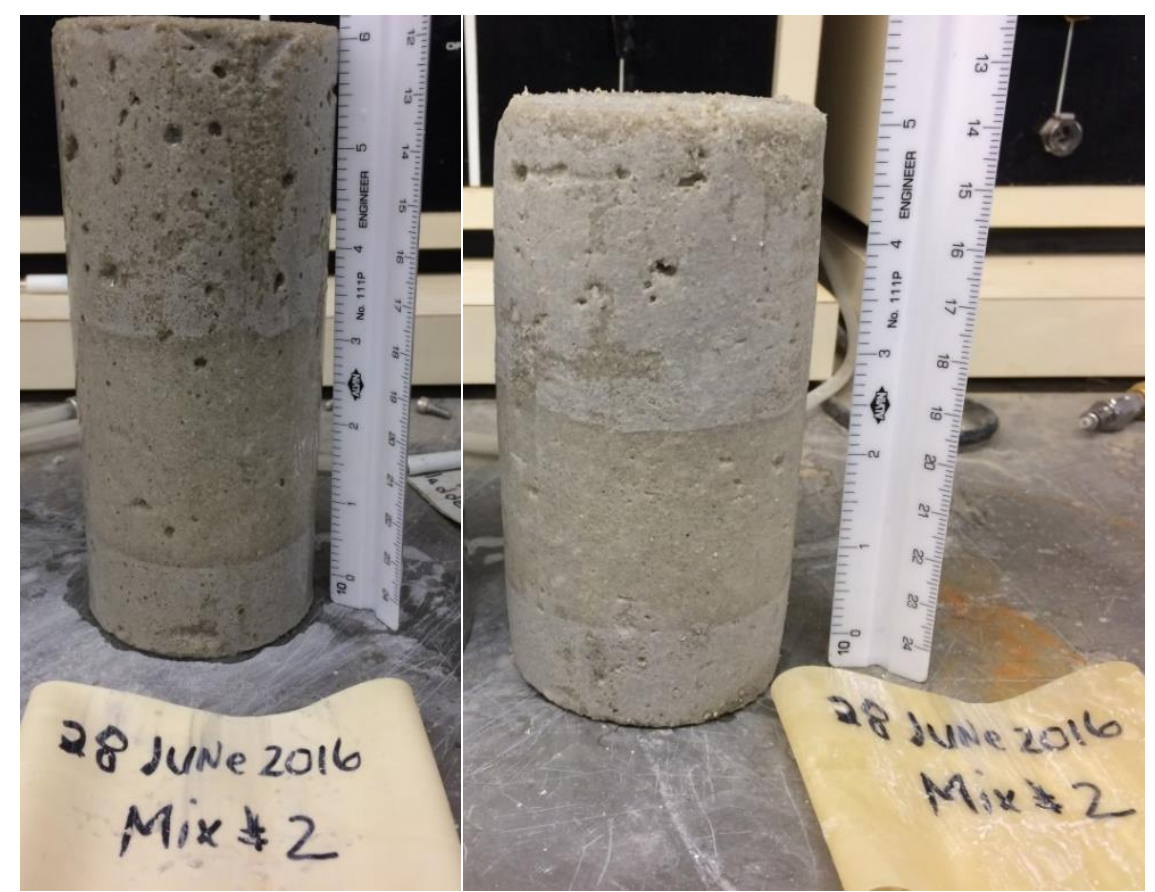

Fig. 4. 15 Mix 2 (June 28, 2016) before (left) and after (right) testing

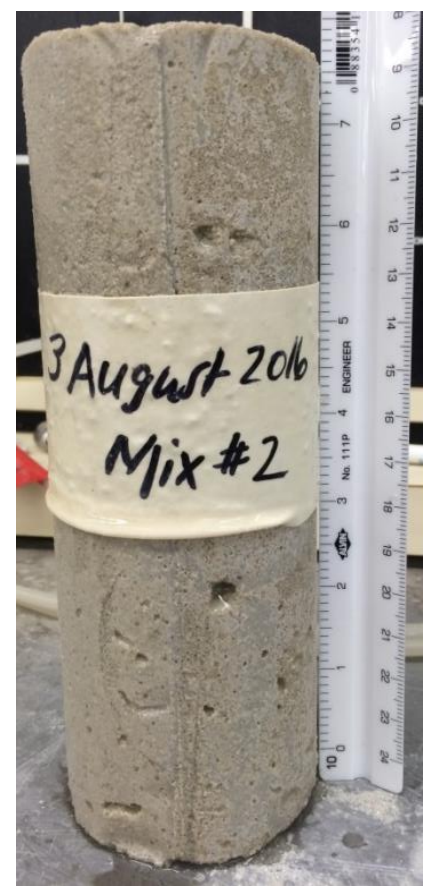

Fig. 4. 16 Mix 2 (August 3, 2016) before testing 
Mix 3

Mix 3 specimens consist of: $6 \%$ cement, and $4 \%$ bentonite, by dry weight. These specimens were tested during the initial stages of the research, but also reflect changes in the testing procedures. The following paragraphs describe processes that may account for non-uniform results for this mix. Figures 4.17 through 4.20 are the consolidation, stress-strain, volumetric strain, and permeability curves for Mix 3.

For the June 2, 2016 specimen, the bentonite was not hydrated for 24 hours prior to mixing. This could account for more brittle behavior in Figure 4.18, but these specimens also contain the highest percentage of cement. The specimen was consolidated at $10 \mathrm{psi}$, at a consolidation rate of $10 \mathrm{psi} / \mathrm{hour}$, which appears rapid due to the amount of secondary consolidation showing in Figure 4.17. The testing ceased at $4.8 \%$ strain because the stress-strain curve leveled off, however the testing probably should have continued because failure was not achieved as shown in Figure 4.18. In general, the permeability changed very little from $0.8 \%$ to $1.6 \%$ triaxial shear increments. Then the permeability increased more for the $1.6 \%$ to $4.8 \%$ triaxial shear increments, as shown in Figure 4.20. This order of magnitude change in permeability also confirms that this specimen was more brittle than ductile.

The bentonite was hydrated for 24 hours prior to mixing for the June 29, 2016 specimen. Additional water was added. This specimen was consolidated at 2 psi, and a consolidation rate of 2 psi/hour, however Figure 4.17 also shows that excessive secondary consolidation of the specimen occurred even at this slower rate. In general, the permeability decreased for the first two (2) triaxial shear increments. Then the 
permeability increased for the remaining duration of the test. This order of magnitude change in permeability also confirms that the specimen behaved in a brittle manner.

The September 28, 2016 specimen was prepared near the end of the research period. By this time the consolidation rate was 2 psi/ hour with 2 psi consolidation for all specimens tested. The bentonite was hydrated and additional water was added to the original mix design. There were issues with the computer programs and data storage with this test, so testing ended at the $4.8 \%$ strain increment.

Three specimens of Mix 3 were prepared during this research. Two mixes were prepared fairly close in time to each other, the other toward the end of the research period. In general, it appears the consolidation time was not adequate for the mix even after the consolidation rate was changed from $10 \mathrm{psi} / \mathrm{hr}$ to $2 \mathrm{psi} / \mathrm{hr}$. The slopes of the curves follow mostly the same slope, however there is excessive secondary consolidation. The comparison of the stress-strain curves shows the earliest specimen is the most brittle, however all specimens are more brittle than the other mixes tested. This corresponds to the percentage of cement, $6 \%$, the highest amount used for the mix designs in this research. The specimens start with contractive behavior, then turn more dilative, with the earlier mix more so, illustrated in Figure 4.19. The order of magnitude changes in permeability of two of the three specimens also indicate the mix acts in a more brittle manner. The stiffness of the specimens was determined using the bulk modulus. Table 4.12 presents the values for each specimen. The average bulk modulus for Mix 3 was $260.7 \mathrm{ksi}$. 
Table 4. 12 Bulk Modulus values for Mix 3

\begin{tabular}{lc}
\hline Specimen & Bulk Modulus (ksi) \\
\hline June 2, 2016 & 386.4 \\
June 29, 2016 & 166.7 \\
September 28, 2016 & 229.1 \\
\hline
\end{tabular}

Figures 4.21 through 4.22 shows the Mix 3 specimens before and after testing. While both mixes pictured failed by bulging, the June 29, 2016 mix has a faint failure plane, highlighted by the dotted line in Figure 4.22. Before and after testing pictures were not taken for the September 28, 2016 specimen.

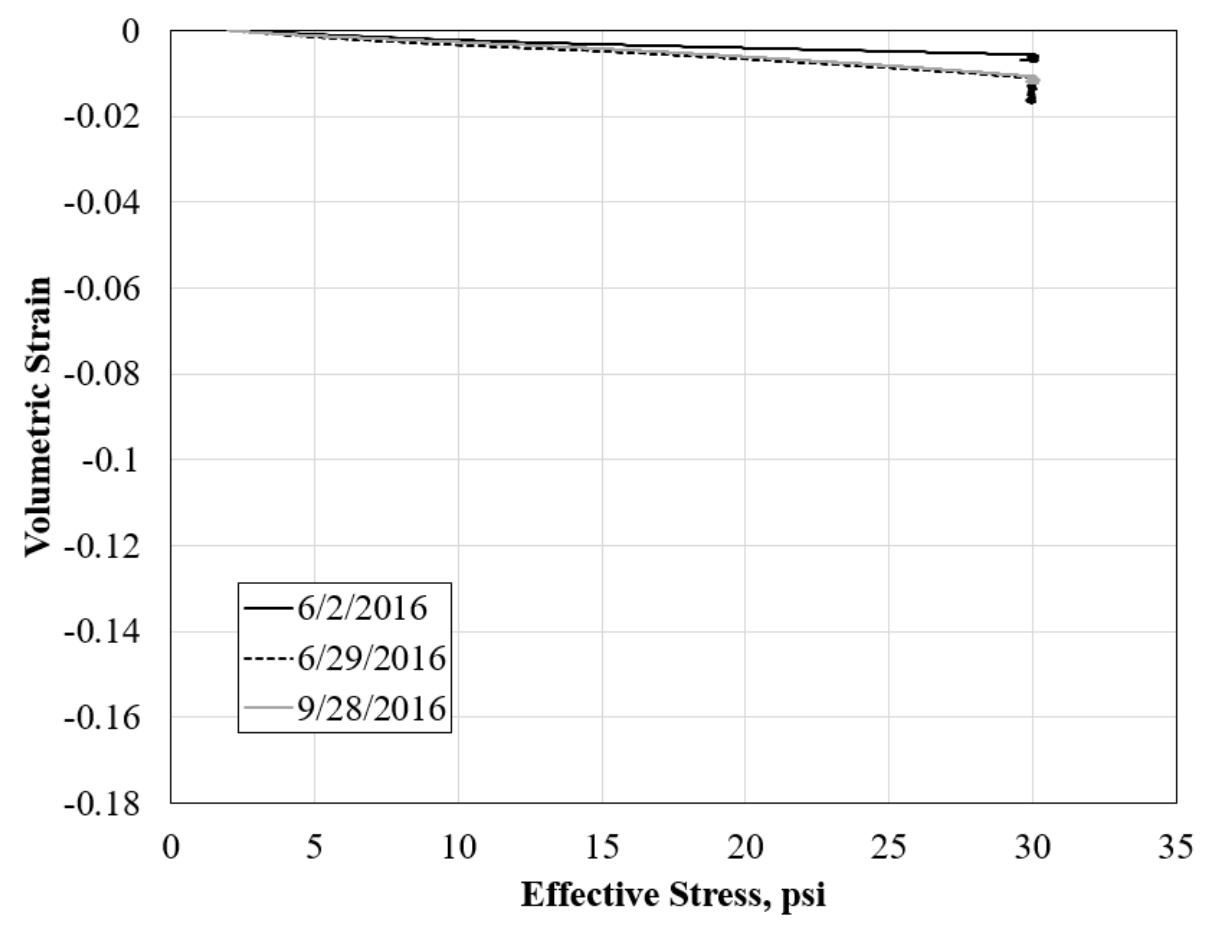

Fig. 4. 17 Mix 3 consolidation curves comparison 


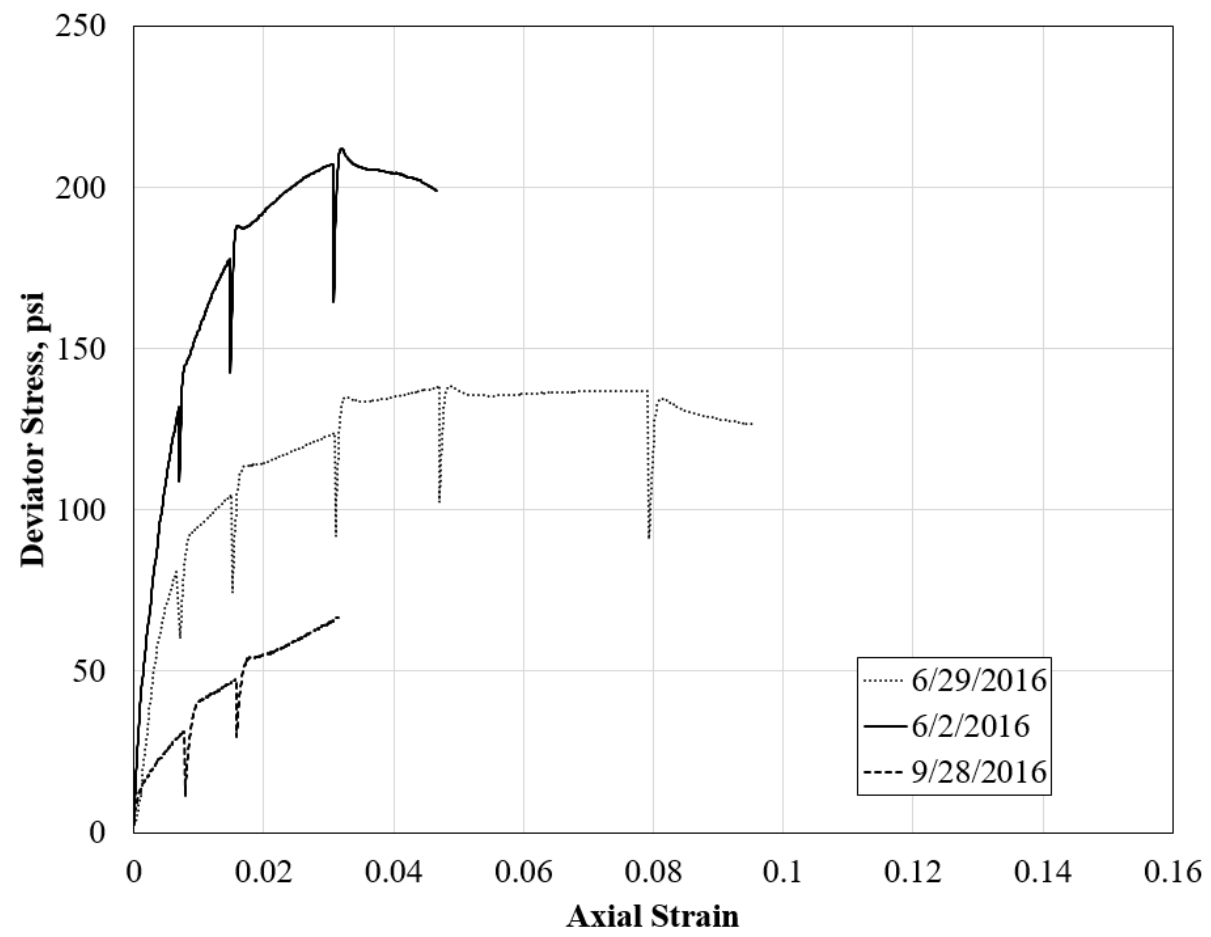

Fig. 4. 18 Mix 3 stress-strain curves comparison

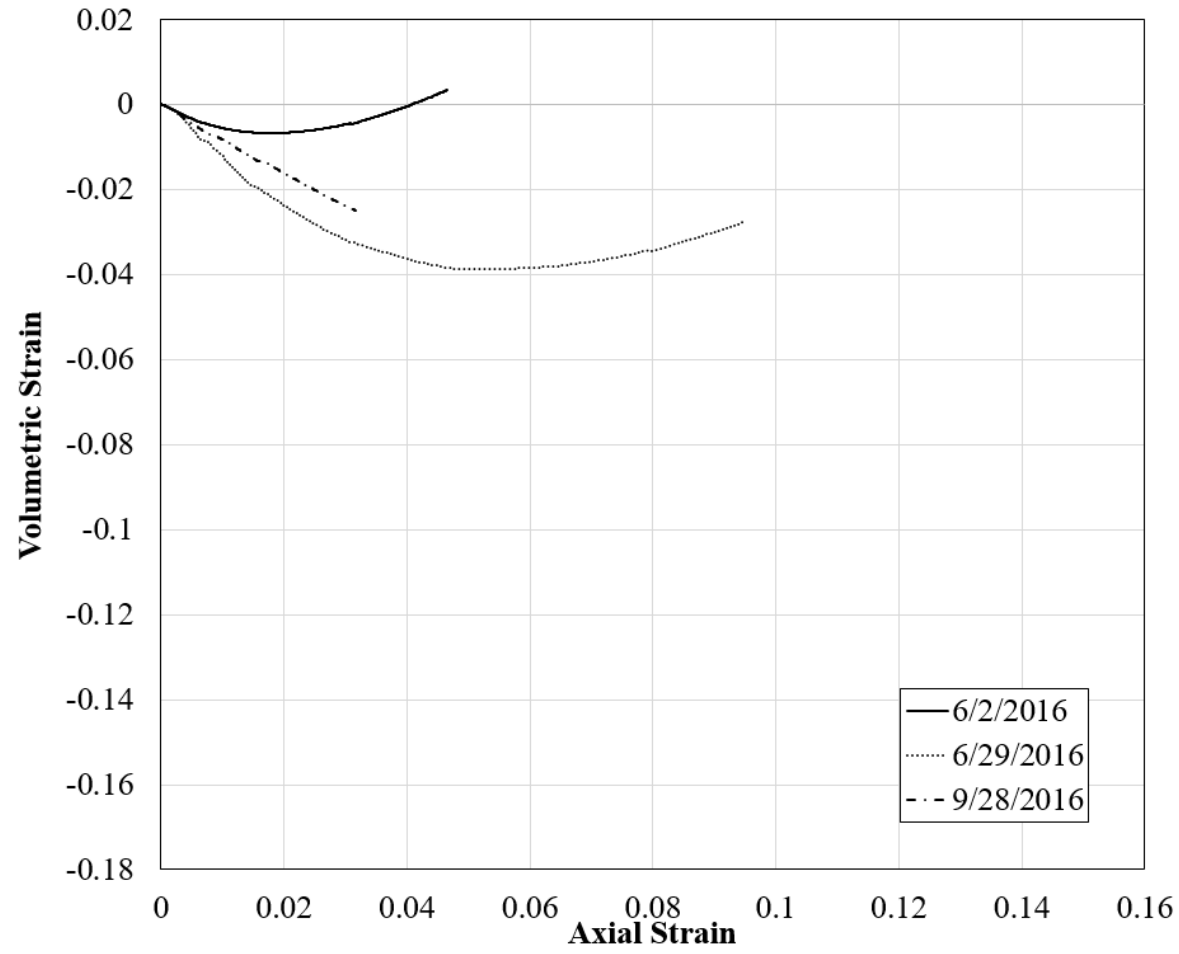

Fig. 4. 19 Mix 3 volumetric strain curves comparison 


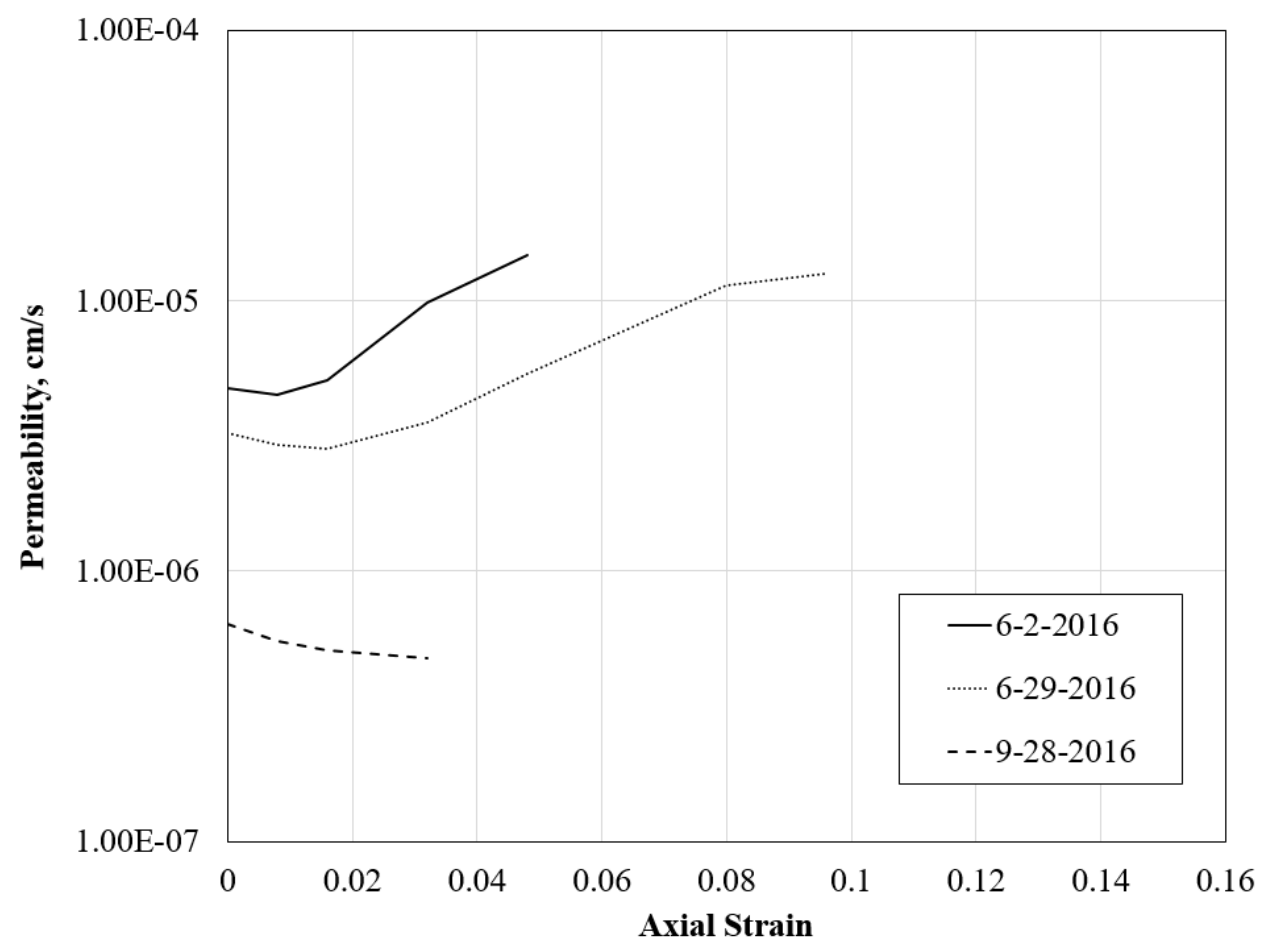

Fig. 4. 20 Mix 3 permeability curves comparison

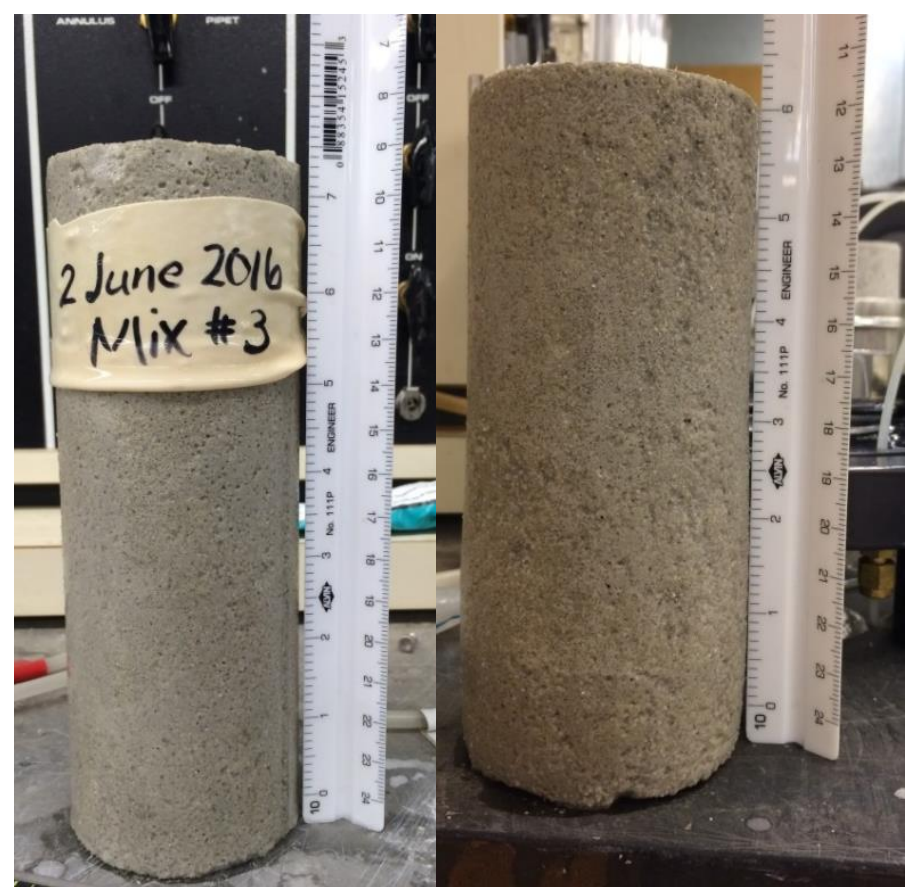

Fig. 4. 21 Mix 3 (June 2, 2016) before (left) and after (right) testing 


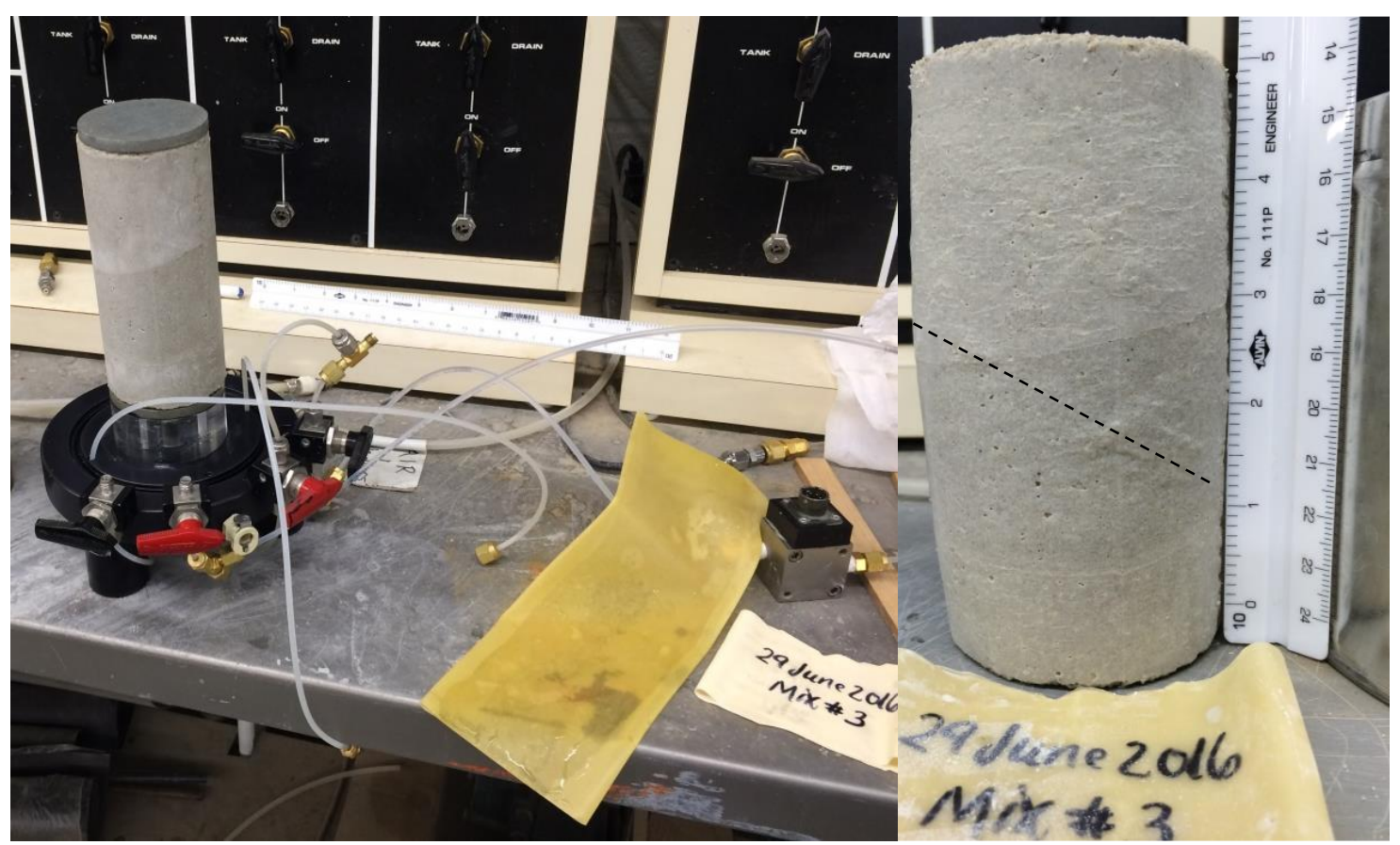

Fig. 4. 22 Mix 3 (June 29, 2016) before (left) and after (right) testing

Mix 4

Mix 4 specimens consist of: $2 \%$ cement, and $23 \%$ kaolinite, by dry weight. Only one specimen of this mix was tested during this research, and as noted above, used kaolinite instead of bentonite. The following paragraphs describe processes that may account for anomalies in the material properties. Figures 4.23 through 4.26 are the consolidation, stress-strain, volumetric strain, and permeability curves for Mix 4.

For the June 3, 2016 specimen, the bentonite was not hydrated for 24 hours prior to mixing. This could account for more brittle behavior in Figure 4.24, but this specimen also contains the lowest percentage of cement. The specimen was consolidated at $10 \mathrm{psi}$, 
at a consolidation rate of $10 \mathrm{psi} / \mathrm{hour}$, which appears rapid due to the amount of secondary consolidation showing in Figure 4.23. The testing ceased at $8.0 \%$ strain, as seen in Figure 4.24, because the flow pumps ran out of travel and were not re-set in time, however testing to $11.2 \%$ strain was completed. In general, the permeability decreased from $0.8 \%$ to $3.2 \%$ triaxial shear increments. Then the permeability increased more for the $3.2 \%$ to $8.0 \%$ triaxial shear increments, as seen in Figure 4.26. This specimen has the lowest permeability of the specimens tested during this research. The small change in permeability also indicates more ductile behavior.

Since only one specimen of this mix was tested during this research, there is no comparison between specimens to be made. The consolidation of the specimen appears mostly appropriate; however, more time for primary consolidation is advised. Both the stress-strain curve, Figure 4.24, and volumetric strain curve, Figure 4.25, indicate the specimen was ductile. It should be noted that testing to $8.0 \%$ strain did not achieve failure of the specimen. During the analysis above, it was noted that the use of low plasticity clay presented unexpected testing results. The specimen exhibited ductile behavior while also having stiffness. The Bulk modulus for this specimen was $231.7 \mathrm{ksi}$. These results warrant additional research of different clay types used in mix designs.

Figure 4.27 shows the Mix 4 specimens before and after testing. The failure mechanism appears to be bulging of the sample, distinct failure planes are not readily visible. 


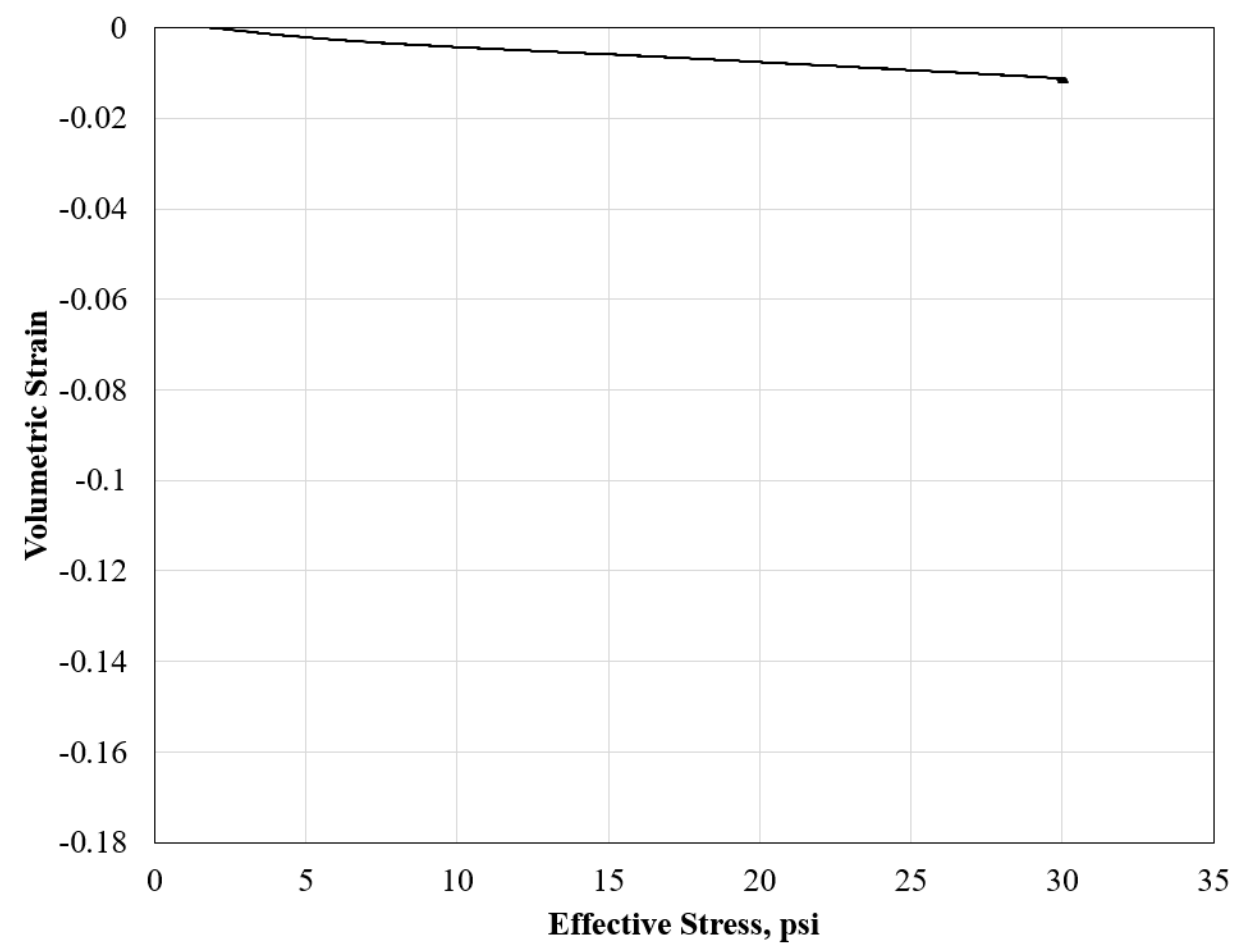

Fig. 4. 23 Mix 4 consolidation curve

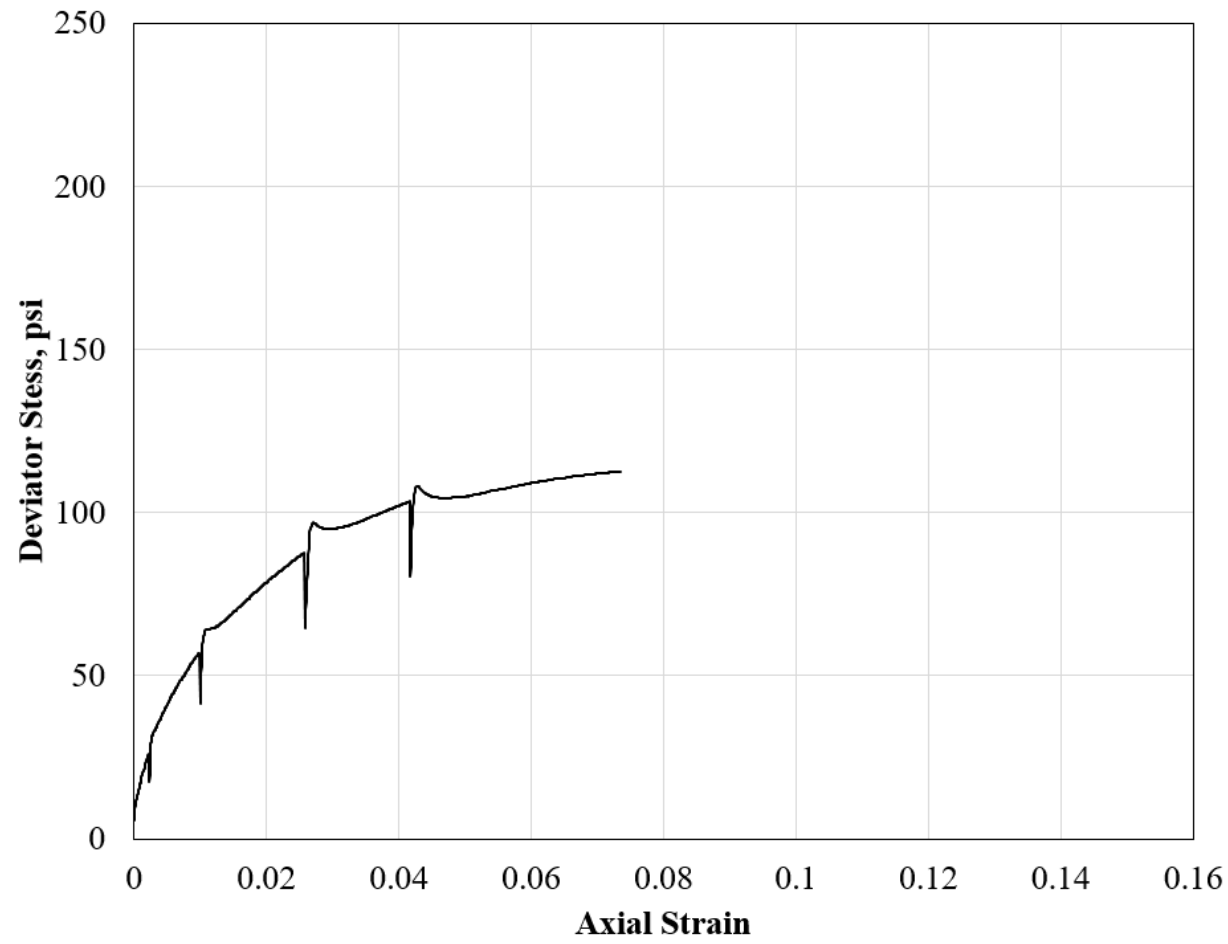

Fig. 4. 24 Mix 4 stress-strain curve 


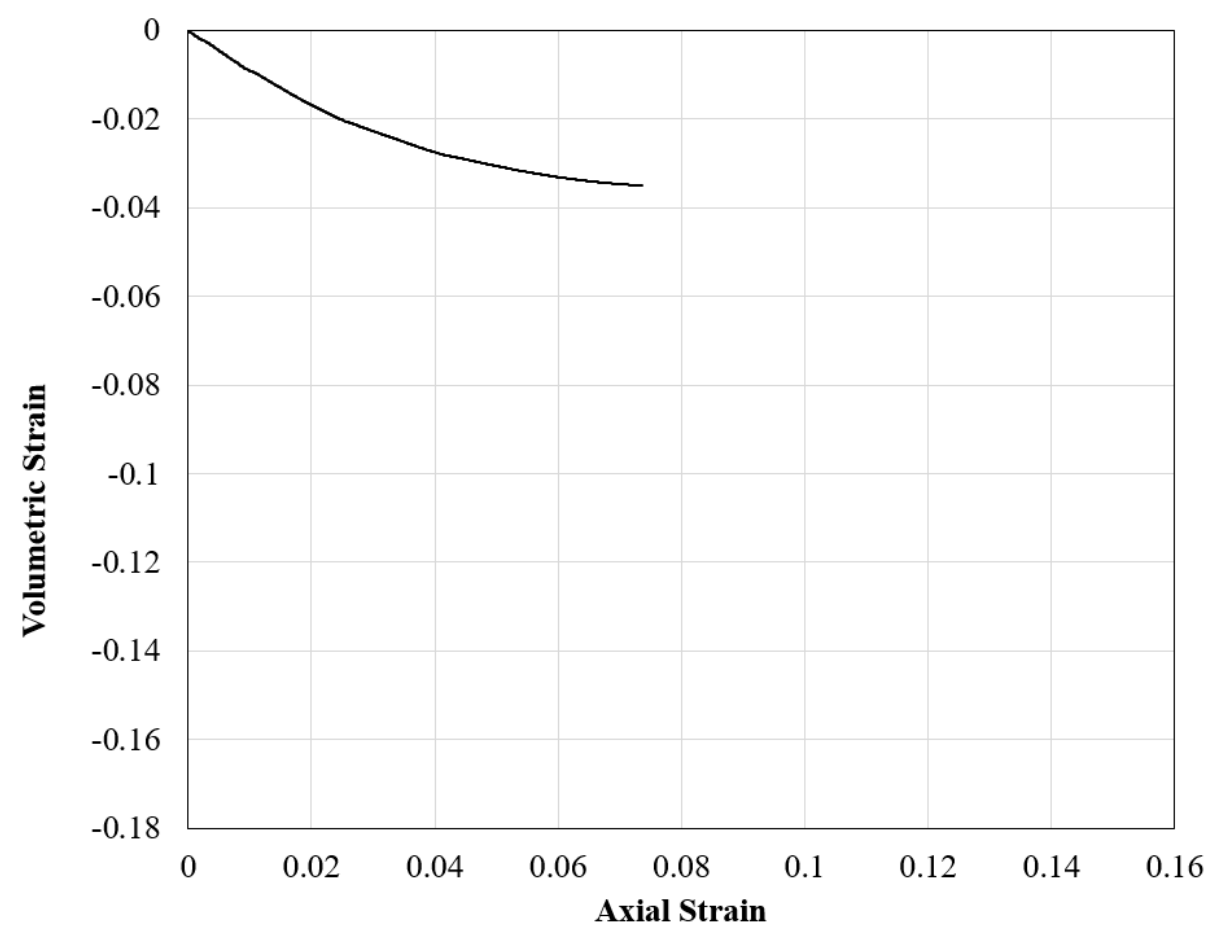

Fig. 4. 25 Mix 4 volumetric strain curve

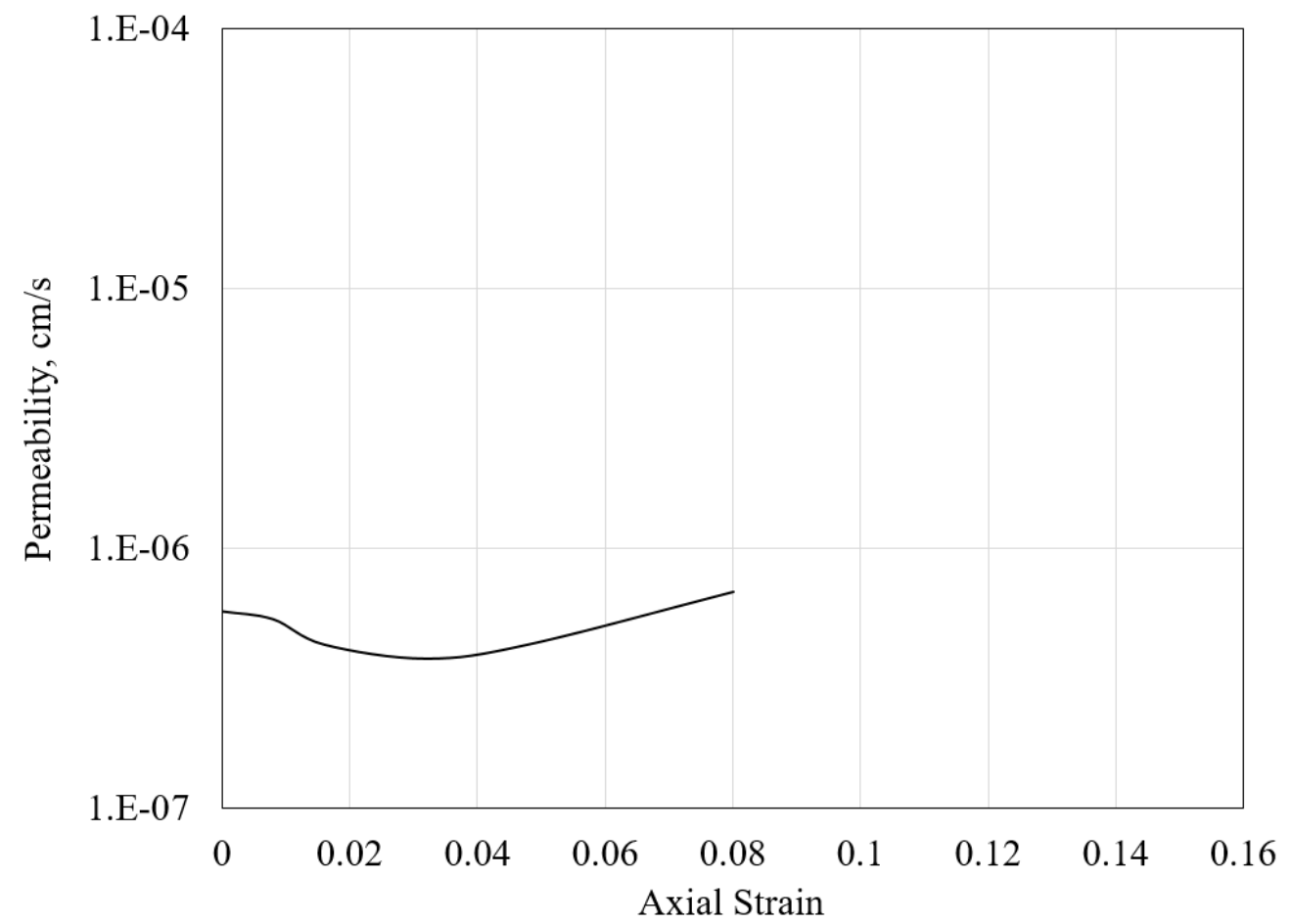

Fig. 4. $26 \mathrm{Mix} 4$ permeability curve 


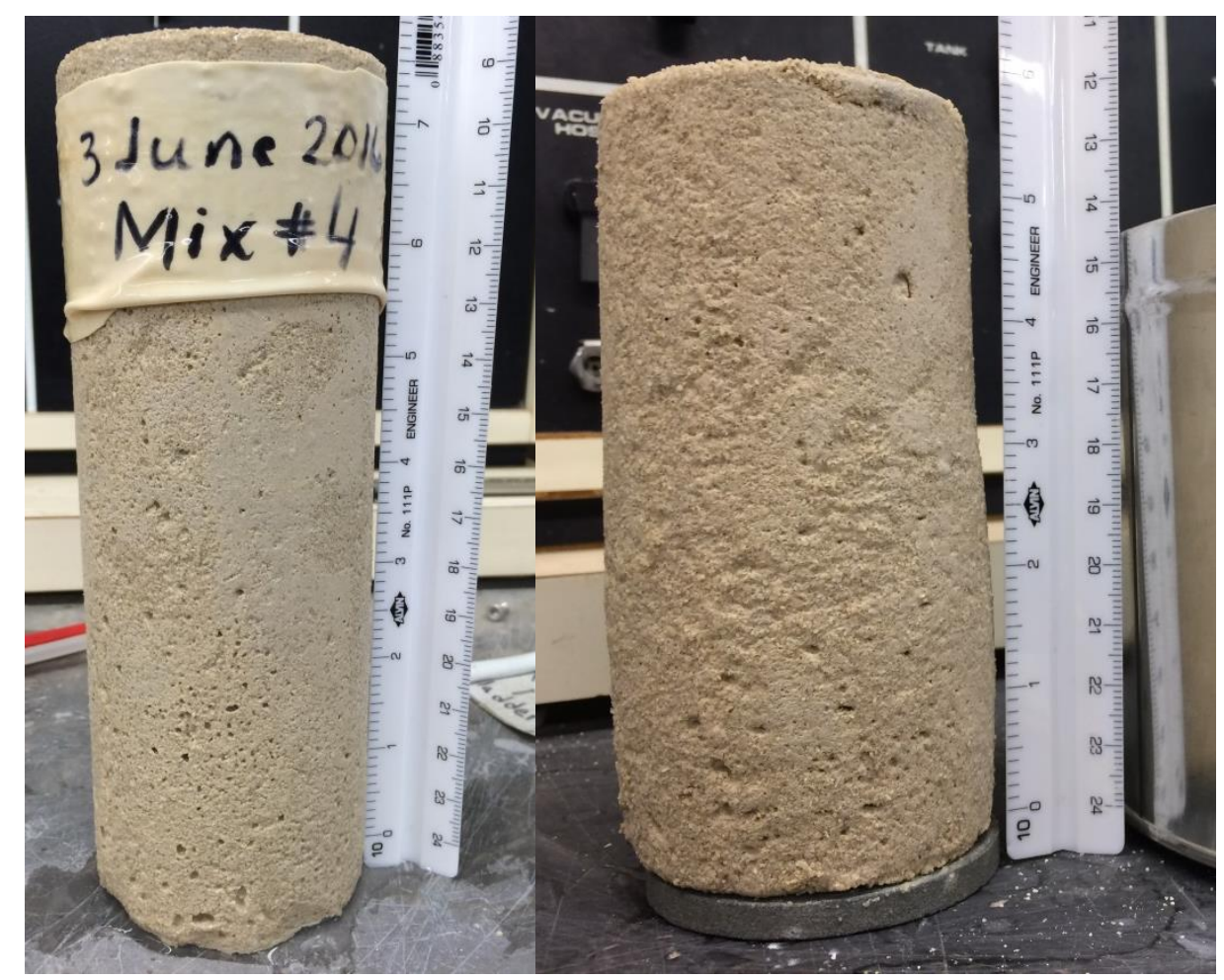

Fig. 4. 27 Mix 4 (June 3, 2016) before (left) and after (right) testing

Mix 7

Mix 7 specimens consist of: $6 \%$ cement, and $2 \%$ bentonite, by dry weight. These specimens were tested during the middle to end of the research, therefore the testing procedure does not change between specimens. The following paragraphs describe processes that may account for non-uniform results for this mix. Figures 4.28 through 4.31 are the consolidation, stress-strain, volumetric strain, and permeability curves for Mix 7.

The July 25, 2016 specimen was used for demonstration of the testing procedure of this research for the United States Society on Dams (USSD) symposium on Internal 
Erosion and Piping, therefore some of the testing procedure steps were expedited. The bentonite was hydrated for 24 hours and additional water was added. The specimen was consolidated at 2 psi, at a consolidation rate of 2 psi/hour, which appears adequate and is shown in Figure 4.28. After 6 hours of consolidation, it was noted that there was a leak around the O-ring on the bottom of the test cell. In order to keep the specimen for testing, the pressure was lowered to 72.8 psi for the cell pump pressure and 60 psi for the bottom pump pressure. The final cell pressure would then be 90 psi instead of the standard 130 psi. Both consolidation curves, with the leak and after the pressure was lowered, is shown in Figure 4.28. For later comparison purposes, the data before the leak was addressed was used. After approximately 4 hours of initial permeation, the specimen and equipment was moved to the Symposium location. There, triaxial shear testing increments commenced. Whereas the testing procedure calls for permeation to stop during triaxial shear, this test continued permeation throughout the triaxial shear increments. The permeation time between triaxial shear increments was also curtailed since permeation was continuous. The testing was stopped at $11 \%$ strain before failure was achieved.

The bentonite was hydrated for 24 hours and additional water was added for the September 7, 2016 specimen. The specimen was consolidated at 2 psi, at a consolidation rate of 2 psi/hour, which appears adequate and is shown in Figure 4.28. A large indentation was noted on the specimen, which may have created a preferential pathway for the water flow during the testing. The remaining triaxial test increments were increased by $3.2 \%$ to a final strain of $14.4 \%$, as shown in Figure 4.29. However, the top 
and bottom flow pumps ran out of travel around $13.13 \%$ strain, therefore the calculations end there. This explains the sharp drop in the Stress-Strain Curve at a stain of $13.13 \%$; it does not represent failure of the specimen, which was more gradual.

Two specimens of Mix 7 were prepared during this research. These mixes were prepared near the end of the research period. In general, it appears the consolidation time was adequate for the mix after the consolidation rate was changed from $10 \mathrm{psi} / \mathrm{hr}$ to 2 $\mathrm{psi} / \mathrm{hr}$. The slopes of the curves follow mostly the same slope, when the initial consolidation curve from July 25, 2016 is compared to the other specimen. The comparison of the stress-strain curves shows a good correlation between the two specimens, with one reaching failure. Both specimens start with contractive behavior, indicating the specimen was ductile, as illustrated in Figure 4.30. It is difficult to compare the changes in permeability since the two tests were run at different pressures and the permeability ran constantly for the July 25, 2016 specimen. In general, the change in permeability throughout the testing procedure was small, indicating a ductile mix. The stiffness of the specimens was assessed using the bulk modulus. Table 4.13 presents the bulk modulus values. The average bulk modulus for Mix 7 was $38.5 \mathrm{ksi}$.

Table 4. 13 Bulk Modulus Values for Mix 7

\begin{tabular}{ll}
\hline Specimen & Bulk Modulus (ksi) \\
\hline July 25, 2016 & 35.6 \\
September 7, 2016 & 41.3 \\
\hline
\end{tabular}


Figures 4.32 and 4.33 shows the Mix 7 specimens before and after testing. The failure mechanism appears to be bulging of the sample, distinct failure planes are not readily visible. The indentation noted for the September 7, 2016 is circled in Figure 4.33.

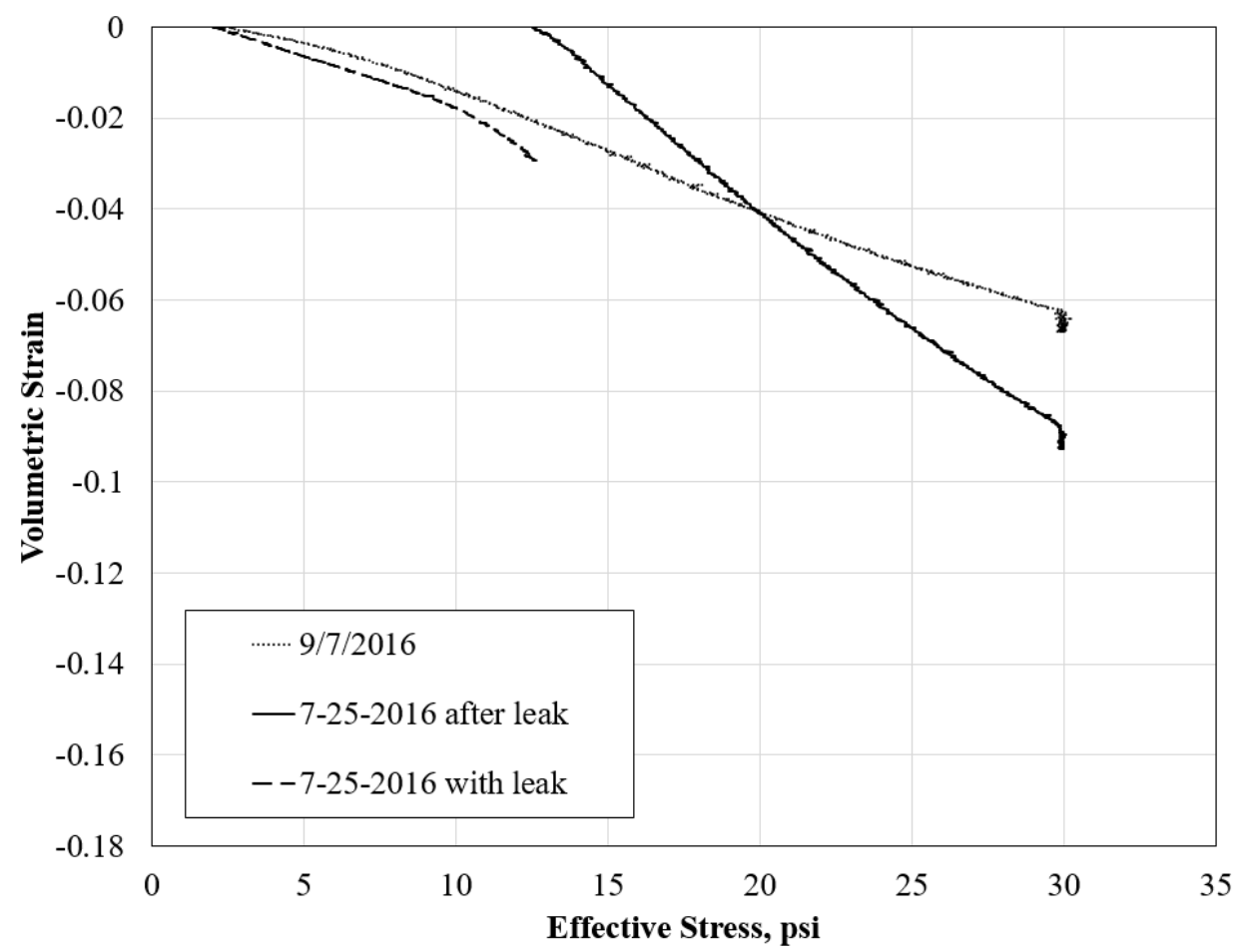

Fig. 4. $28 \mathrm{Mix} 7$ consolidation curves comparison 


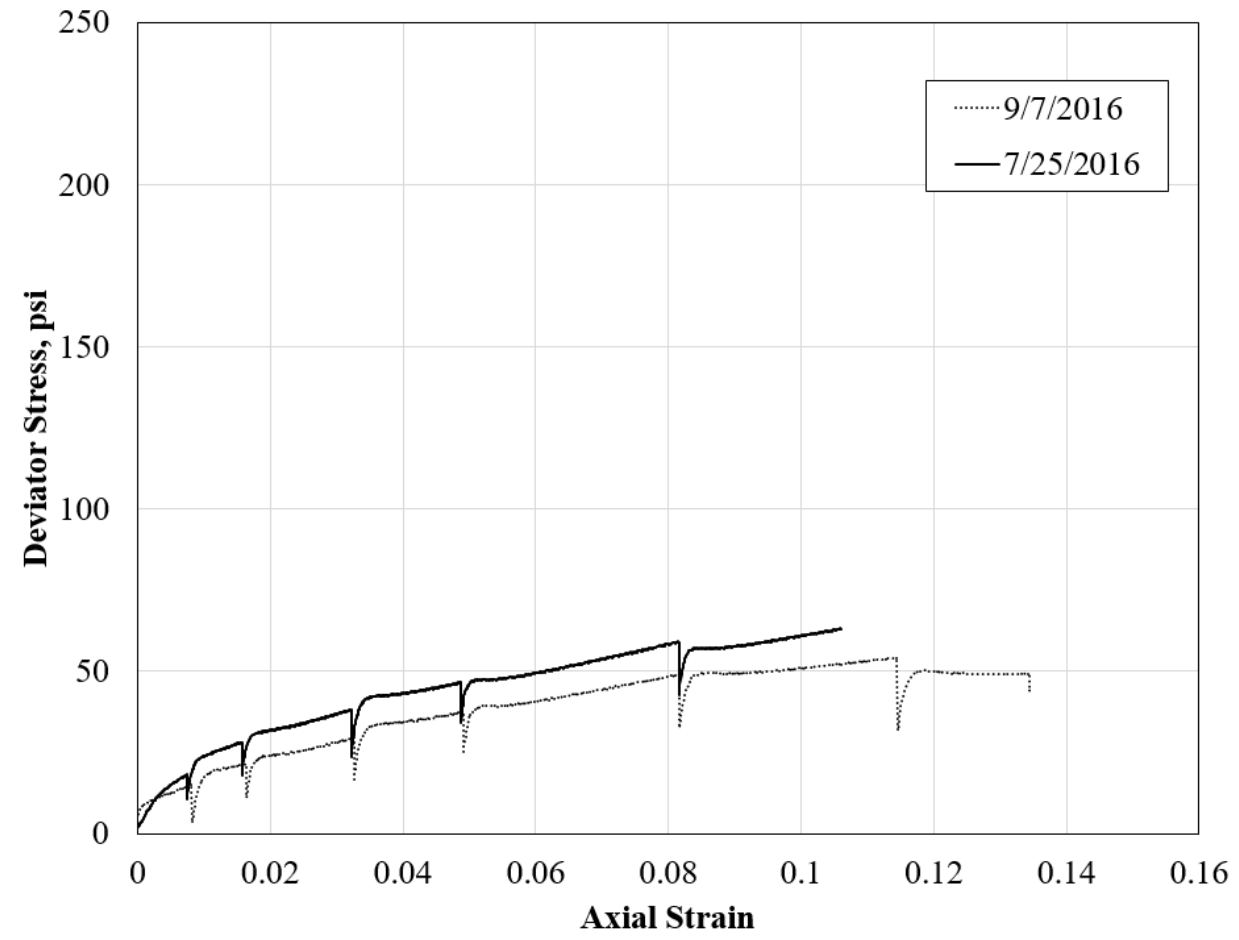

Fig. 4. 29 Mix 7 stress-strain curves comparison

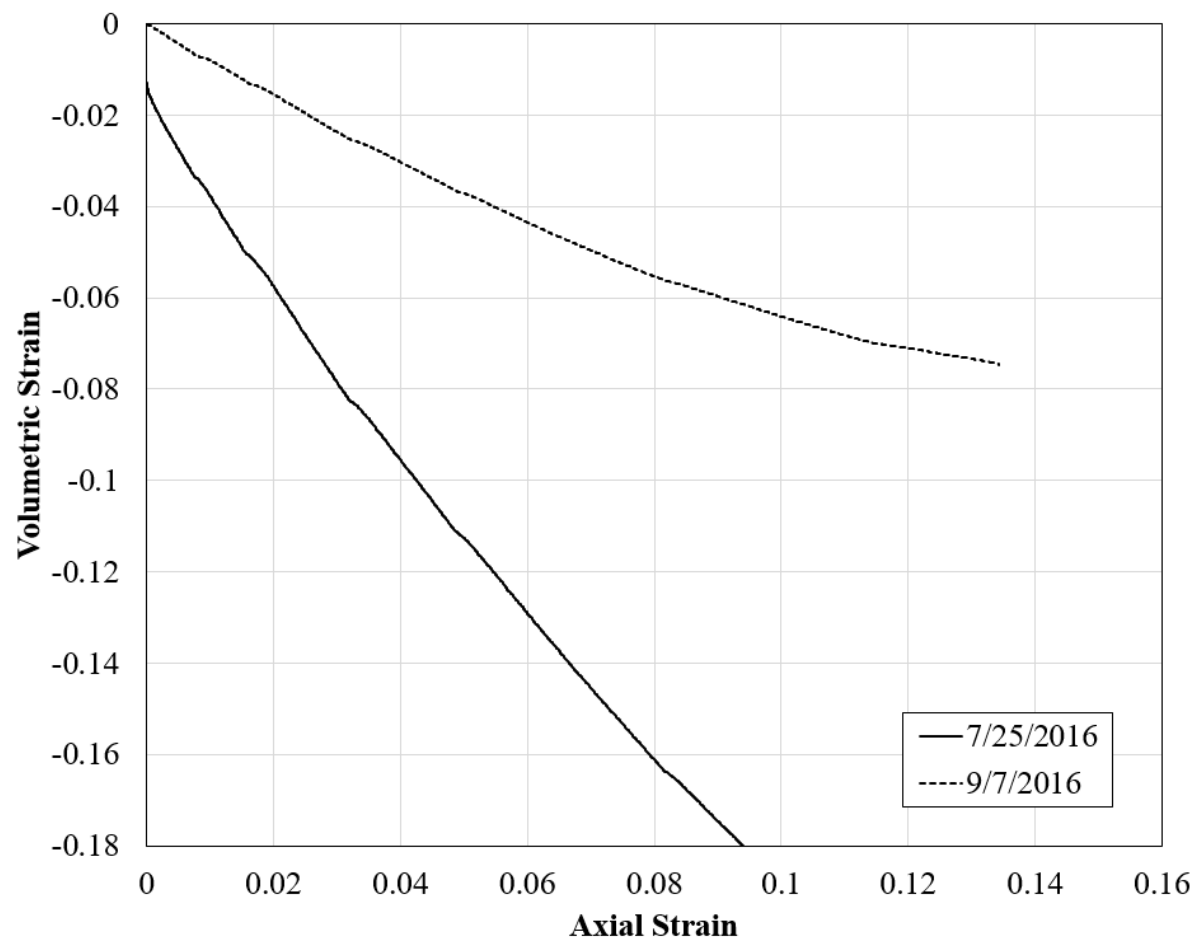

Fig. 4. 30 Mix 7 volumetric strain curves comparison 


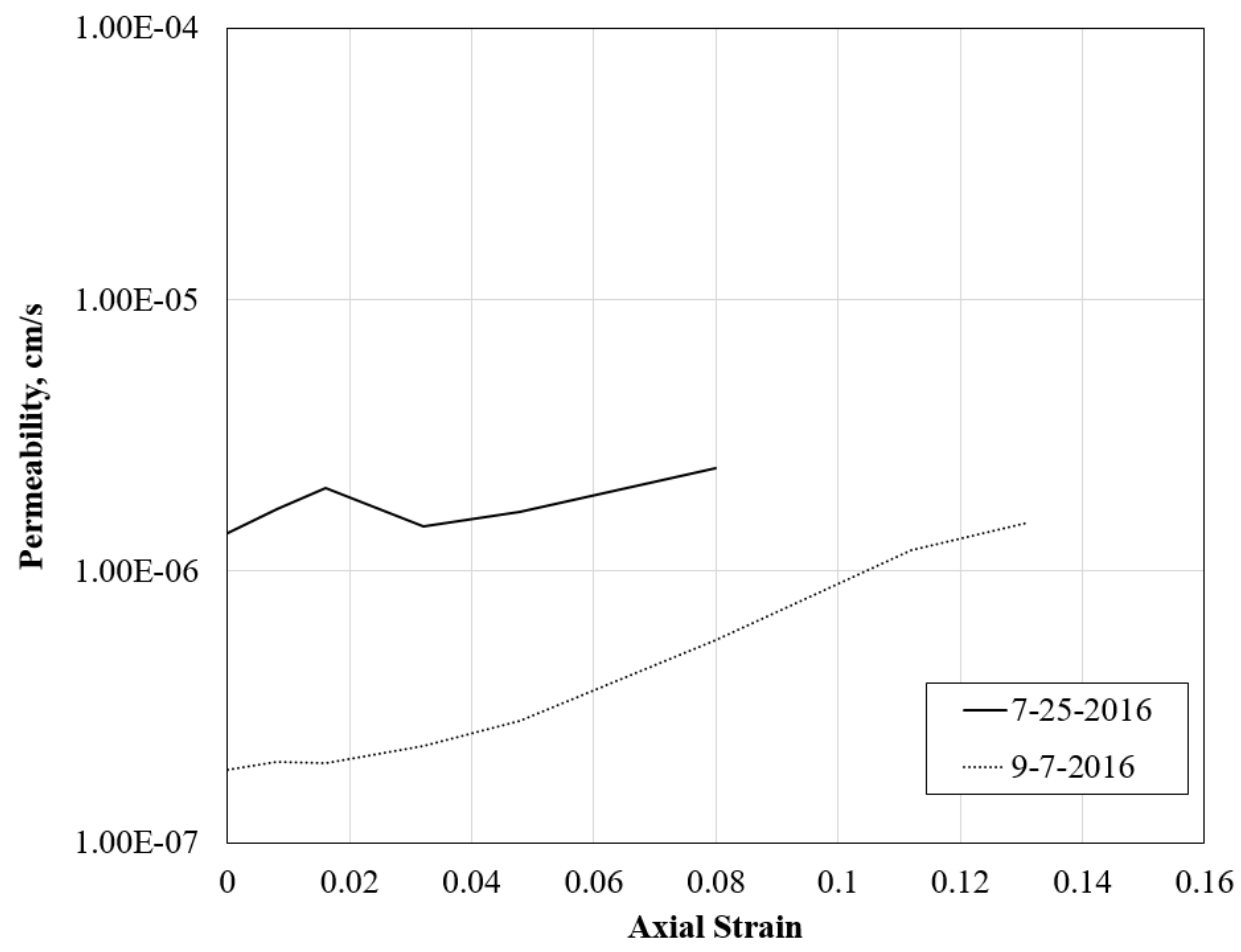

Fig. 4. 31 Mix 7 permeability curves comparison

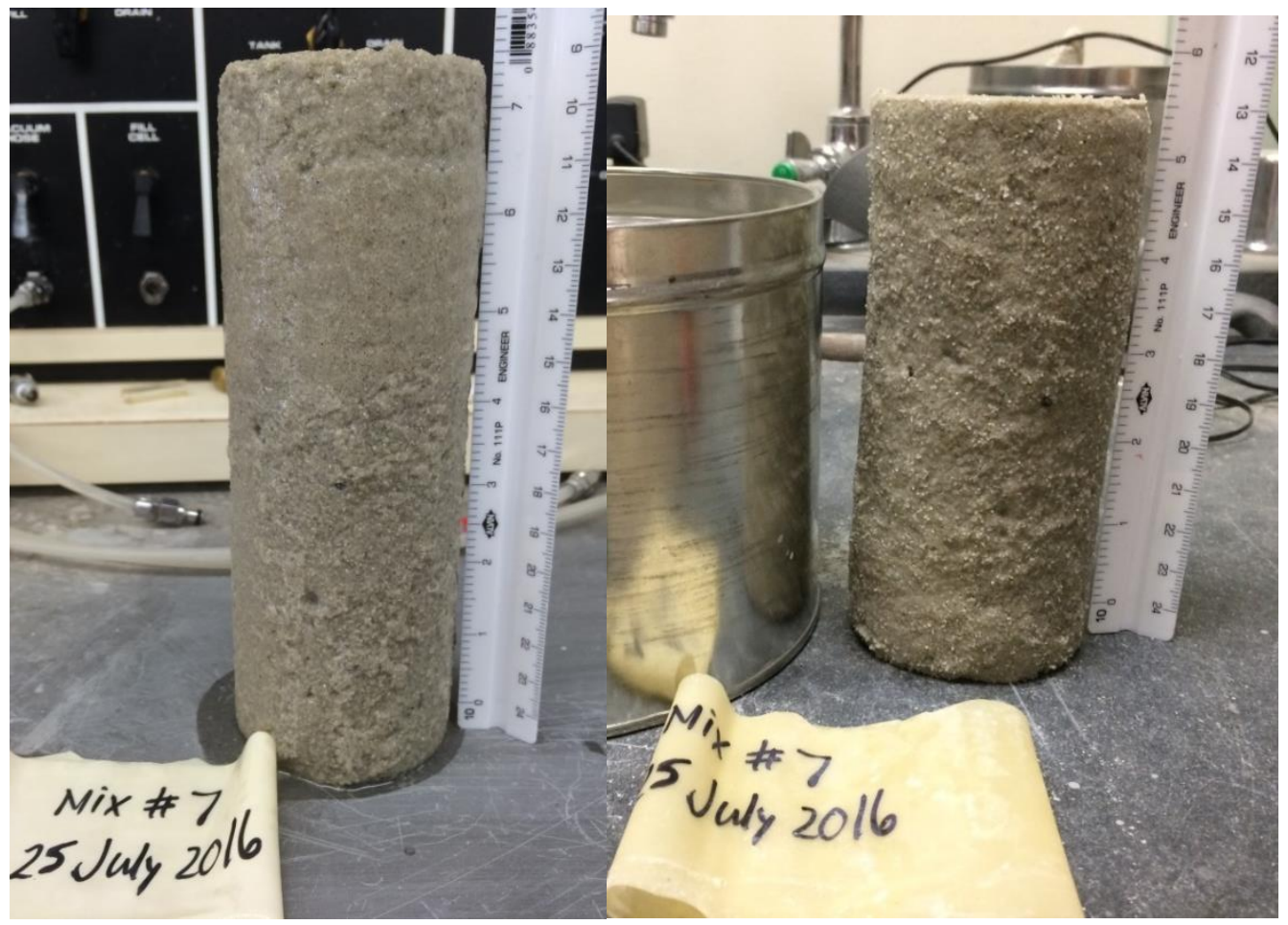

Fig. 4. 32 Mix 7 (July 25, 2016) before (left) and after (right) testing 


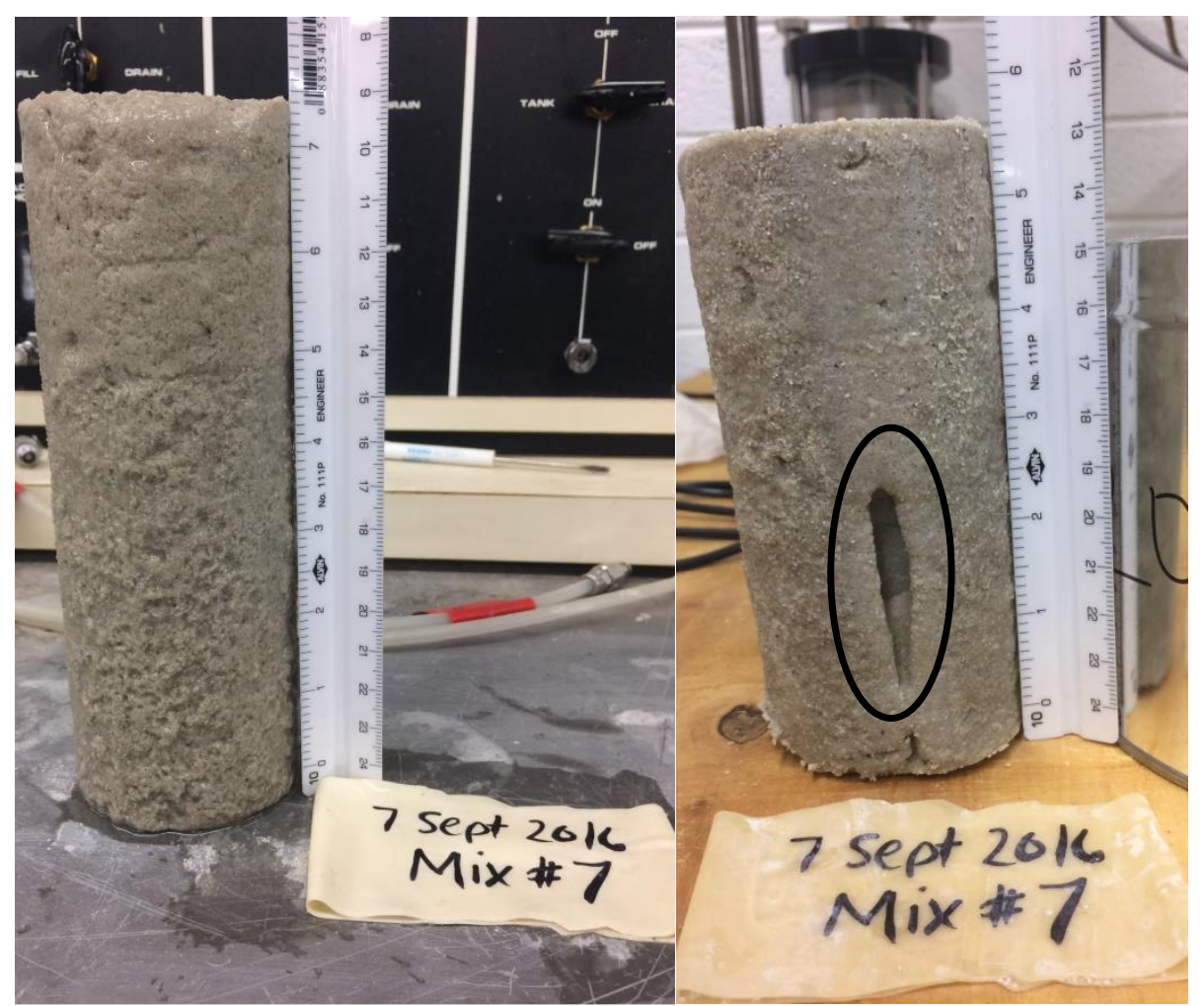

Fig. 4. 33 Mix 7 (September 7, 2016) before (left) and after (right) testing

Mix 8

Mix 8 specimens consist of: $6 \%$ cement, and $6 \%$ bentonite, by dry weight. These specimens were tested towards the end of the research; therefore, the testing procedure does not change between specimens. The following paragraphs describe processes that may account for non-uniform results for this mix. Figures 4.34 through 4.37 are the consolidation, stress-strain, and volumetric strain curves for Mix 8.

The July 26, 2016 specimen had the bentonite hydrated for 24 hours and additional water was added to the original mix design. The consolidation rate was 2 psi/ hour with 2 psi consolidation, which appears adequate based on Figure 4.34. A leaked 
was noted coming around the top of the road after the $1.6 \%$ strain triaxial shear increment. The remaining triaxial test increments were increased by $3.2 \%$ to a final strain of $11.2 \%$, as shown in Figure 4.35. However, the Digi-Flow K program stopped recording between the $8.0 \%$ and $11.2 \%$ strain triaxial shear increments. Therefore, the $11.2 \%$ triaxial shear data was not used in the calculations or the figures, and the specimen did not reach failure.

Since only one specimen of this mix was tested during this research, there is no comparison between specimens of this mix to be made. The consolidation time used for the specimen looked appropriate based on the curve, as there was not excessive secondary consolidation. The stress-strain curve. Figure 4.35, indicates a more brittle specimen, while the volumetric strain curve, Figure 36, shows the specimen exhibited ductile behavior, contractive behavior. The change in permeability was relatively small, indicating the specimen was more ductile, as shown in Figure 4.37. The stiffness of the specimen was measured using the bulk modulus, which was $390.9 \mathrm{ksi}$.

Figure 4.38 shows the Mix 8 specimen before testing. A photograph was taken not at the completion of the testing procedure. Since the specimen did not reach failure, there were no observable failure planes. 


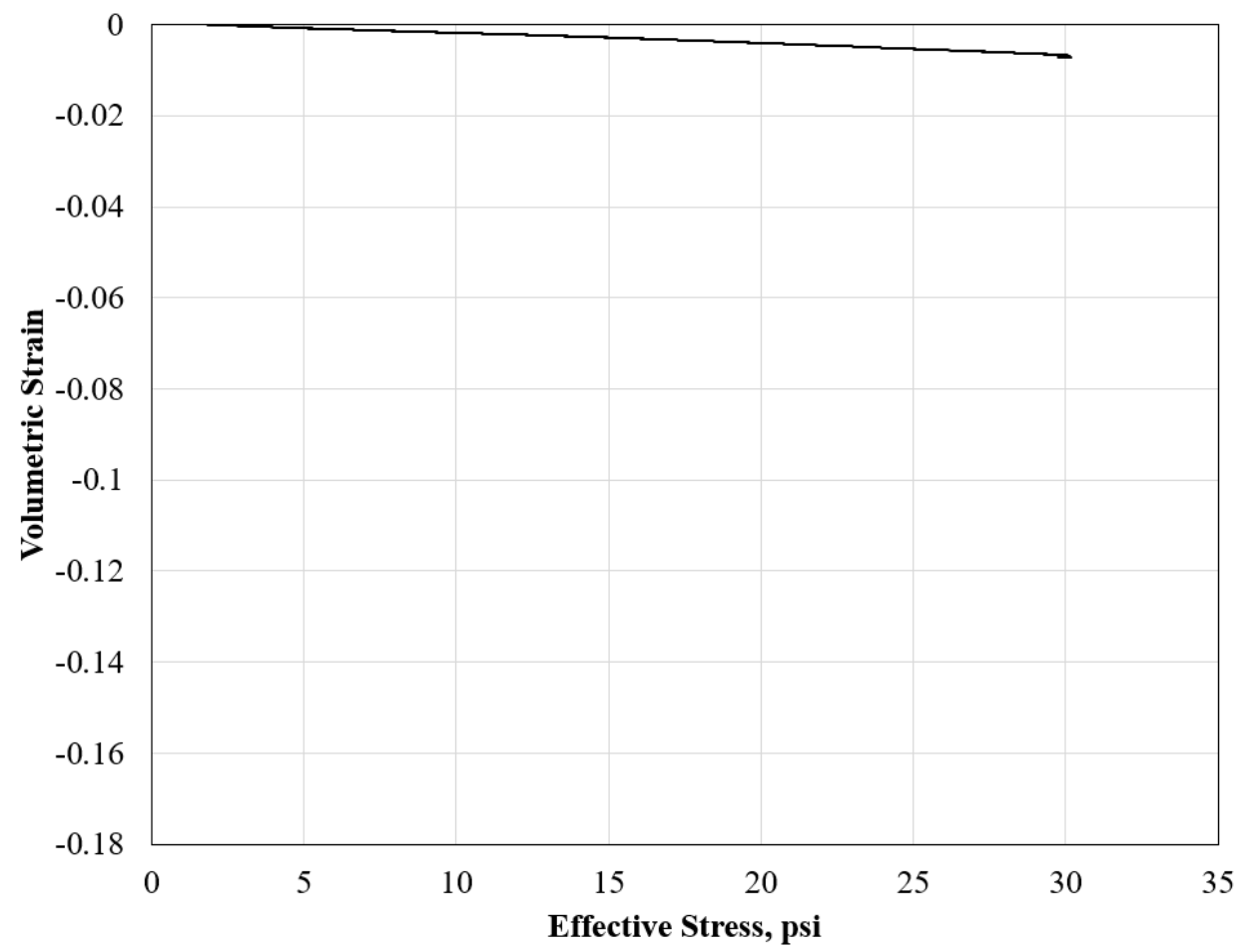

Fig. 4. 34 Mix 8 consolidation curve

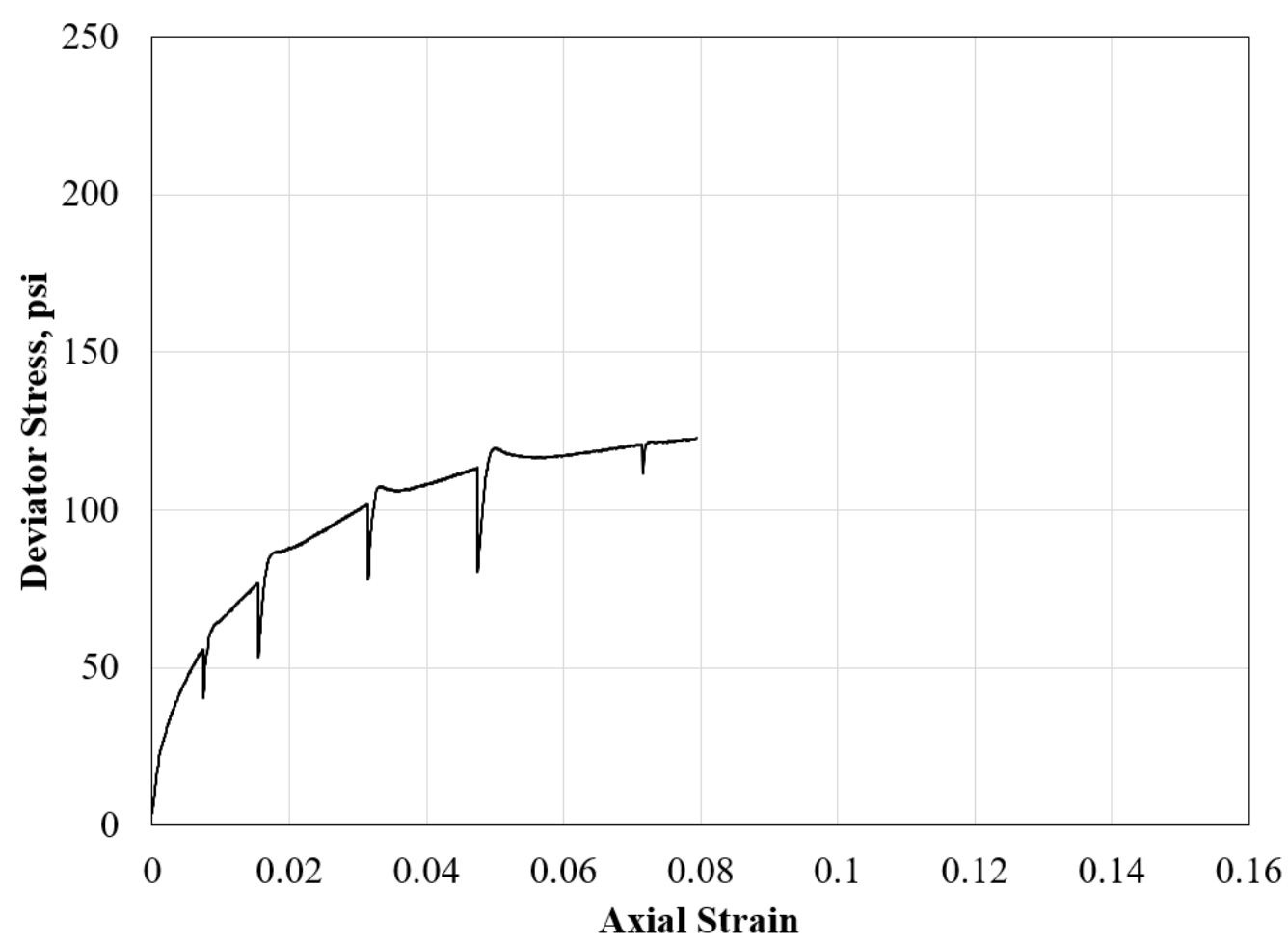

Fig. 4. 35 Mix 8 stress-strain curve 


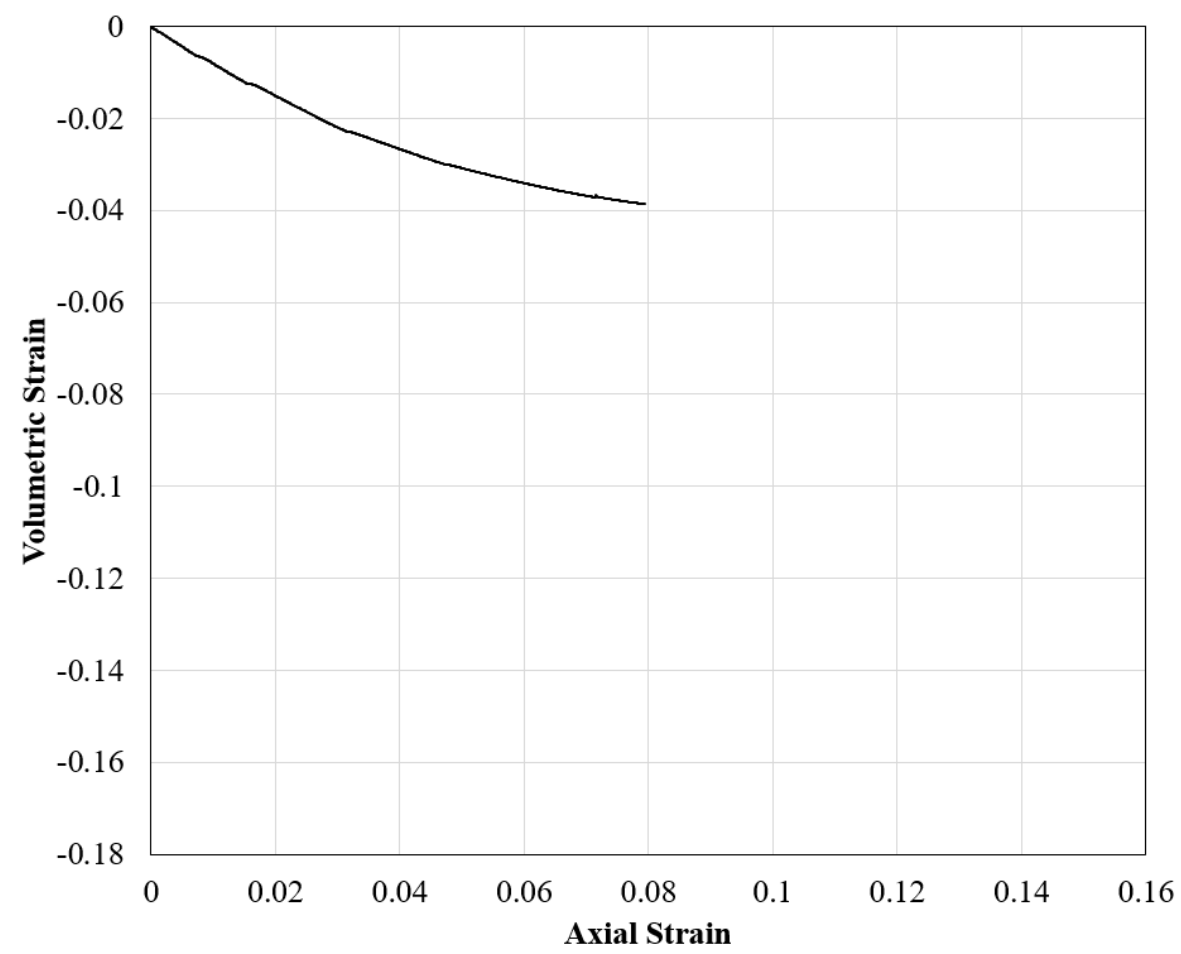

Fig. 4. 36 Mix 8 volumetric strain curve

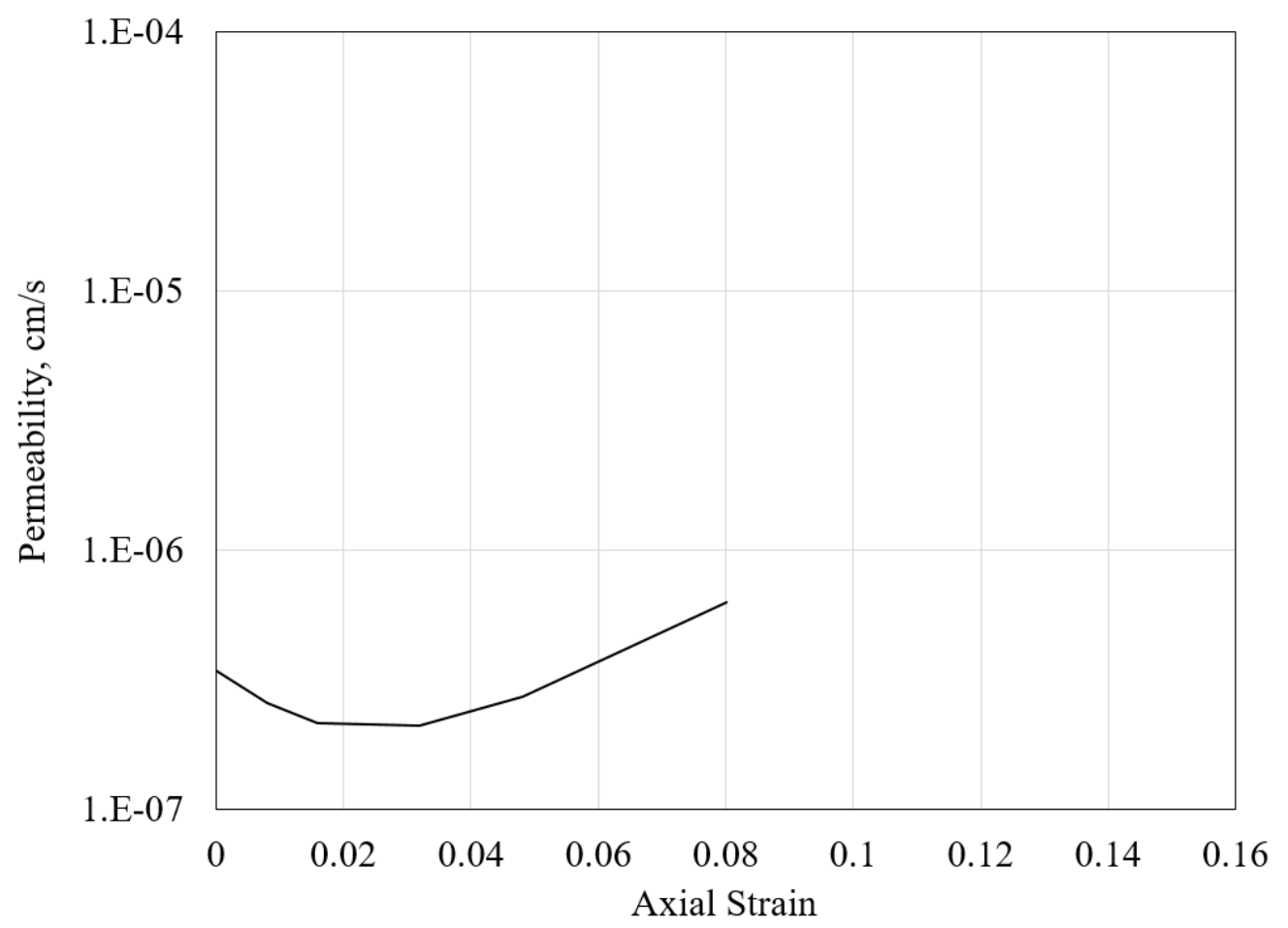

Fig. 4. 37 Mix 8 permeability curve 


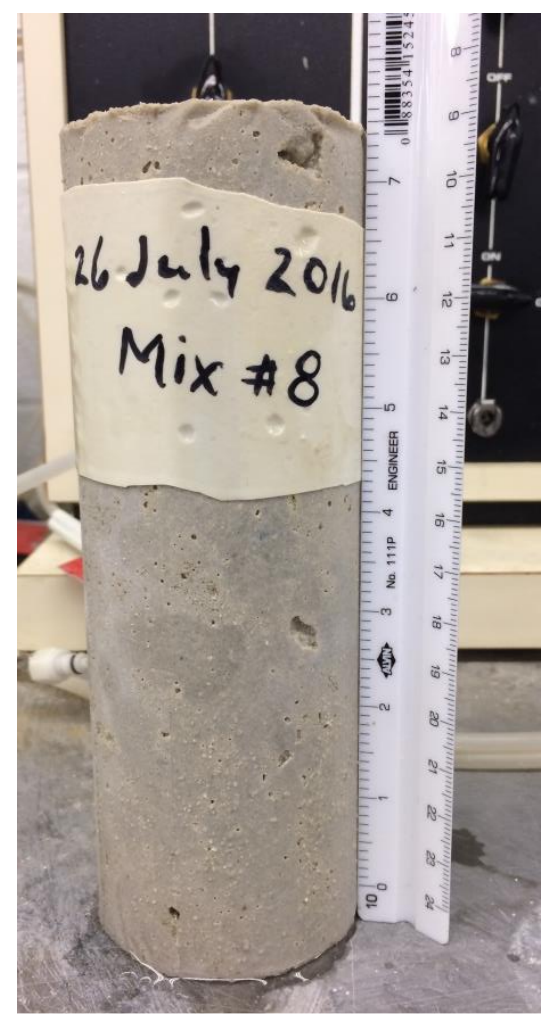

Fig. 4.32 Mix 8 (July 26, 2016) before testing 


\section{CHAPTER 5}

\section{SUMMARY, COMPARISONS, AND CONCLUSIONS}

Current design and construction of new cutoff walls expend large amounts of time on research and development of compatible mixes for the specific subsurface conditions encountered. This is due to a lack of non-proprietary information on mix designs and verification testing on successfully installed soil-cement and plastic concrete cutoff walls. By developing and implementing a new testing method to assess several key material properties of cutoff wall backfill materials, this research and development time could be greatly reduced for the client or owner.

This research presents a new approach to assessing ductility, stiffness, volumetric strain and permeability by combining permeability testing with consolidated drained (CD) triaxial testing. Previous work by others focused mainly on comparing triaxial test results to unconfined compressive strength tests to assess probable in-situ conditions of the cutoff wall backfill material. Classically, the ductility of a mix has been assessed using stress-strain curves and volumetric strain curves. In this new procedure, the ductility is assessed by looking at the change in permeability during the triaxial testing and then confirmed using the classic methods.

During the development of the testing procedure, many variables and processes evolved. The process evolved over approximately one year before the current method presented was suitable for use. Time between testing procedure steps provided the largest variable to the process. Since no other testing has been done like this research, all times needed to be chosen and assessed. Time was also a limitation for the recording of 
data. A small time was chosen to obtain as much data as possible, however most tests took at least one week to complete, most of the time taking longer than the system recorded for. The rate of consolidation proved to be a key factor in the testing procedure. Many different lengths of time were tried before determining a specimen needed at least twelve hours to fully consolidate. To more accurately measure the gradient and permeability through the specimen, a differential pressure transducer was added to the system. This created its own issues in that even minor leaks in the system, while not a problem with conventional triaxial testing, could alter the outcome of the testing on this scale. Both flow control and pressure control were used during the testing procedure. In actual field conditions either scenario of flow is possible. Due to the limited capacity of the flow pumps used, flow control was chosen during permeation and pressure control during triaxial shear.

Essentially every test run had flaws. The previous chapter goes into detail of any issues encountered in each test to explain and understand any anomalies in the results. The most common issues encountered dealt with time and rate of consolidation, data limitations, pump volume limitations, and leaks in the equipment.

General Observations for all Mixes

Each parameter was compared between specimens for the different mixes. In general, the specimens within each mix behaved in a similar manner. Ideally, more specimens would create a better comparison, however due to time constraints, this was not possible. 
Figure 5.1 is the compilation of the all of the consolidated curves for the specimens tested for this research. Consolidation rates changed from 3,600 psi/ hour, to $10 \mathrm{psi} /$ hour, and finally to $2 \mathrm{psi} /$ hour as the testing procedure evolved. The higher consolidation rates produced excessive secondary consolidation, the vertical portions of the curves, for most of the specimens, indicating that the rate was too rapid. Post-testing back calculations of actual time necessary for adequate consolidation can be made based on the calculated bulk modulus, and is suggested for future research.

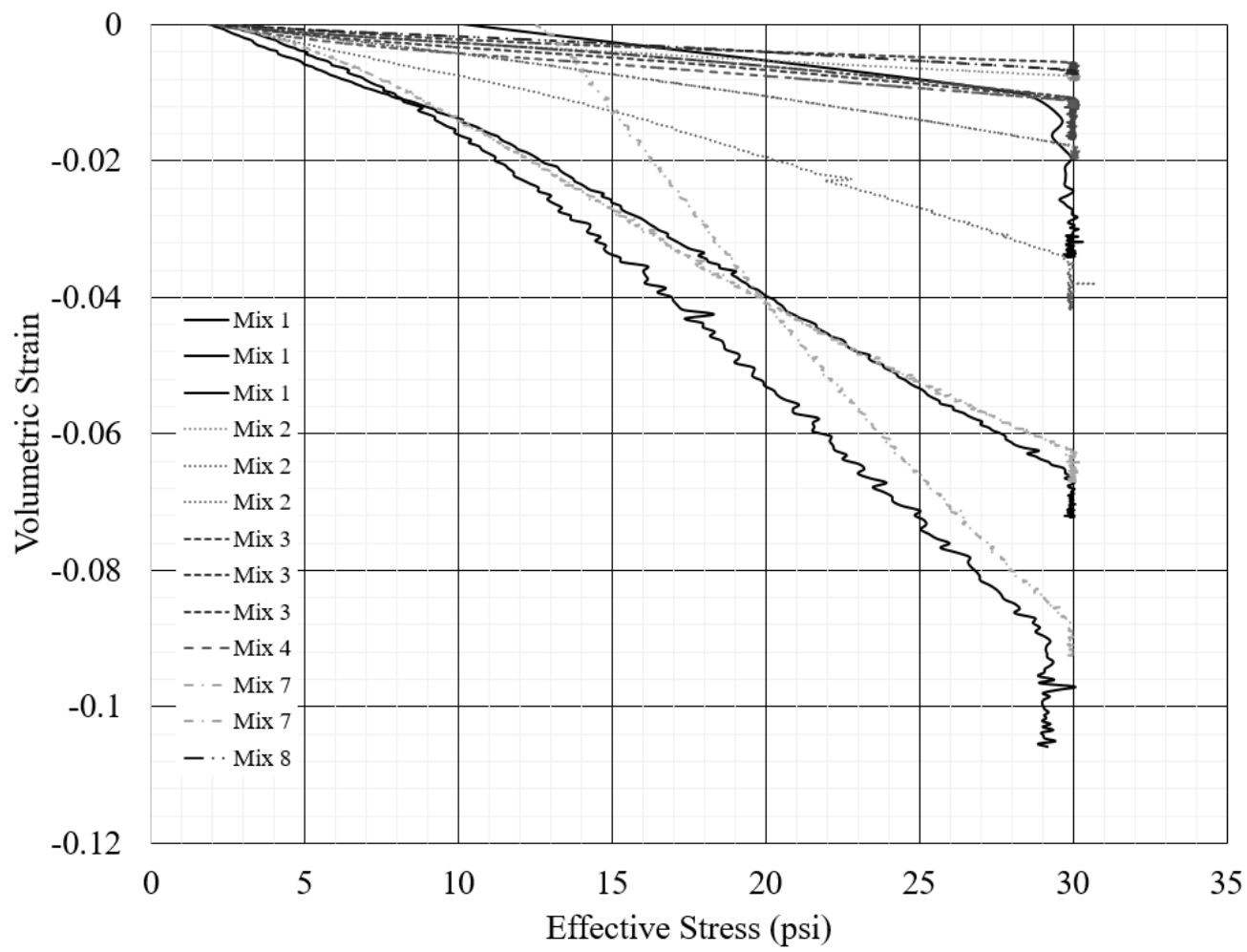

Fig. 5. 1 Consolidation curves for all mixes tested 
Ideally, all specimens would be tested to failure, as defined in Figure 5.2 so that material property behavior could be better assessed in the plastic zone. Figure 5.3 presents the compilation of all of the stress-strain curves for the specimens tested during this research. Many of the specimens did not reach failure, and some tests had to be stopped early due to equipment limitations and other issues.

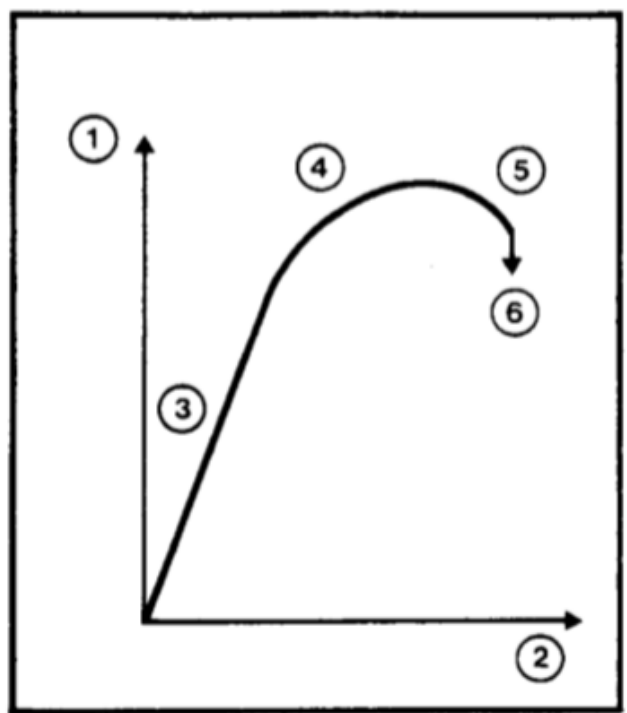

Forme générale de la relation contrainte-déformation

General form of the stress-strain relationship
(1) Contrainte.
(l) Stress.
(2) Déformation.
(2) Strain.
(3) Zone élastique.
(3) Elastic zone.
(4) Zone plastique.
(4) Plastic zone.
(5) Fluage.
(5) Creep.
(6) Rupture.
(6) Failure.

Fig. 5. 2 General form of the stress-strain relationship (ICOLD 1985) 
From Figure 5.3, Mixes 1, 2, and 7 exhibit the most ductile behavior, while Mixes 3, 8 , and 4 are more brittle. Mixes 1 and 2 contain the least amount of cement, $2 \%$ and $4 \%$ cement, respectively, and the most bentonite at $8 \%$ and $6 \%$. Mix 7 does not follow this pattern, as this mix contains the most cement and least bentonite at $6 \%$ and $2 \%$. Other factors, discussed in the previous chapter may help to explain this observation. The brittle behavior of Mixes 3 and 8 aligns with the $6 \%$ cement, but not with the amount of bentonite which is $4 \%$ and $6 \%$, respectively. The Mix 2 specimen in the brittle region is also not explained with just the cement and bentonite contents of the specimen.

Figure 5.4 presents the compilation of all of the volumetric strain curves for the specimens tested during this research. The behavior of these curves, for the most part, compliment the data discussed in the stress-strain curves. Mixes 1, 2, and 7 exhibit the most contractive behavior which corresponds to ductile specimens. Mixes 3,4, and 8 exhibit the most dilative behavior, indicative of brittle specimens. Again, several of the Mix 2 specimens appear in both the ductile and brittle zones.

Figure 5.5 presents the compilation of all of the permeability curves for the specimens tested during this research. Note a logarithmic scale is used for the permeability axis. These curves are the most important, as it pertains to this research, because the change in permeability in the plastic zone of the stress-strain curves can be compared to the change in permeability in that same zone. A summary of observations for each mix follows. 
Mix 1 specimens vary throughout the testing by less than one order of magnitude, but start at a difference of approximately one order of magnitude. This is large variability, but could be explained by the fact the one specimen had hydrated bentonite while the other did not. The two specimens represented in the permeability graph did not reach failure. The change in permeability of these specimens is among the largest of all of the mixes tested, indicating the specimens should be considered brittle, however that overall increase is only about one order of magnitude.

The Mix 2 specimens represented in Figure 5.5 follow a similar trend until 5\% strain, but at different initial permeabilities. Hydrated bentonite was used for both of these specimens, however, one is ductile and one is brittle based on the stress-strain curves and the volumetric strain curves. The overall change in permeability for both of these specimens is among the smallest of all of the mixes, as discussed in Chapter 4.

The Mix 3 specimens started with the highest permeability and had larger increases during testing of all of the specimens tested. This compliments the stress-strain curves and volumetric strain curves that suggest this material is brittle.

The Mix 4 specimen presents an interesting discussion on the use of lower plasticity clay in the design. The stress-strain curve and the volumetric strain curve suggest this mix is more brittle, however this specimen had the lowest increase in permeability of all of the specimens tested. This indicates that the mix has both stiffness and ductility. 
The Mix 7 specimens are in the ductile range in the stress-strain curves and volumetric strain curves, but on both ends of the spectrum with changes in permeability during testing. One of the specimens exhibited the largest change in permeability of all the specimens tested. This is probably due to other factors, discussed previously.

Finally, the Mix 8 specimen represents a kind of intermediate material between ductile and brittle in all aspects. The mix is more brittle than the mixes with less cement, and the permeability also indicates a smaller change than other mixes.

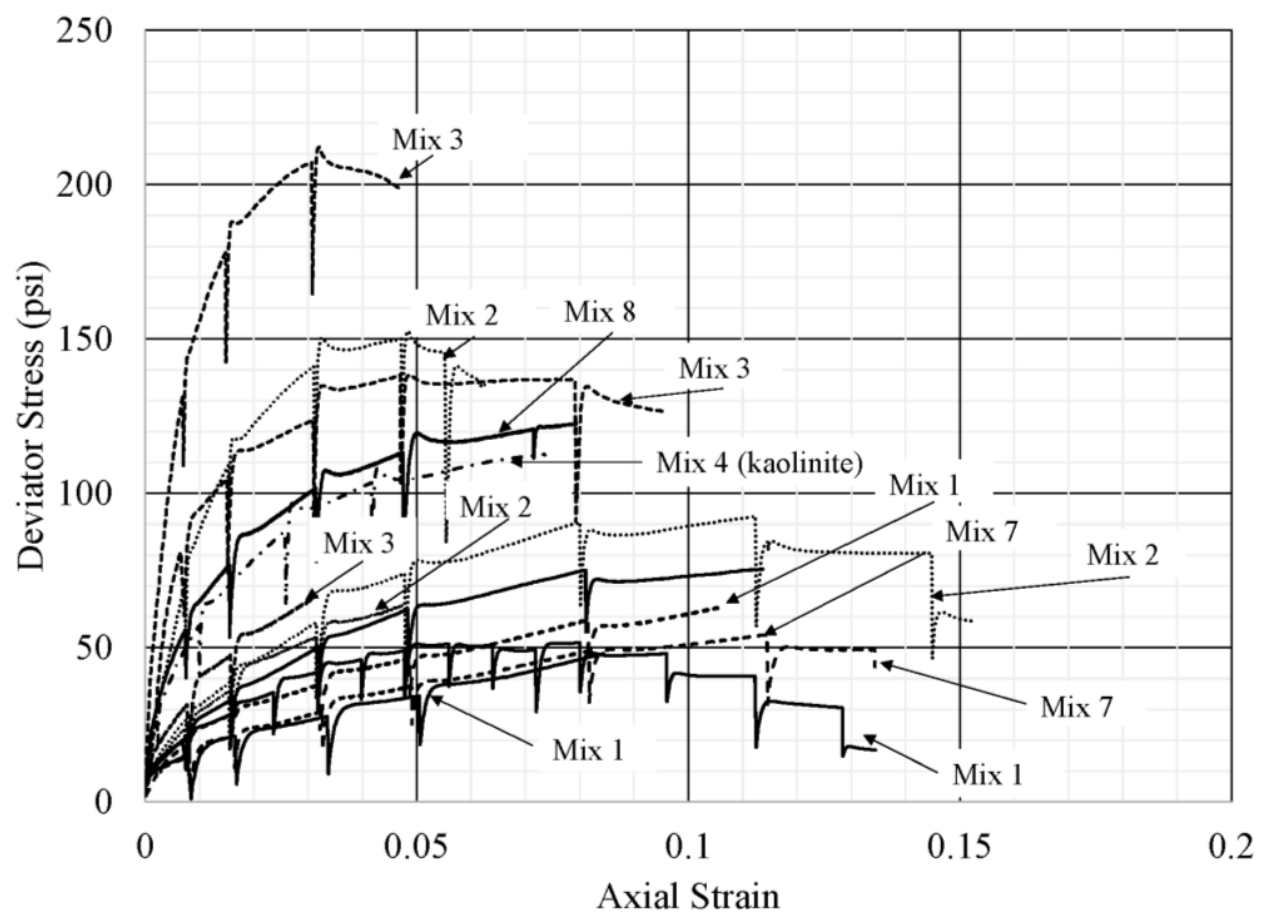

Fig. 5. 3 Stress- strain curves for all mixes tested 


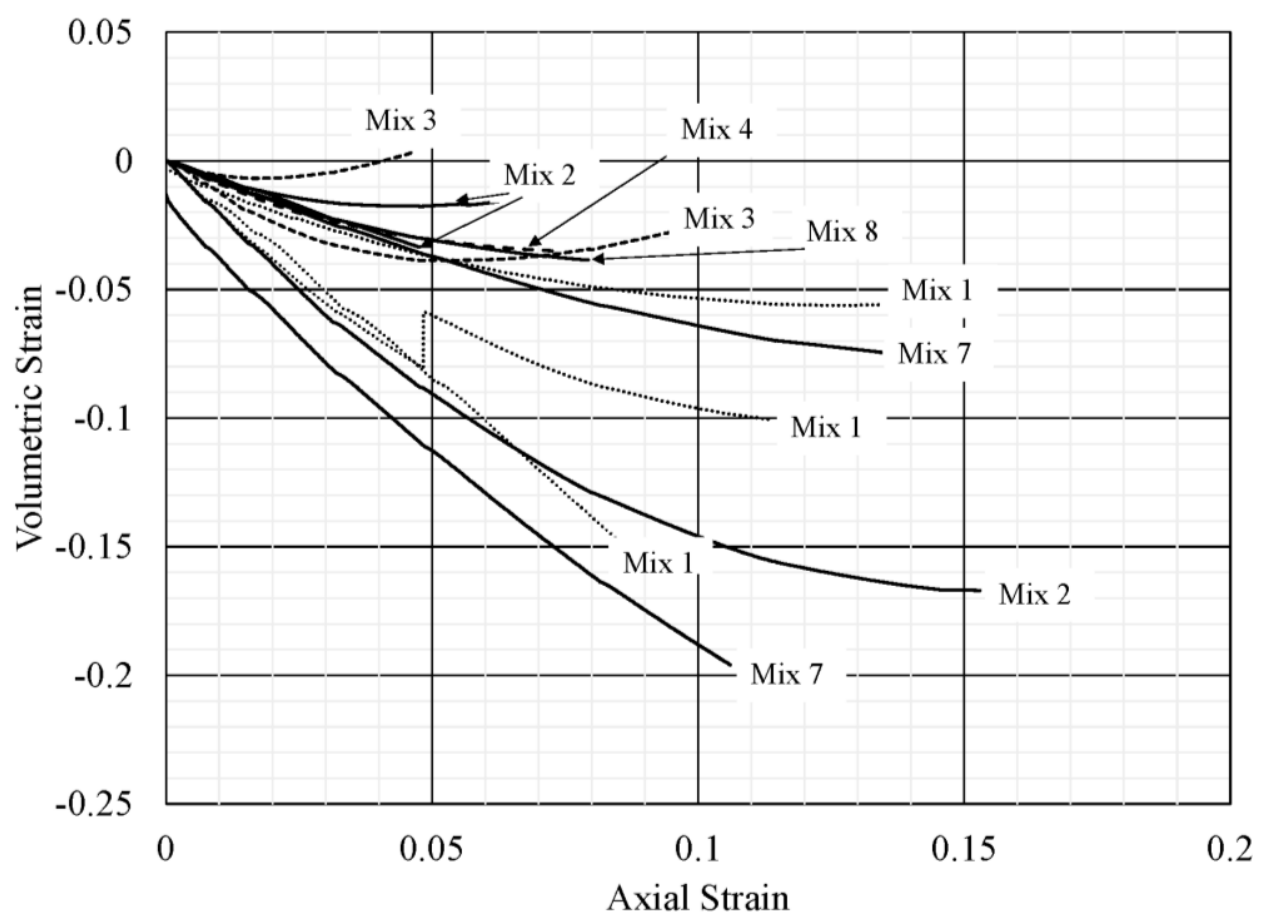

Fig. 5. 4 Volumetric strain curves for all mixes tested

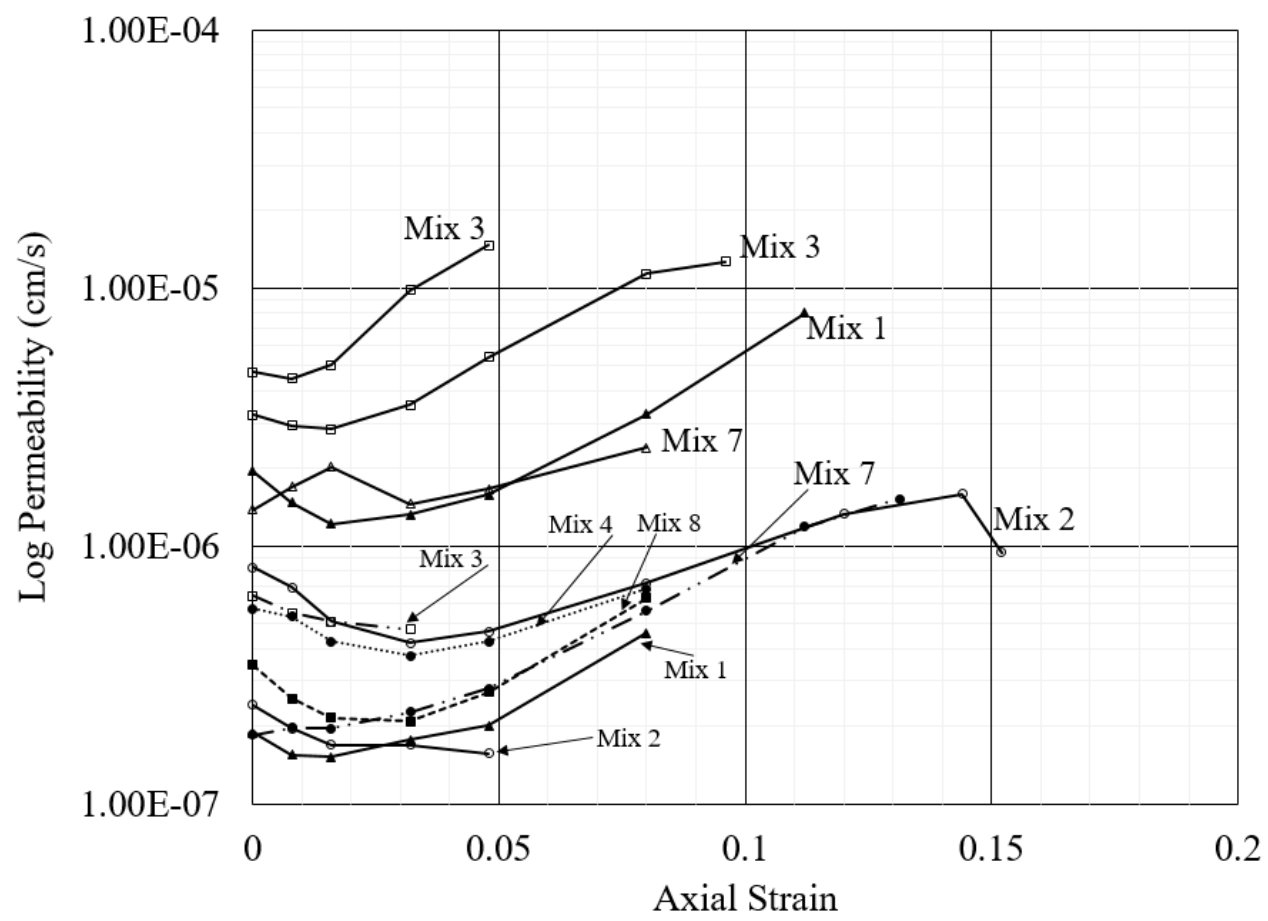

Fig. 5. 5 Permeability curves for all mixes tested 
Comparison of 2 Percent Cement-Bentonite Ratio Mixes

A comparison of material properties can also be made between mix designs with the same percentage of cement (by weight). Mixes 1 and 4 both contain $2 \%$ cement (by weight), and $8 \%$ bentonite and $23 \%$ kaolinite, respectively. Figs. 5.6, 5.7, 5.8, and 5.9 compare the mixes with $2 \%$ cement (by weight).

The consolidation, stress-strain and volumetric strain curves for the $2 \%$ cement mixes correlate to each other fairly well. There are exceptions; however, this seems to be more of a function of an issue during testing as discussed in Chapter 4. Mix 1 strained more than Mix 4, however higher consolidation pressures and rates were used for Mix 1. The Mix 1 specimen closest to Mix 4 in Figure 5.6 was cured quicker than the other specimens of that mix.

The Mix 1 specimens had less strength and exhibited more ductile behavior compared to Mix 4 in the Stress-Strain curves in Figure 5.7. This is especially interesting because Mix 4 has almost three times the amount of clay as Mix 1, but has more strength. Three of the four specimens of the mixes in this comparison did not reach failure, so overall evaluation of ductility of the mixes could change with this additional information.

Figure 5.8, the volumetric strain curve, also indicates that Mix 1 is more ductile than Mix 4. Mix 1 specimens exhibit contractive behavior, while Mix 4 has more dilative behavior. It is again interesting to note that Mix 4 has almost three times the amount of clay as Mix 1 , however it behaves in a more brittle manner. This is most likely due to the mineralogy and plasticity of the clay itself. 
One of the Mix 1 specimens and the Mix 4 specimen have comparable changes in permeability. These represent two specimens that did not reach failure. Overall, there is a general decrease in permeability, during the contractive stage of the specimens, then an increase in permeability when the specimens start to dilate. If all of the specimens reached failure, the change in permeability would be greater based on the slope of the curves and the Mix 1 specimen that did fail.

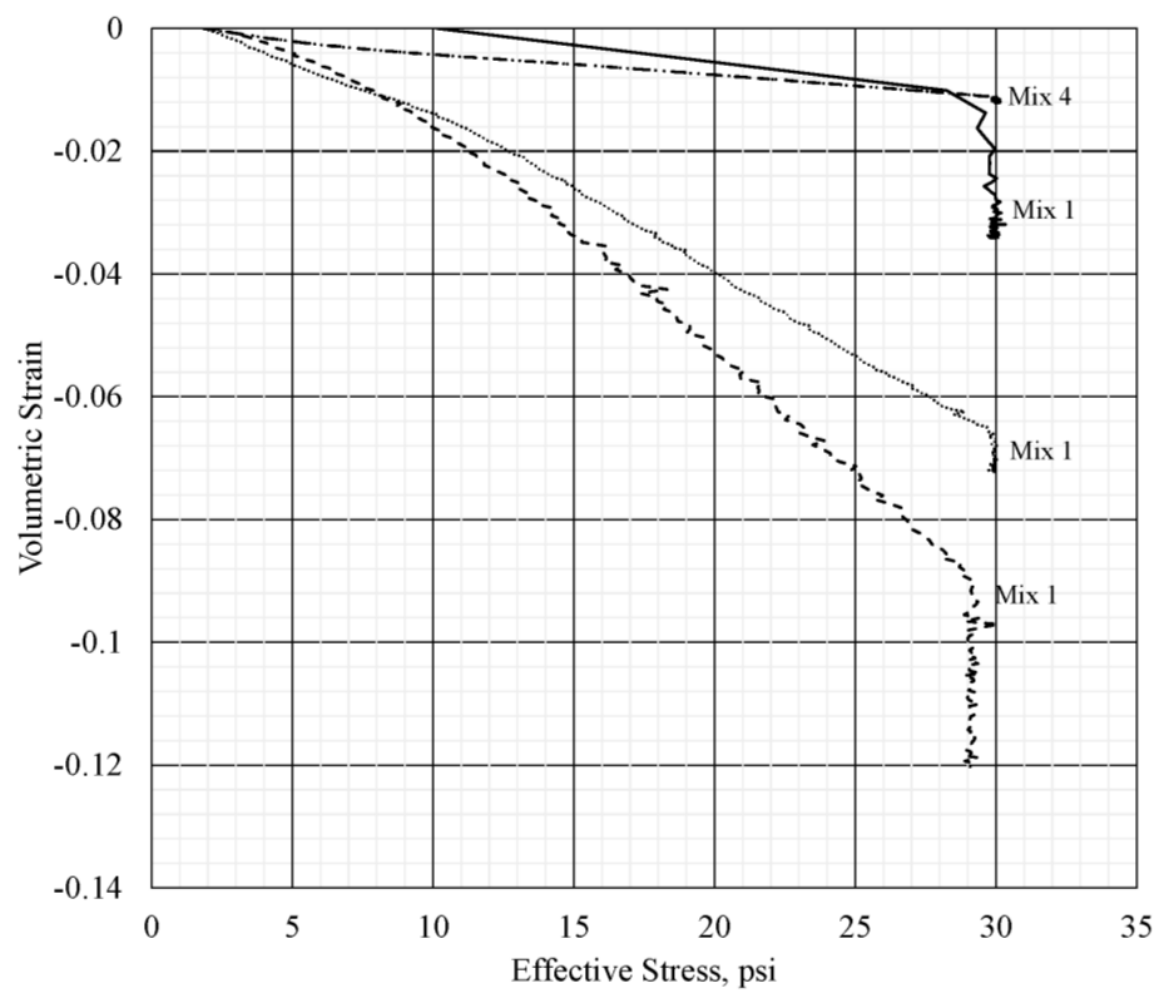

Fig. 5. 6 Consolidation curves for 2 percent cement mixes 


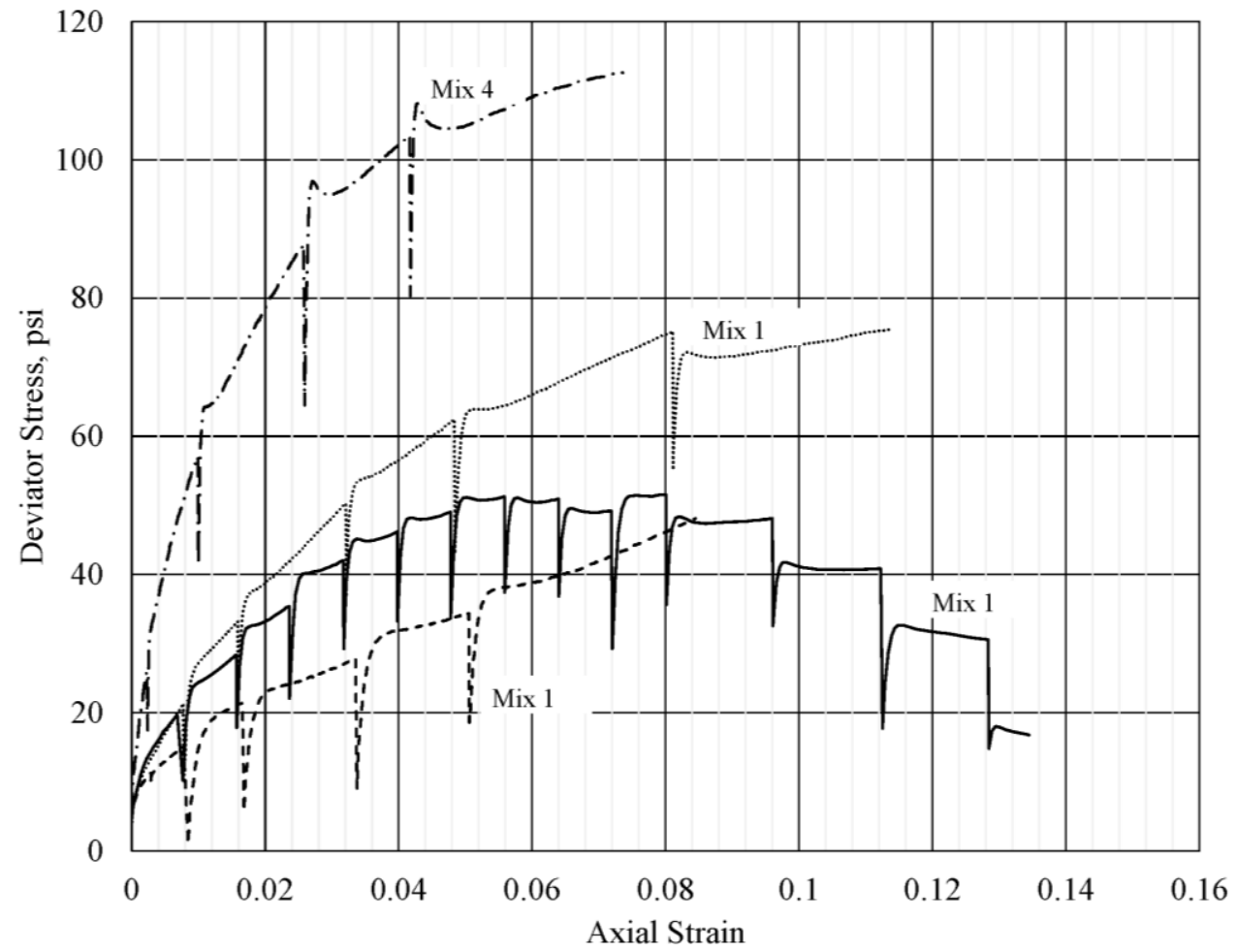

Fig. 5. 7 Stress-Strain curves for 2 percent cement mixes

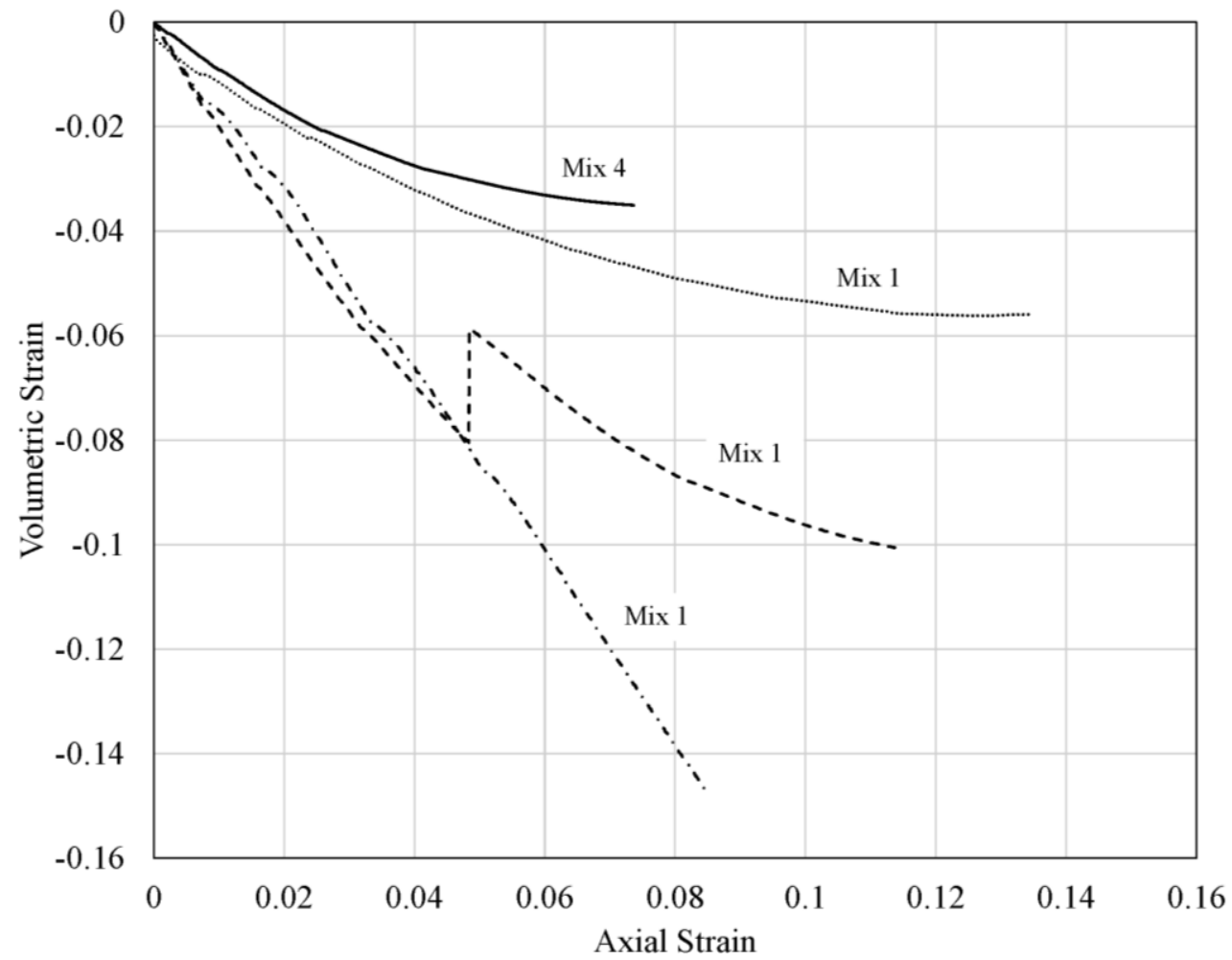

Fig. 5. 8 Volumetric strain curves for 2 percent cement mixes 


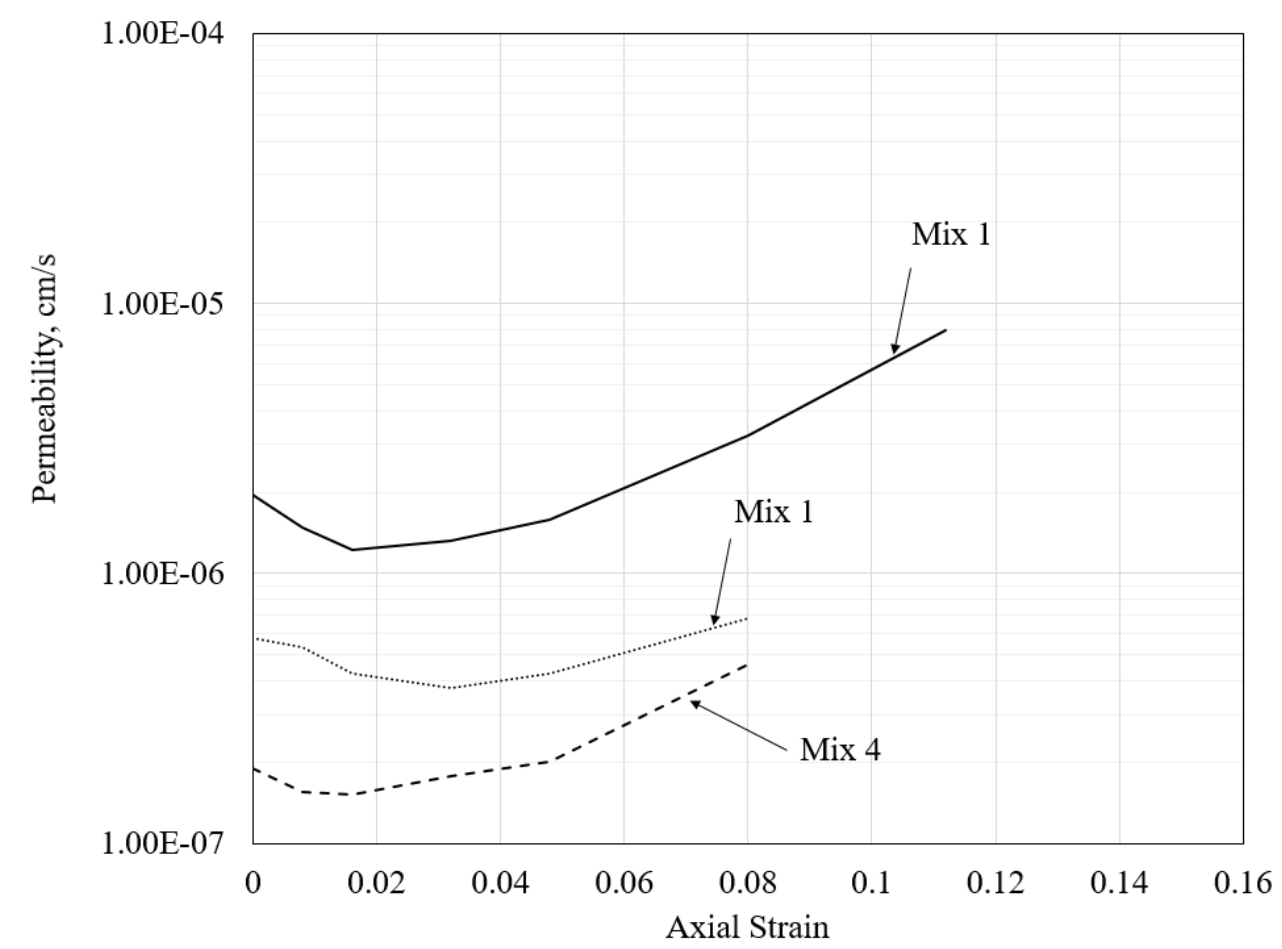

Fig. 5. 9 Permeability curves for 2 percent cement mixes

\section{Comparison of 6 Percent Cement-Bentonite Ratio Mixes}

Mixes 3, 7 and 8 contain $6 \%$ cement (by weight), and 4\%, $2 \%$ and $6 \%$ bentonite, respectively. Figs. 5.10, 5.11, 5.12, and 5.13 compare the mixes with $6 \%$ cement (by weight).

Mixes 3 and 8 the least amount volumetric strain of all of the mixes, as shown in Figure 5.10. The Mix 3 specimen with the most secondary consolidation had a higher consolidation pressure and rate than the other two. The Mix 7 specimens behaved differently, possibly due to the $2 \%$ bentonite content, because it was consolidated at same slow rate and pressure of one of the Mix 3 specimens and the Mix 8 specimen. 
The stress-strain curves in Figure 5.11 correlate the brittleness of the mixes to the amount of bentonite poorly. It is assumed that with more bentonite the mix is more ductile. Mix 7, with the least amount of bentonite is the most ductile. Mix 8, is in between Mixes 3 and 7, while Mix 3 is the most brittle. This pattern is also confirmed in Figure 5.12, the volumetric strain curves. It is clear that other factors are affecting the ductility. This could be due to the additional water added when the bentonite was hydrated on some of the specimens, or the consolidation rate and consolidation pressure.

Mixes 7, 8 and one of the Mix 3 specimens have relatively similar changes in permeability during testing. The Mix 3 specimen tested later in the research is the one that correlates better, indicating that a change in the testing procedure could be the reason for the difference from the other two specimens of that mix.

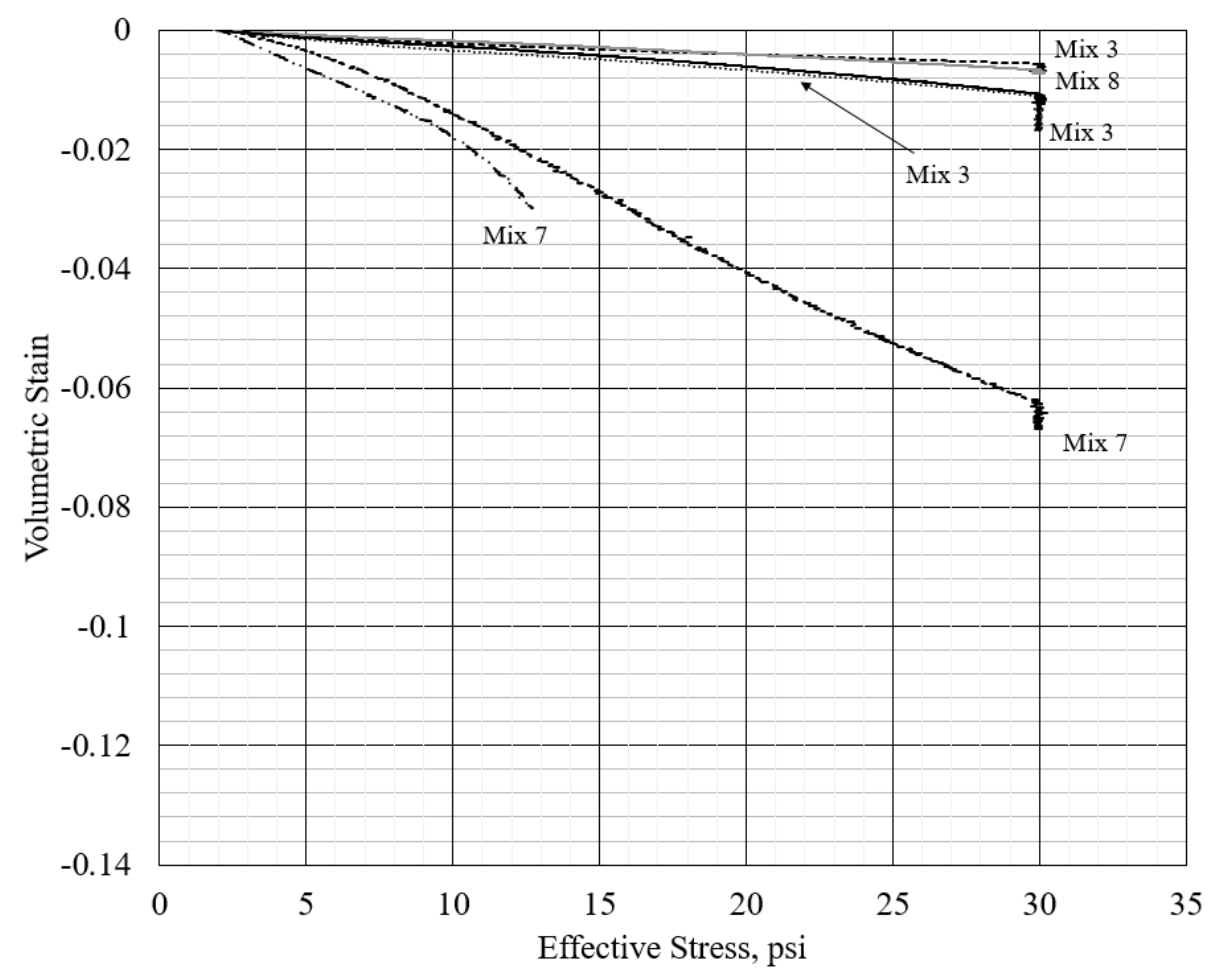

Fig. 5. 10 Consolidation curves for 6 percent cement mixes 


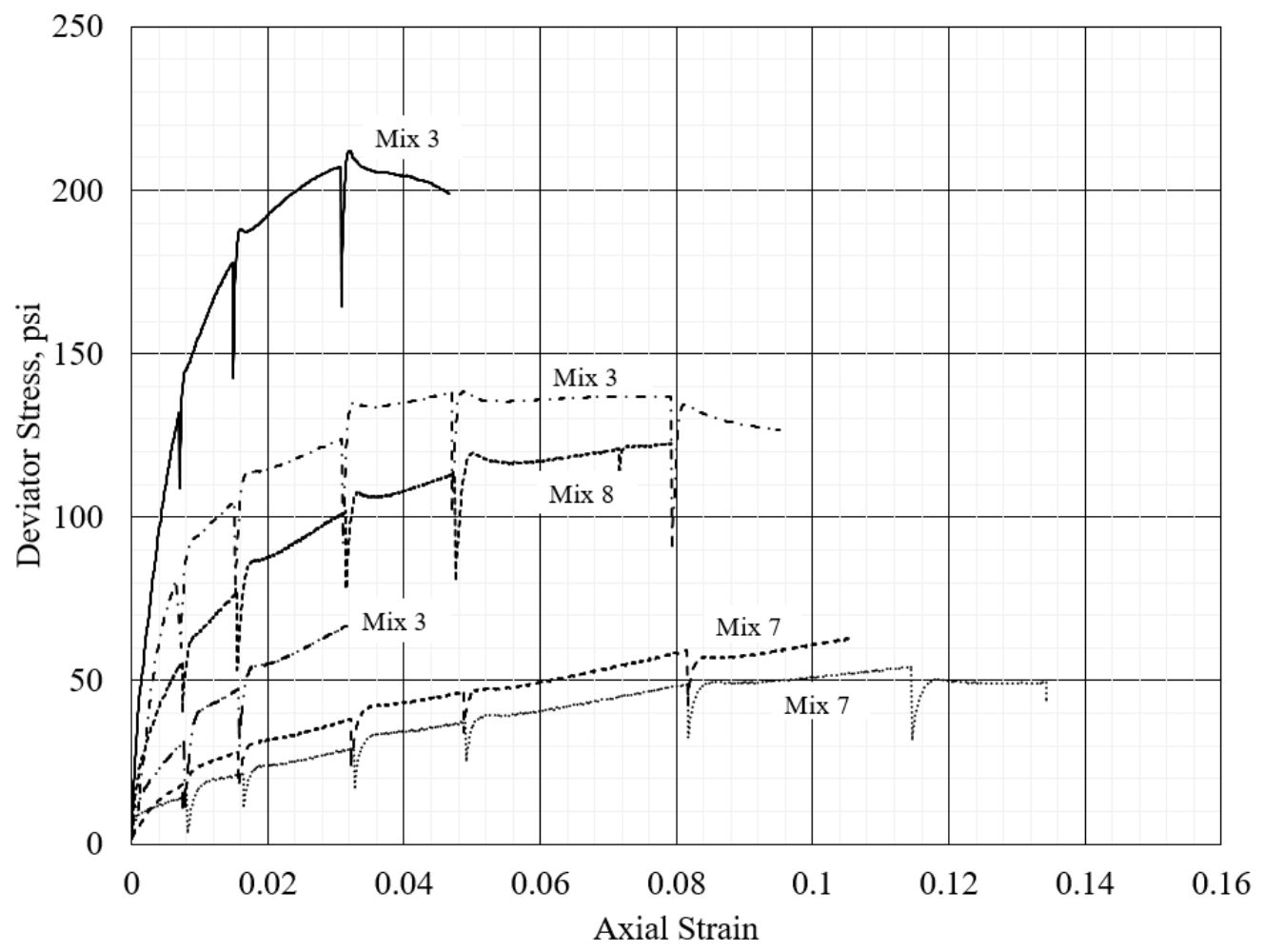

Fig. 5. 11 Stress-strain curves for 6 percent cement mixes

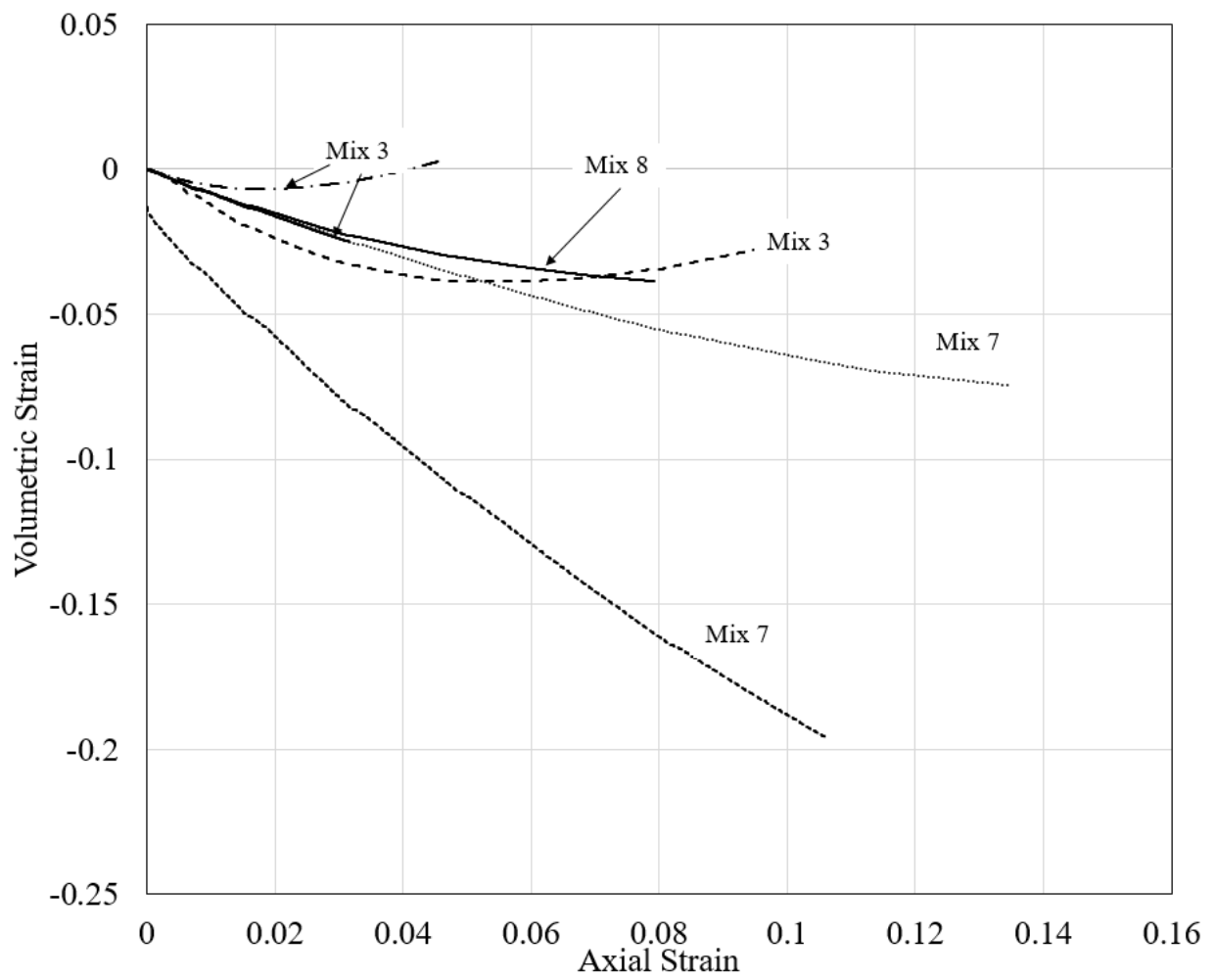

Fig. 5. 12 Volumetric strain curves for 6 percent cement mixes 


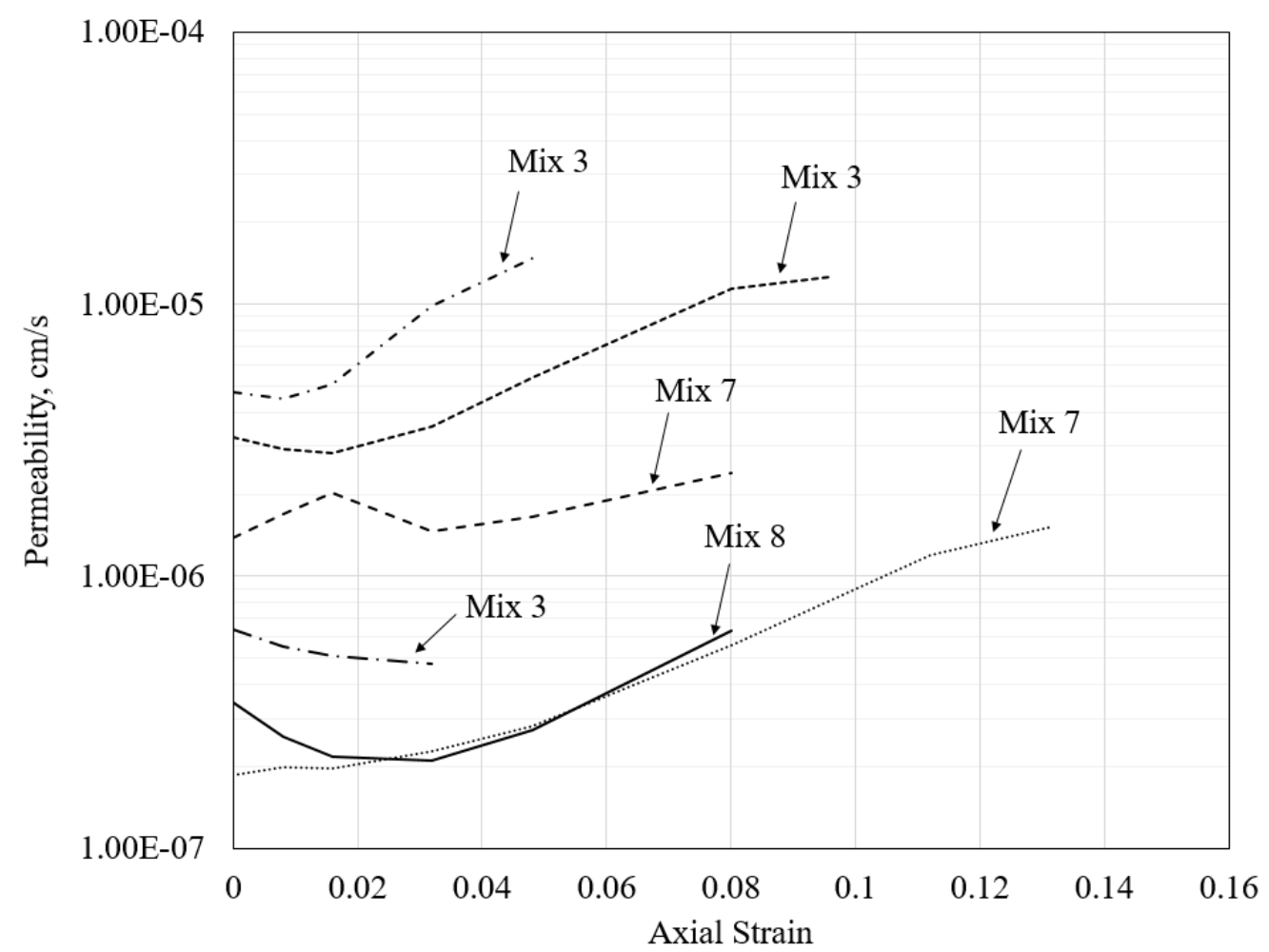

Fig. 5. 13 Permeability curves for 6 percent cement mixes

Observations on Possible Healing Behavior in Mixes Based on Permeability

Since the permeability testing was run simultanesouly with the triaxial shear testing, changes in permeability between shearing increments were observed and decreases, and sometimes increases were noted. As desribed in the testing procedure of Chapter 3, a triaxial shear increment was run then the specimen was allowed to rest for a period of 4 to 24 hours before the next shear increment. An average initial permeability measurement was taken at approximately 1 hour after the completion of the triaxial shear increment, then again approximately 1 hour before the start of the next shear increment. A comparison could then be made of the behavior of each specimen during that relaxation period and the change in permeability. Figure 5.14 and 5.15 illustrate the 
changes in permeability that were observed. These figures group together mixes into two categories. Mixes with 10 percent cement and bentonite ratios are in Figure 5.14. Mixes with more than 10 percent cement and bentonite ratios are in Figure 5.15. The solid lines represent the initial permeability reading, while the dotted lines represent the final permeability between the triaxial shear increments. A decrease in permeability in Mix 3 at the highest strain is shown with an arrow in Figure 5.14. Mixes 1 and 2 show little to no change in permeability between triaxial shearing increments. Mix 7 also exhibits a pronounced decrease in permeability towards the highest strains in Figure 5.15. It should be noted that this observation could also be caused by clogging of the seepage pathways formed in the triaxial shear process, and should also be examined.

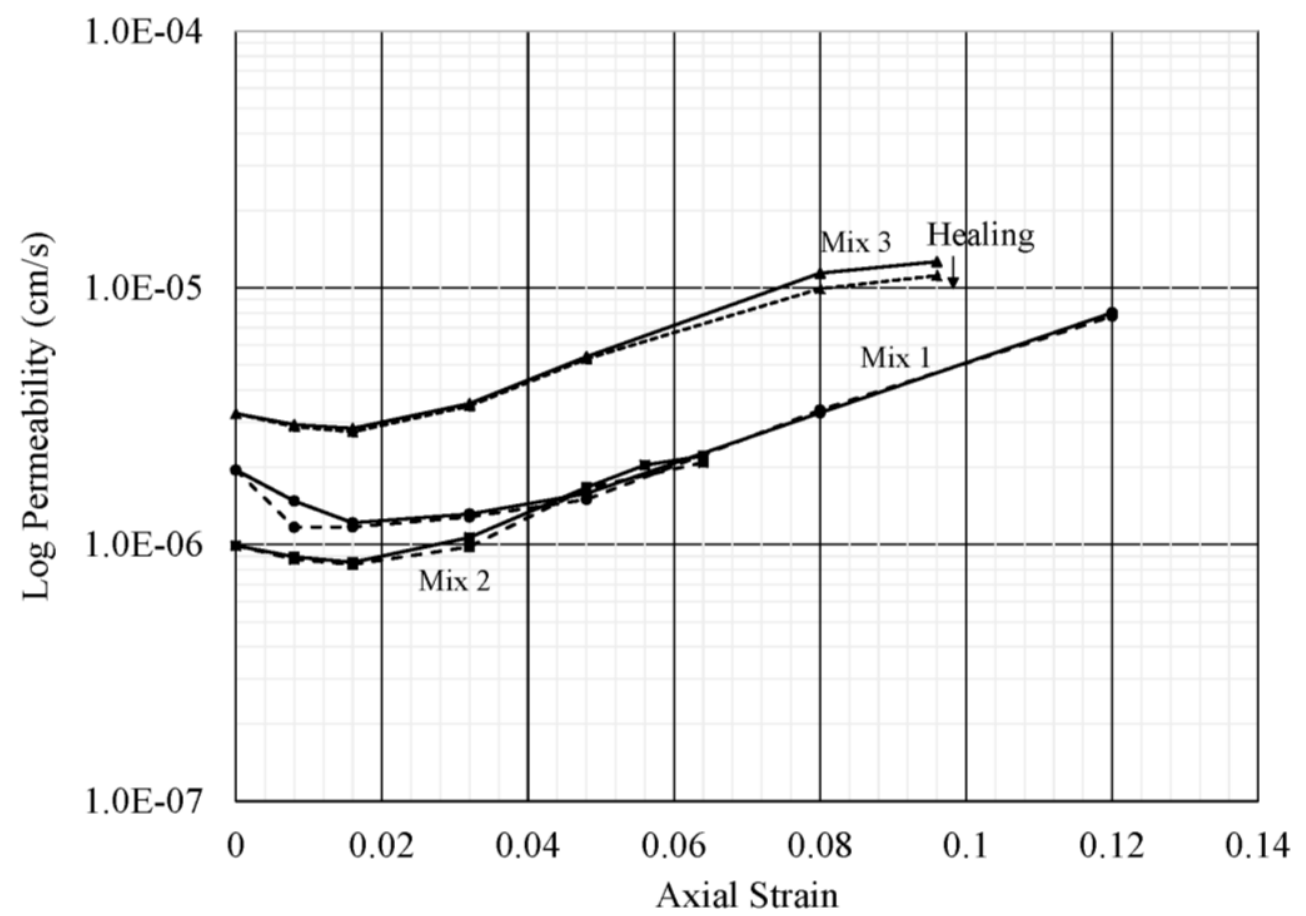

Fig. 5. 14 Change in Permeability during the testing for the 10 percent cement-bentonite ratio mixes 


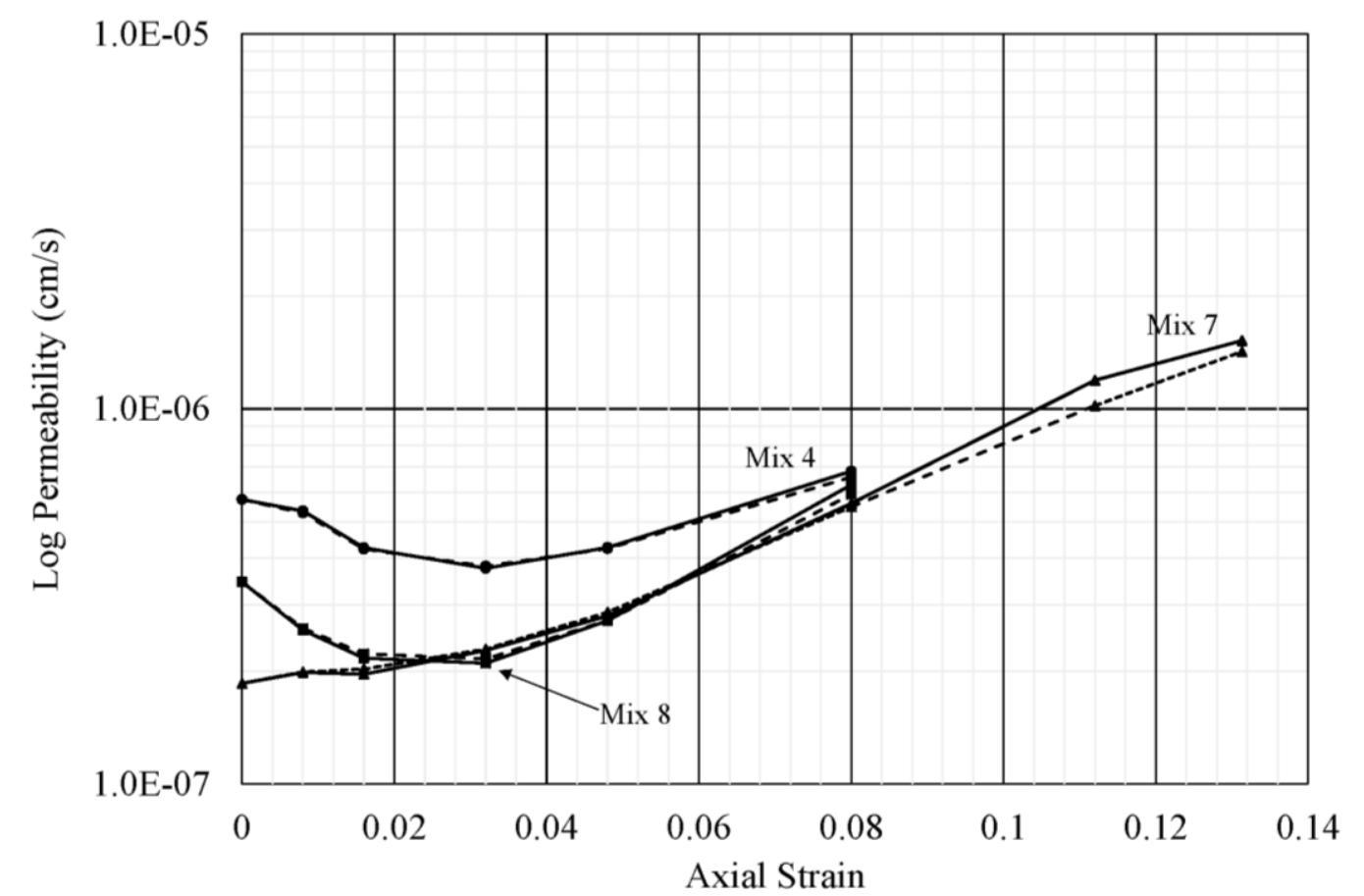

Fig. 5. 15 Change in Permeability during testing for the mixes with more than 10 percent cement-bentonite ratio

\section{Conclusions}

This research proposes the use of changes in permeability measurements as a better indication of the material properties of a cutoff wall backfill material. The method consists of triaxial testing with simultaneous permeability measurements. By combining these two tests, very low permeability values $(1 \mathrm{E}-7$ to $1 \mathrm{E}-5 \mathrm{~cm} / \mathrm{s})$ can be measured in a short amount of time (minutes as opposed to days). Earlier proof of concept testing showed this method works for material with permeability as low as $1 \mathrm{E}-9 \mathrm{~cm} / \mathrm{s}$. Changes in permeability are also measured throughout the triaxial test to show how materials behave during the shearing process. This allows comparisons to be made on how the change in permeability can reflect the ductility and stiffness of the material in the plastic 
zone of the stress-strain curve. Healing of the specimens can also be identified in the materials through decreases in the permeability between triaxial shear increments.

Since the testing procedure evolved during the research period, not all comparisons are as clear and require additional explanations of specifics such as: hydration of bentonite, consolidation rate, consolidation pressure, leaks in the system, computer and data logging issues. Earlier specimens in the research did not hydrate the bentonite before mixing. Later specimens hydrated the bentonite, but additional water had to be added. Consolidation rate started close to instantaneous at 3,600 psi/hour, which was later lowered to $10 \mathrm{psi} /$ hour, and finally $2 \mathrm{psi} /$ hour, which greatly affected the amount of secondary consolidation of the specimen. The back pressure also changed from 10 psi to 2 psi. Miniscule leaks in the system present a greater problem for this testing procedure due the being able to accurately measuring low permeability.

In general, there is good agreement between smaller changes in permeability and more ductile materials. This research also demonstrates that differences in behavior can be observed using permeability. This is important because it proves that permeability can be used as a more accurate parameter for understanding the material properties of cutoff wall backfill materials in situ as cracks form in the barrier.

Minimal long-term performance data is available on existing plastic concrete cutoff walls and it is imperative to understand the interaction of constitute materials of the plastic concrete before using them in cutoff walls, especially due to risk assessment uncertainties of using this type of backfill in higher risk conditions. The use of low 
plasticity clay, such as kaolinite, also shows great potential as a lower cost alternative to bentonite in plastic concrete mixes. The kaolinite does not appear to reduce the strength of the cement in the mix as much as bentonite, thus more can be added to the mixes further reducing the costs.

A common issue with cutoff walls is the potential for differential consolidation from top to bottom of the wall, USBR (2014). Therefore, the wall is stronger at the bottom than at the top. This issue was not directly addressed by this testing; as isotropic consolidation was assumed for the specimens. Future research will investigate the effect of consolidation on the material properties using this testing procedure.

While the testing procedure is time consuming and extremely sensitive to miniscule leaks, it provides a new avenue to assess material properties and gain a better understanding of the behavior of the intermediate cutoff wall backfill material. Further testing could provide enough information to make this type of backfill material more widely used in the United States on larger projects at larger cost savings. 


\section{REFERENCES}

Abbaslou, H., Ghamozadeh, A.R., Amlashi, A.T. (2016). "The Compatibility of Bentonite/Sepiolite Plastic Concrete Cut-Off Wall Material." Construction and Building Materials, 124, pp. 1165-1173.

Alzayani, N.J., Royal, A.C.D., Ghataora, G.S., and Jefferson, I. (2016). "CementBentonite in Comparison with Other Cemented Materials." Journal of Environmental Geotechnics. DOI: 10.1680

Anderson, S., Wilson, B. and Tonner, M. (2009). "Design and Construction of a Cut-off Wall in Permafrost.” Deep Foundations Institute, January, 2010, 9 p.

ASTM D4767-11, Standard Test Method for Consolidated Undrained Triaxial Compression Test for Cohesive Soils, ASTM International, West Conshohocken, PA, 2011, www.astm.org. DOI: 10.1520/D4767-11.

ASTM D7181-11, Standard Test Method for Consolidated Drained Triaxial Compression Test for Cohesive Soils, ASTM International, West Conshohocken, PA, 2011, www.astm.org. DOI: 10.1520/D7181-11

Bagheri, A.R., Alibabaie, M. and Babaie, M. (2008). "Reduction in the permeability of plastic concrete for cut-off walls through utilization of silica fume." Construction and Building Materials. 22 (2008). 124-1252.

Banzhaf, Peter E. and Colmorgen, Eckart. (2011). "Reliable Seepage Control by Plastic Concrete Cut-off Walls. $21^{\text {st }}$ Century Dam Design-Advances and Adaptations." $31^{\text {st }}$ Annual USSD Conference, San Diego, California, April 11-15, 2011. p. 585-601.

Bigras, A., Gagné, B., Rattue, A., Garand, P., Hammamji, Y., and Vannobel, P. (2005). "Treatment of Deep Pervious Foundations at the Peribonka Dam Site." Canadian Dam Association (CDA), 2005 Annual Conference, Calgary, Alberta, Canada, October 3-6, 2005.

Bruce, Donald A., Ressi di Cervia, Arturo and Amos-Venti, Jeannine. (2006). "Seepage Remediation by Positive Cut-off Walls: A Compendium and Analysis of North American Case Histories." 23 p.

Donnelly, C.R., Rigbey, S.J., Rigbey, G., and Clark, C. (2007). “The Design and Construction of the Shikwamka Replacement Dam." CDA 2007 Annual Conference. St. John's, NL, Canada, September 22-27, 2007. 
Donnelly, C.R., Tatone, B., Hoyle, W., Boucher, N., Hinchberger, S., Godbout, N., and Protulipac, D. (2013). "An Evaulation of the Geotehcnical and Environmental Performance of the Shikwamkwa Dam Five Years Later." Hydrovision Conference, Denver, Colorado, July 2013.

Ghazahi, Mahmoud, Sararzadeh, Zolfaghar and Hashemolhoseini, Hamid. (2004). "Response of Plastic Concrete Cut-off Wall in Earth Dams to Seismic Loading Using Finite Element Methods." $13^{\text {th }}$ World Conference on Earthquake Engineering. Vancouver, Canada, August 2004.

Hinchberger, S., Weck, J. abd Newson, T. (2010). "Mechanical and hydraulic characterization of plastic concrete for seepage cut-off walls." Can. Geotech. J. 47. 461471. doi: 10.1139/T09-103.

ICOLD (1985). "Filling Materials for Watertight Cut-Off Walls," International Committee of Large Dams, Paris, Bulletin N. 51.

Jafarzadeh, F., and Mousavi, H. (2012). "Effect on Specimen's Age on Mechanical Properties of Plastic Concrete Walls in Dam Foundations." Electronic Journal of Geotechnical Engineering. Volume 17. Pp. 473-482.

Javed, F., Nasim, M.A. (2005). "Construction of Seepage Measurement System at Jatiluhur Dam, Indonesia.” Electronic Journal of Geotechnical Engineering, 2005.

Joshi, K., Kechavarzi, C., Sutherland, K., Ng, Man Yin Albert, Soga, K., and Tedd, Paul (2010). "Laboratory and In Situ Tests for Long-Term Hydraulic Conductivity of a Cement-Bentonite Cutoff Wall." Journal of Geotechnical and Geoenvironmental Engineering, April 2010, pp. 562-572.

Kahl, Thomas W., Kauschinger, Joseph, L. and Perry, Edward B. (1991). "Plastic Concrete Cuttoff Walls for Earth Dams.” US Army Engineer Waterways Experience Station, Vicksburg, M.S.

Khiavi, Maajid P. and Ghorbani, Mortaza A. (2014). "Effects of Micro Silica on Permeability of Plastic Concrete." Journal of Materials Science and Engineering. A 4(12). 372-375. Doi: 10.17265/2161-6221/2014.12.006.

Mahboubi, A. and Ajorloo, A. (2005). "Experimental study of the mechanical behavior of plastic concrete in triaxial compression." Cement Concrete Research. 35(2). 412-419. 
Menzies, B. (1988). "A Computer controlled hydraulic triaxial testing system. ASTM STP 977. 1988. Advanced triaxial testing of soil and rock." ASTM International, West Conshohocken, PA, 2011, www.astm.org. DOI: 10.1520/STP977-EB, pp. 82-94.

Mirghasemi, Mahab, Pakzad, M. and Shadravan, B. (2005). "The World's largest cutoff wall at Karkheh Dam.” Hydropower \& Dams. Isuue 2. 2-6.

Naderi, Mehmood. (2005). "Effects of Different Constituent Materials on the Properties of Plastic Concrete." International Journal of Civil Engineering. 3(1), 10-18.

O’Brien, Steve, Dann, Christopher, Hunter, Gavin and Schwermer, Mike. (2009). "Construction of the Plastic Concrete Cut-off Wall at Hinze Dam." ANCOLD Proceedings of Technical Groups. $9 \mathrm{p}$.

Olsen, H.W., Morin, R.H., and Nichols, R.W. (1988). "Flow Pump Applications in Triaxial Testing." ASTM STP 977. 1988. Advanced triaxial testing of soil and rock. ASTM International, West Conshohocken, PA, 2011, www.astm.org. DOI: 10.1520/STP977-EB, pp. 68-81.

Pashazahad, Akbar and Chekaniazar, Moteza. (2011). "Estimating an Appropriate Plastic Concrete Mixing Design for Cutoff Walls to Control Leakage under the Earth Dam." Journal of Basic and Applied Scientific Research. 1(9), 1295-1299.

Rice, John D. and Duncan, Michael (2010A). "Findings of Case Histories on the LongTerm Performance of Seepage Barriers in Dams." Journal of Geotechnical and Geoenvrionmental Engineering, Vol. 136, No.1, January 2010, pp. 2-15.

Rice, John D. and Duncan, Michael (2010B). "Deformation and Cracking of Seepage Barriers in Dams due to Changes in the Pore Pressure Regime." Journal of Geotechnical and Geoenvrionmental Engineering, Vol. 136, No.1, January 2010, pp. 16-25.

Shi, Xiao-Xing and Wang, Li. (2015). "Test on Mechanical Properties of Cemented Soils Using Secondary Development Data Acquisition Test System.” Seventh International Conference on Measuring Technology and Mechatronics Automation. DOI 10.1109/ICMTMA.2015.271

Tatone, B., Donnelly, C., Protulipac, D., and Clark, C. (2009). "Evaluation of the Hydraulic Efficiency of a Newly Constructed Plastic Concrete Cut-Off Wall," CDA 2009 Annual Conference, Whistler, BC, Canada, October 3-8, 2009.

Trautwein, S. (2000A). “DigiFlow-K Instruction Manual. Version 1.00.” March 2000. Trautwein Soil Testing Equipment Company, Houston, TX. 
Trautwein, S. (2000B). “Sigma-1 Triaxial Instruction Manual. Version 1.01.” October 1998. Trautwein Soil Testing Company, Houston, TX.

USACE (1993). "EM-1110-2-1901 Engineering and Design Seepage Analysis and Control for Dams. Department of the Army," United States Army Corps of Engineers. Washington, District of Columbia.

USACE (1992). "REMR Technical Note GT-SR-1.3 Suppl 5. Design Procedure for Plastic Concrete Cut-off Walls." Department of the Army, United States Army Corps of Engineers. Washington, District of Columbia.

USBR (2014). "Design Standards No. 13 Embankment Dams DS-13(16)-14: Phase 4 Final." The United States Bureau of Reclamation.

Yan, L., Trapp, D.A. and Sy, A. (2008). "Construction of a Plastic Concrete Seepage Cutoff Wall for the New Coquitlam Dam." International Conference on Case Histories in Geotechnical Engineering, August 11-16, 2008. Paper 7.12 p.

Zhang, Jianhong, Hu, Liming, Pu, Jialiu and Yin, Kunting (1999). "Behavior of Plastic Concrete Diaphragm Walls in Three Gorges Project.” Tsinghua Science and Technology. ISSN 1007-0214. 4(1). 1367-1370.

Zhang, Peng, Guan, Qiaoyan and Li, Qingfu (2013). "Mechanical Properties of Plastic Concrete Containing Bentonite." Research Journal of Applies Sciences, Engineering and Technology. 5(4).1317-1322. 